\title{
Engagement, Empowerment, and Empathy: Cosmetics in the work of Suzy Lake and Janine Antoni
}

by

\section{Jessa Laframboise}

A thesis submitted to the Faculty of Graduate and Postdoctoral Affairs in partial fulfillment of the requirements for the degree of

\author{
Master of Arts \\ in \\ Art History \\ Carleton University \\ Ottawa, Ontario
}

(C)2020 Jessa Laframboise 


\section{$\underline{\text { Abstract }}$}

This thesis explores the use of cosmetics in Suzy Lake's $A$ Genuine Simulation of... (1973-1974) and Janine Antoni's Butterfly Kisses (1996-1999). Issues of beauty and decorum were considered to be the foundation of women's oppression during the rise of second-wave feminism in North America during the late 1960s. Feminists sought to critique the beauty industry and liberate themselves from the masks of makeup that had become a part of their everyday lives. As waves of feminists developed new perspectives and values, the way in which issues of beauty and decorum were understood shifted. Suzy Lake and Janine Antoni are two prominent contemporary artists who have explored issues of gender, identity, beauty, and adornment in Western feminist art. Despite differences between Lake's A Genuine Simulation of... and Antoni's Butterfly Kisses, the process of cosmetic adornment during the making of $A$ Genuine Simulation of... and Butterfly Kisses connects these pieces. This thesis investigates the works' process-driven qualities, and seeks to make sense of how each artist engaged in beauty rituals. It argues that reflection on the artists' acts can deepen our understanding of the issues presented in the works. When observing A Genuine Simulation of... and Butterfly Kisses, viewers can engage with the artists' processes; those who have experience (directly or indirectly) with beauty rituals and adornment have the opportunity to use their personal experiences as a means to understand the acts which Lake and Antoni participate in. In drawing on their own experiences to comprehend the artists' processes of creation, Lake and Antoni lead viewers towards reflection, empowerment, and empathy with respect to their own cosmetic adornment and the adornment of others. 


\section{$\underline{\text { Acknowledgements }}$}

First and foremost, I would like to recognize my advisor, Jill Carrick. Thank you, Professor Carrick, for helping me shape my ideas into a fully formed master's thesis. Your guidance has made me a better writer and a more thoughtful art historian. I would also like to extend my gratitude to Professor Stéphane Roy for always being available and for lending me his support along the way.

To Carly Atkinson, thank you for helping me through the editing process and providing me with helpful feedback. To the members of my defence committee, I appreciate you taking the time to review my thesis and for supporting my academic journey. And to the artists, Suzy Lake and Janine Antoni, thank you for creating work that is inspiring and for supporting this project.

To my friends who helped me throughout this journey by giving me advice, feedback, and many laughs, thank you. To my work-out companion, art history colleague, and friend Elizabeth Stewart, your encouragement and perspective during the last two years has been something I am so grateful for.

To my parents, Jodi, and Terry, thank you for always showing an interest in my work and encouraging me to pursue my passions. You have dedicated the last 25 years to helping me realize my potential. Thank you for always lifting me up when I needed it.

I grew up surrounded by smart, bold, and determined women, all of whom I wish to thank. Jodi, Beverley, Dayle, Kari, Meagan, Emily, and Allie, each, and every one of you have taught me in your own ways how to be strong and speak up for what I believe in. My passions for feminism and art are informed by what I see in all of you. 
Finally, thank you to Carter, my partner, best friend, and soon to be husband. Thank you for being invested in my work, talking me through writer's block, helping me with ideas that I did not yet have the words for, and for providing me with much needed comic relief. You have been by my side throughout this entire journey. I have asked so much of you and, in return, you have shown me unconditional love. Your unwavering belief in my work drives me to dream big. 


\section{$\underline{\text { Dedication }}$}

I would like to dedicate this thesis in memory of my late grandfather William MacFarlane. Like myself, my grandfather had a passion for education. He dedicated his life to teaching and believed in the power of learning. He taught me some of my greatest life lessons, lessons I have taken with me as I embarked on this project; have pride in your work, power through the hard times, remain poised, and be proficient.

"Pride, power, poise, proficiency is our clan motto and forever we uphold." - William Macfarlane (1935-2016) 


\section{$\underline{\text { Table of Contents }}$}

Abstract $\quad$ i

$\begin{array}{ll}\text { Acknowledgements } & \text { ii }\end{array}$

Dedication $\quad$ iv

Introduction $\quad 1-24$

Makeup: An Introduction $\quad 1$

Methodology, Research, and Chapter Outline $\quad 2$

Problems and Limitations $\quad 5$

Meet the Artists $\quad 7$

A Harmful Cultural Practice? 10

The Beauty Debates in Feminist Literature $\quad 14$

"Own Your Beauty": How Feminism Affected the Makeup Industry 19

Language and Gender $\quad 21$

Feminist Artists 'Makeup' Their Own Rules 24

Chapter One: Suzy Lake and A Genuine Simulation of... (1973/74) 27-61

Introduction $\quad 27$

Exhibition History and Previous Interpretations 30

$\begin{array}{ll}\text { Makeup and Miming } & 38\end{array}$

Taking a Closer Look: A Visual Analysis of A Genuine Simulation of...

Reflection and Empowerment 55

$\begin{array}{ll}\text { Conclusion } & 60\end{array}$

Chapter Two: Janine Antoni and Butterfly Kisses (1996-99) 62-97

Introduction $\quad 62$

Exhibition History and Previous Interpretations 64

Covered, Girl: Beauty Practices and the Materiality of Cosmetics 70

Visual Analysis of the 1993 and 1996-99 Versions of Butterfly Kisses 73

Understanding the Mystery of the Making: A Phenomenological Exploration of 77

Butterfly Kisses

Viewer Engagement and Empathy $\quad 85$

$\begin{array}{ll}\text { Conclusion } & 97\end{array}$

Conclusion $\quad 98-103$

List of Illustrations $\quad 104-117$

Bibliography $\quad 118-144$ 


\section{$\underline{\text { Introduction }}$}

\section{Makeup: An Introduction}

Makeup in Western culture is a tool that people use to alter their appearance, and it is often associated with vanity. Some use it for the purpose of play and experimentation, while others use makeup to enhance their individual features. ${ }^{1}$ Whether users create subtle differences in their appearance or seek to recreate themselves in a more drastic way, they are altering their looks; people can give themselves redder lips, fuller eyelashes, rosy cheeks, and a slimmer nose, along with many other possibilities. By looking in a mirror, people can see the outer changes that they make with cosmetics; however, what the mirror does not show is how cosmetics and beauty rituals can affect our lives and identities. Having the ability to look critically at makeup and beauty is key to defining one's relationship to the products and processes in a positive way. It takes more than one's reflection in the mirror to recognize how beauty rituals can affect a person's life, though personal reflection is required. Reflecting on cosmetic adornment can help ensure that adornment acts are not rendered invisible by the normalcy of day-to-day beauty routines, allowing people to develop healthier relationships with their cosmetic practices.

Suzy Lake and Janine Antoni are two artists who use cosmetics and have engaged in beauty rituals to create works of art. Through different approaches — photography and drawingLake and Antoni perform the act of adornment as a means of expressing their respective positions within the beautification tradition. This thesis aims to gain an understanding of the adornment processes in Lake's A Genuine Simulation of... (1973/74) (Figure 1.0) and Antoni's

Butterfly Kisses (1996-99) (Figure 1.1), and to use these works to provide a historical analysis of

\footnotetext{
${ }^{1}$ Rebecca F. Plante, "Putting on Makeup," in Popular Culture as Everyday Life, eds. Dennis D. Waskul and Phillip Vannini (New York; Oxfordshire: Routledge, 2016), 168.
} 
makeup in feminist art that speaks to our current sociopolitical climate. While examining the visual and thematic details of these pieces, I seek to illuminate how the artists' works contribute to the exploration of cosmetics, beauty, and identity in feminist art; my thesis argues that viewing and understanding their adornment acts can affect viewers in meaningful ways. Engagement with Lake and Antoni's adornment processes in their work can lead viewers to experience personal forms of empowerment and empathy with respect to their own beauty rituals and the rituals of others.

\section{Methodology, Research, and Chapter Outline}

As an emerging feminist artist and historian, I have dedicated a lot of time to research on cosmetics and beauty routines. The desire to know more about my relationship to beauty practices, and cosmetics' relationship to Western culture more broadly, drove me to pursue this research. The status of makeup within society has been subject to continuous change throughout history; however, my area of interest covers only a small part of this vast history. In this thesis, I am primarily concerned with an analysis of Western beautification rituals of the twentieth century. My focus on makeup in the twentieth century is chosen purposefully; not only is it the period during which Lake and Antoni created works centred on cosmetics, but it is also the period where feminist beauty debates were introduced into literature and popular culture.

A Genuine Simulation of... (1973/74) and Butterfly Kisses (1996-99) have never appeared in the same exhibition together. Furthermore, according to the artists' curricula vitae on their websites, Lake and Antoni have never had any of their works exhibited in the same show. Although both are renowned international artists, the majority of Lake's selected group and solo exhibitions, listed on her CV, have taken place in Canada. The selected shows that appear on 
Antoni's CV indicate that she has only exhibited her work in Canada a few times since the 1990s. Furthermore, I have not come across any literature in my research that explores the relationship between Suzy Lake, Janine Antoni, and their work; in Jane Wark's 2006 publication Radical Gestures: Feminism and Performance Art in North America, both artists are considered but they are not placed in direct conversation with one another. ${ }^{2}$

I present my thesis in four sections: the present introduction, Chapter One: Suzy Lake and A Genuine Simulation of... (1973/74), Chapter Two: Janine Antoni and Butterfly Kisses (1996-99), and the conclusion. I have separated the subsequent discussions of each artist into two chapters because their pieces were created during different generations of feminism: secondwave feminism and third-wave feminism. I seek to consider Lake and Antoni's work within the contexts in which they were created. I also consider the individual motives that both artists had for using cosmetics in the creation of their work. Throughout both chapters I trace the connections between A Genuine Simulation of... and Butterfly Kisses through my engagement with these works. I weave in my own exploration of these works from a twenty-first-century, fourth-wave feminist perspective to elaborate on how I have interpreted connections between Lake and Antoni.

Chapter One focuses on Lake's A Genuine Simulation of ... and considers themes and topics that are relevant to 1970s feminism, such as Brechtian theory—which theorized principles that became popular in feminist art during this decade. Through a close looking exercise, I also recount my engagement with Lake's work and explore how A Genuine Simulation of... acts as a tool of empowerment for viewers. In Chapter Two, I apply the same strategy to Antoni's work,

2 Jane Wark, Radical Gestures: Feminism and Performance Art in North America (Montreal; Kingston: McGill-Queen's University Press, 2006). 
but I approach the piece from a 1990s feminist perspective. I also describe my engagement with Butterfly Kisses by providing a detailed overview of how I recreated the performance aspect of Antoni's work to better understand the process of making Butterfly Kisses. This engagement will support my position that Butterfly Kisses, like $A$ Genuine Simulation of ..., can affect viewers in a meaningful way; in this case, Antoni's work can evoke empathy in its audience.

I believe that my strategy to combine critical and scholarly literature with my own personal accounts is relevant because, with this thesis, I am contributing to feminist art, a movement built on personal experiences, reflection, and collaboration. During its heyday, second-wave feminism adopted the slogan "The Personal is Political," a phrase coined by Carol Hanisch of both the New York Radical Women and Redstockings feminist groups. Recounting, in her essay "The Personal is Political", her experiences when she participated in group meetings with other women, Hanisch explains that women would pose questions about their personal lives and then

...go around the room answering the questions from [their] personal experiences. Everybody talks that way. At the end of the meeting [they] try to sum up and generalize from what's been said and make connections... [T] he reason [Hanish] participate[d] in these meetings [was] not to solve any personal problems. One of the first things [members] discover in these groups is that personal problems are political problems. ${ }^{3}$

What Hanisch refers to are consciousness-raising sessions, designed to understand and describe "the particular oppression of women in ways that could reach other women." This strategy placed emphasis on personal feelings and experiences, and was preceded by the " $17^{\text {th }}$ century challenge of science to scholasticism: 'study nature, not books,' and put all theories to the test of

\footnotetext{
${ }^{3}$ Carol Hanisch, "The Personal Is Political," in Radical Feminism: A Documentary Reader, ed. Barbara A. Crow (New York; London: New York University Press, 2000), 113-114.

${ }^{4}$ Kathie Sarachild, "Consciousness-Raising: A Radical Weapon," in Feminist Revolution: An Abridged Edition with Additional Writing, ed. Redstockings of the Women's Liberation Movement (New York: Random House, 1978), 144.
} 
living practice and action." Writer and feminist Kathie Sarachild explains, "Everything we have to know, have to prove, we can get from the realities of our own lives." ${ }^{\prime 6}$ Using this second-wave feminist strategy as inspiration, I step in and out of the role of the art historian throughout my thesis and discuss my personal relationship to cosmetics and beauty practices. In doing this, I strive to cultivate connections between what I have experienced and what artists and historians explore in their work. This approach will help demonstrate how others can engage with the works of Lake and Antoni and what can come of it—namely, empowerment and empathy.

In the present chapter, I outline the problems and limitations faced during the course of my research. I also introduce Suzy Lake and Janine Antoni in more detail. Following this introduction of the artists, I provide a brief history on the presence of beauty traditions and cosmetics in Western feminism, focusing largely on the twentieth-century; this sketch provides readers with a background on the history of cosmetics in North America and gives context to Lake and Antoni's practices, both of which are deeply influenced by this history. Next, I offer a brief literature review and explore how feminist literature has responded to the feminized beautification rituals that arose in the 1960s. I then acknowledge the gendered language present in beauty culture. I end the introduction by providing an overview of cosmetics and decorum in feminist art.

\section{Problems and Limitations}

Imagine being an art historian and studying art only through documentation, and never experiencing it the way that others have. As a consequence of the current global pandemic, this

\footnotetext{
${ }^{5}$ Sarachild, "Consciousness-Raising: A Radical Weapon," 145.

${ }^{6}$ Ibid.
} 
has been my unfortunate experience. COVID-19 has changed the way that galleries and libraries operate, and - as a result - I was unable to see A Genuine Simulation of... and Butterfly Kisses in person. Prior to these changes in protocol, I was able to view some of the archival materials for $A$ Genuine Simulation of... while doing a practicum placement at the National Gallery of Canada; however, there is more that I had hoped to see at the National Gallery of Canada, and at galleries in Ontario, Montreal, and New York City. The implementation of pandemic restrictions means that, for my analysis, I am working with digital documentation and a meagre number of physical exhibition catalogues. Given this mode of viewing, I am limited in how closely I can observe the work. Pursuing A Genuine Simulation of... solely through documentation is constraining due to the lack of images and resources available. Likewise, there is little digital documentation of Butterfly Kisses. For example, when I type in "Butterfly Kisses Janine Antoni” (or some variation of the phrase) into my search engine, it becomes clear that documentation is limited to a selection of images that do not present Butterfly Kisses at varying angles or ranges.

A Genuine Simulation of... is relatively large, but-when I observe Lake's photodocumented performance through other forms of documentation, whether it be on my computer or in a book - the size of the piece is deceiving. When I learned the actual size of $A$ Genuine Simulation of ..., I discovered that it was larger than I had expected. Lake's 1973/74 photographic piece is 152 centimetres long and 142 centimetres wide; however, when I view this work on my laptop, it is reduced to the dimensions of my computer screen. Similarly, when I view Butterfly Kisses, it does not appear to be 82 centimetres by 82 centimetres. The dimensions of digital documentation shrink Antoni's work into a miniature eyelash drawing; this representation leads Antoni's eyelash markings to appear tangled, like a web of mascara, and the minute, intricate details can go unnoticed. The imagery also becomes flattened and, in effect, the materiality is 
harder to decipher. Furthermore, the original paper could be showing wear that would speak to Antoni's process and how she interacted with the paper during the performance. Each crease or crinkle across the surface of the paper is a significant characteristic that photography can conceal.

While my recognition of certain visual details in each piece can be skewed, if I embrace the documentation, I maintain that viewing A Genuine Simulation of... and Butterfly Kisses in this way does not prevent me from engaging with the artists and the themes that they present. As I will demonstrate in this thesis, what I believe to be a bigger limitation than the digital documentation is a viewer's inability to recognize and therefore understand the acts that the artists perform (that is, the act of cosmetic adornment).

\section{Meet the Artists}

Suzy Lake is a Canadian-American artist born in Detroit, Michigan in 1947 to a conservative, working-class family. ${ }^{7}$ Lake explains, during a 2017 artist talk at the University of Guelph,

I saw inconsistencies in the American dream that raised questions. But I came from a very conservative Republican household in Detroit, so my questions went nowhere. When I went to university, human rights in larger forums opened up questions of attitudes and for the first time I saw the glass ceiling of gender."

In a 2013 interview with journalist Bill Clarke for Canadian Art, Lake also stated,

A lot of us could see cracks in the American Dream, and we knew what we were fighting for - racial and social equality — but when changes started to happen, we didn't quite know who we had become. I knew that I was no longer the eldest daughter raised

${ }^{7}$ Georgiana Uhlyarik, Introducing Suzy Lake (London: Black Dog Publishing, 2014), 19.

${ }^{8}$ Suzy Lake, "Big Ideas in Art \& Culture: Suzy Lake," Arts Everywhere Festival, filmed January 19, 2017, accessed June 6, 2020, video, 3:20, http://festival.artseverywhere.ca/event/big-ideassuzy-lake/. 
simply to become someone's wife. ${ }^{9}$

Georgiana Uhlyarik, curator at the Art Gallery of Ontario and co-curator of the 2014 exhibition Introducing Suzy Lake, acknowledges that Lake's political consciousness, which informed her extensive body of work, grew out of the artist's early experience with social movements in Detroit. $^{10}$

By 1968, Lake decided to leave the United States due to continuing social and political instability. ${ }^{11}$ She eventually settled in Montreal, where she pursued a Master of Fine Arts at Concordia University. Lake explains:

After I first arrived in Montreal, I was trying all kinds of different things to figure out how to bring content into my works, so that what was happening on the street made sense with what was happening in the studio. I was trying to figure out who I was as a result of a lot of radical social change. ${ }^{12}$

Montreal was where Lake began a forty-year career that continues today. She has been recognized as one of "the first female artists in Canada to adopt performance, video, and photography to explore the politics of gender, the body, and identity." ${ }^{\prime 3}$ She has also become known for her dedication to developing arts and culture in her communities; she taught at the Montreal Museum School of Art, was a founding member of Véhicule Art Inc., a "non-profit non-political center directed for and by artists" in Montreal, helped to found the Toronto Photographers Workshop, and has participated in numerous lecture circuits around Ontario, including at Ryerson University and the University of Guelph. ${ }^{14}$

\footnotetext{
${ }^{9}$ Bill Clarke, "A Maker of Change," Canadian Art 29, no. 4 (Winter 2013): 110.

${ }^{10}$ Uhlyarik, Introducing Suzy Lake, 23.

${ }^{11}$ Ibid.

${ }^{12}$ Ibid., 109.

${ }^{13}$ Lake, "Big Ideas in Art \& Culture: Suzy Lake."

14 "CV," Suzy Lake, accessed September 10, 2020, http://www.suzylake.ca/untitled-custom-page.
} 
Janine Antoni is a visual artist who was born in Freeport, Bahamas. She moved to the United States, where she pursued an education in visual arts. In the late 1980s, she attended the Rhode Island School of Design; during her time there, teachers and feminist artists Maureen Connor and Mira Schor were direct influences. ${ }^{15}$ Inspired by second-wave feminist body and performance artists, Antoni herself began working as an artist at the height of the third-wave feminist movement. Antoni frequently references her predecessors, including Carolee Schneemann, Hannah Wilke, and Ana Mendieta, and emphasizes that her "strategy has more to do with the feminist artists of the 70s - the humor, the process, the emphasis on performance, the intensely visceral quality of their work." ${ }^{16}$ Antoni's work also exhibits a clear understanding of historical art movements such as Abstract Expressionism and Minimalism. The exhibition catalogue for Antoni’s 1996 exhibition Janine Antoni/Matrix 129 explains,

Weaving various strands of art history together with her own personal (and ultimately private) explorations, Antoni's boldly seductive work explores how contemporary definitions of art-making and aesthetics are elaborately entwined with our cultural constructs of sexual and gender identification. By calling attention to these conventions, as they have been established by art history and by social definitions of women and beauty, Antoni throws many assumptions into question. ${ }^{17}$

These strategies have become quintessential to Antoni's artistic process and subsequent body of work.

Antoni eventually established her career as an artist in New York City. She rather quickly rose to prominence in the early 1990s, during which time she created some of her most wellknown works. Art historian Wendy Vogel refers to Antoni’s 1993 sculptural piece Gnaw as “one

\footnotetext{
${ }^{15}$ Mira Schor, WET: On Painting, Feminism, and Art Culture (Durham; London: Duke University Press, 1997), 226.

${ }^{16}$ Laura Cottingham, "Janine Antoni: Biting Sums Up My Relationship to Art History,” Flash Art (Summer 1993): 104.

${ }^{17}$ Janine Antoni/Matrix 129 (Hartford: Wadsworth Atheneum Museum of Art, 1996), Exhibition catalogue, 2.
} 
of the most buzzed-about works in the controversial 1993 Whitney Biennial, which showcased the era's youngest artists' engagement with identity politics."18 Antoni received recognition in the art community because of her process-driven projects, which were described as "[i]ntense physical rituals." ${ }^{\prime 19}$ Antoni activates her body when she creates art and, whether she is licking someone's eyeball, licking a self-portrait bust made of chocolate or submerging her entire body in a bathtub filled with lard, the way that she uses her body during the process of making gives meaning to her work. ${ }^{20}$

\section{A Harmful Cultural Practice?}

Throughout modern history, makeup practices were largely accepted as a daily routine for the majority of North American women. Sociologist and gender studies professor Rebecca Plante explains that, by the 1950s, between eighty and ninety percent of adult women reported wearing lipstick. ${ }^{21}$ Writer and makeup artist Lisa Eldridge writes that, during the early to midtwentieth century, "popping on a face brightening slick of lipstick was considered well made up." ${ }^{22}$ Wearing cosmetics had become a regular necessity for women when they went out in public. ${ }^{23}$

Sheila Jeffreys argues that cosmetics were, at one point, a positive social practice associated with community, and Kathy Peiss explains, "By drawing upon female sociability and

\footnotetext{
${ }^{18}$ Wendy Vogel, “Turning Inside Out: Janine Antoni’s New Perspective on Sculpture and Dance," Modern Painters, March 2015, 43.

${ }^{19}$ Ibid.

20 “About," Janine Antoni Immaculate Conception Inc., accessed May 15, 2020, http://www.janineantoni.net/biocv.

${ }^{21}$ Plante, "Putting on Makeup," 167.

${ }^{22}$ Lisa Eldridge, "Afterword: I Want to Look Like You," in Face Paint: The Story of Makeup (New York: Abrams Image), 314.

${ }^{23}$ Sheila Jeffreys, Beauty and Misogyny (New York; East Sussex: Routledge, 2005), 113.
} 
customs...women entrepreneurs made formerly hidden and even unacceptable beauty practices public, pleasurable, and normal." ${ }^{24}$ In the late nineteenth and early twentieth centuries, the cosmetic industry provided many opportunities for entrepreneurial women. Ruth Brandon further describes how, "[i]n all other areas of commerce, women were at a disadvantage, but the beauty business was different." ${ }^{25}$ As Geoffrey Jones notes, "Many female businesses, and not only in beauty, began with products made in the owners' own kitchen. ${ }^{26}$ Carla Rice corroborates Jones' statement, explaining that, "surprisingly, ordinary women were industry innovators. Canadian working-class farm girl Elizabeth Arden, Jewish immigrant Helena Rubinstein, and AfricanAmerican domestic servant and daughter of slaves Madame C.J. Walker became successful entrepreneurs. ${ }^{27}$ Many women built beauty empires that outlasted their lifetimes.

Eventually, female entrepreneurs branched out of their homes and opened small salons in their communities. ${ }^{28}$ Kathy Peiss notes:

Handicapped in pursuing standard business practices, they resourcefully founded salons, beauty schools, correspondence courses and mail-order companies; they pioneered in the development of modern franchising and direct-sales marketing strategies. The beauty trade they developed did not depend upon advertising as its impetus. Rather, it capitalized on patterns of women's social life - their old customs of visiting, conversation, and religious observance... ${ }^{29}$

Peiss further asserts that the makeup industry was small, but it was in the hands of those who recognized beauty culture as a "system of meaning that helped women navigate the changing

\footnotetext{
${ }^{24}$ Kathy Peiss, Hope in a Jar: The Making of America's Beauty Culture (New York: Metropolitan Books, 1998; Toronto: YYZ Books, 2004), 95.

${ }^{25}$ Ruth Brandon, "Beauty is Power!" in Ugly Beauty: Helena Rubinstein, L'Oréal and the Blemished History of Looking, ed. Ruth Brandon (Toronto: McClelland \& Stewart, 2011), 8. ${ }^{26}$ Geoffrey Jones, "How Do I Look?" in Beauty Imagined: A History of the Global Beauty Industry, ed. Geoffrey Jones (Oxford; New York: Oxford University Press, 2010), 58.

${ }^{27}$ Carla Rice, "In the Mirror of Beauty Culture," in Becoming Women: The Embodied Self in Image Culture (Toronto: University of Toronto Press, 2014), 236.

${ }^{28}$ Jeffreys, Beauty and Misogyny, 111.

${ }^{29}$ Peiss, Hope in a Jar, 5.
} 
conditions of modern social experience." ${ }^{30}$ Peiss also highlights that, in the beauty industry, women "'found a field that is their own province-working for women with women, and giving that which only women can give — an intimate understanding of feminine needs and feminine desires.' More accurately, it was Rubinstein, Arden, Walker and many other beauty culturists who defined those needs and desires." ${ }^{31}$ Drawing from Peiss' discussion, Sheila Jeffreys writes,

[Women were] getting jobs in offices, stores and occupations where they had to engage in face-to-face interactions. There was a more public marriage market with the development of the dance hall and a new sense of sexual freedom: Moving into public life, they staked a claim to public attention, demanded that others look. This was not a fashion dictated by Parisian or other authorities, but a new mode of feminine selfpresentation, a tiny yet resonant sign of a larger cultural contest over women's identity. ${ }^{32}$

During this period of history, the beauty industry was a meaningful source of independence and creativity for female business owners and their patrons.

Beginning around the 1920s and continuing into the post-war era, the makeup industry started to expand rapidly, and women lost some of their influence in the cosmetics and beauty industry. Ruth Brandon explains that, prior to this development,

[m]en remained noticeably absent from the beauty business... [U]ntil the arrival of Charles Revson's Revlon in the 1950s, women entrepreneurs dominated the beauty scene. This was partly because, as Life magazine observed in 1941, 'Most men do not find an atmosphere conducive to their best work in the tight little matriarchy of the beauty business. ${ }^{33}$

By this point, the beauty industry had garnered significant financial gains and women entrepreneurs had created expansive beauty empires. Ruth Brandon notes that men had "failed to realize what was so obvious to Helena Rubenstein: that half the human race was interested in

\footnotetext{
${ }^{30}$ Peiss, Hope in a Jar, 6.

31 Ibid., 95.

32 Jeffreys, Beauty and Misogyny, 111-112.

${ }^{33}$ Brandon, "Beauty is Power!" 8.
} 
what she had to sell." 34 Of course, the "prospect of enormous profits" ${ }^{35}$ was enough for male entrepreneurs to enter the picture.

As more men entered the business of cosmetics, female entrepreneurs lost control of it, and makeup lost the empowering sense of community that it once had. ${ }^{36}$ Peiss notes, "Beauty culture's original strength — its localism and service orientation-proved a weakness in this changing climate." ${ }^{37}$ Female-owned, female-run beauty salons began going out of business because of the expansion of larger beauty companies, often headed by male executives. ${ }^{38}$ Carla Rice elucidates how "[m]ale owners authorized their involvement in women's appearance work by representing themselves as 'experts' in the 'science of beauty.", 39 Jones cites Anita Roddick, author and founder of The Body Shop, and her 1991 book Body and Soul: Profits with

Principles, The Amazing Success Story of Anita Roddick and The Body Shop where she explains,

The industry is now controlled by men, even though, ironically, it was founded by a handful of powerful women[:]...Helena Rubenstein, Elizabeth Arden, Coco Chanel and Estée Lauder. Most of the cosmetics houses they set up are now no more than baubles in a string of multinational companies. The businessmen who run them betray little grasp of the fact that the notions they are trading in - age, beauty, self-esteem-are more often than not an emotional powder keg for their customers. ${ }^{40}$

Roddick further critiques the evolving beauty industry, stating, "We have an entire industry...that, in order to justify its own spurious existence, must believe that the world is filled with women desperate to cling to their fading youth, eager to believe nonsense dreamed up by

\footnotetext{
${ }^{34}$ Brandon, "Beauty is Power!" 8.

${ }^{35}$ Ibid., 9.

${ }^{36}$ Jeffreys, Beauty and Misogyny, 112.

${ }^{37}$ Peiss, Hope in a Jar, 106.

38 Jeffreys, Beauty and Misogyny, 112.

${ }^{39}$ Rice, "In the Mirror of Beauty Culture," 236.

${ }^{40}$ Geoffrey Jones, "Challenges from New Quarters," in Beauty Imagined: A History of the Global Beauty Industry, ed. Geoffrey Jones (Oxford; New York: Oxford University Press, 2010), 291.
} 
cynical advertising copywriters. ${ }^{\circ 41}$ As feminism began to seep into mainstream popular culture throughout the late twentieth century, the disadvantages that female entrepreneurs and patrons had been experiencing as result of the expanding beauty industry became a topic of interest, and so emerged the beauty debates.

\section{The Beauty Debates in Feminist Literature}

In the 1960 s, as part of the second-wave feminist movement, writers took to their craft and began to define the core values of feminism in greater detail. Beauty debates emerged in this period as a major concern of second-wave feminists; Ana Elias et al. affirm that, "[i]ndeed, the politics of appearance might be said to be foundational to the feminism that emerged in the West..."${ }^{42}$ In the 1980s, writers continued to critically engage with these issues, and several publications addressed feminist writers' perspectives regarding beauty. According to Carol Dyhouse, "[s]econd-wave feminists' concern with the sexual politics of appearance from the 1980s fed into discussions about glamour and consumerism." ${ }^{, 43}$ In 1986, Wendy Chapkis published Beauty Secrets: Women and the Politics of Appearance, and Rita Freedman wrote Beauty Bound in $1988 .{ }^{44}$ Chapkis writes that "beauty is magic offering a first class journey through life for the second sex. [Women] are constantly being assured that beauty will transform men into admirers and drab reality into romantic gestures. ${ }^{~}{ }^{45}$ Carol Dyhouse, discussing Beauty

\footnotetext{
${ }^{41}$ Jones, "Challenges from New Quarters," 291.

42 Ana Elias, Rosalind Gill, and Christina Scharff, "Aesthetic Labour: Beauty Politics in Neoliberalism," in Aesthetic Labour: Rethinking Beauty Politics in Neoliberalism, eds. Ana Elias, Rosalind Gill, and Christina Scharff (London: Palgrave Macmillan, 2017), 6.

${ }^{43}$ Carol Dyhouse, “Glamour for All?" in Glamour: Women, History, Feminism, ed. Carol Dyhouse (London; New York: Zed Books, 2010), 157.

${ }^{44}$ Ibid., 158.

${ }^{45}$ Wendy Chapkis, Beauty Secrets: Women and the Politics of Appearance (Boston: South End Press, 1986), 95.
} 
Bond, sums up the position of many feminist writers in the 80s: "Rita Freedman sets out to explore 'how beauty increases women's status by maintaining women's subordination.”44 However, as the 1980s came to an end, the perspectives of writers and theorists who were engaged in the beauty debates changed with the rise of third-wave feminism.

Lisa Eldridge explains that "[t]he beauty debate heated up in the early nineties," ${ }^{47}$ and Carol Dyhouse similarly acknowledges that, in the 1990s, "feminist writing about the beauty industries developed a harder edge." 48 This harder edge was seen in books including Naomi Wolf's The Beauty Myth: How Images of Beauty Are Used Against Women and Susan Faludi's Backlash: The Undeclared War Against American Women (1991). ${ }^{49}$ Dyhouse explains that both authors of these widely popular and influential books "envisaged patriarchy as fighting back against the gains in freedom women had made in the 1970s. ${ }^{\circ 0}$ In a review of The Beauty Myth, Mary Gotschall writes, "In The Beauty Myth, a provocative new feminist tract which should take place alongside such polemics as Betty Friedan's The Feminine Mystique, Naomi Wolf argues that American women are enslaved by the cultured edict to be beautiful. ${ }^{, 51}$ However, Gotschall laments that the work "lacks moderation, balance, and judiciousness. Miss Wolf goes overboard, hammering away at her central theme with the same fanaticism that she ascribes to women hooked on fad diets." ${ }^{52}$ This criticism is commonplace for Wolf, who has been critiqued for her "extremism" (a critique not uncommon to other writers during this generation). ${ }^{53}$

\footnotetext{
${ }^{46}$ Dyhouse, "Glamour for All?," 158.

${ }^{47}$ Eldridge, "Afterword: I Want to Look Like You," 314.

${ }^{48}$ Dyhouse, "Glamour for All?" 158.

${ }^{49}$ Ibid.

50 Ibid.

${ }^{51}$ Mary G. Gotschall, "Poisoned Apple," review of The Beauty Myth, by Naomi Wolf, National Review, July 8, 1991, 42.

52 Ibid., 44.

${ }^{53}$ Ibid.
} 
Following the feminist literature of the 1990s, Lisa Eldridge notes that "a [later] wave of postmodern feminism put forward less radical thinking." ${ }^{, 54}$ In 2005, Sheila Jeffreys held firm in her book Beauty and Misogyny that "beauty practices in western culture should be understood as harmful cultural practices." ${ }^{55}$ Jeffreys is not alone in this assertion; many third-wave feminist and fourth-wave feminist writers, critics, historians, activists, and artists continue to observe the problematic qualities that beauty rituals maintain. Carla Rice argues in Becoming Women (2014) that, "[w]hile feminist commentary on beauty has mushroomed since the 1970s, many writers continue to wrestle with the same old debate: Are beauty practices manifestations of sexist, racist, and market oppression of women? Or do they afford women opportunities for selfexpression, empowerment, and pleasure?" ${ }^{96}$ Rice cites several authors and their texts, which align with Jeffreys' discussion, and explains, "Some critics contend that patriarchal and commercial interests push women into painful beauty work to satisfy our culturally created desires and assuage fears of difference. ${ }^{" 57}$ Following this statement, Rice references Bonnie Dow's Feminism, Miss America, and Media Mythology (2003), Laura Hurd Clarke and Meredith Griffin's Becoming and Being Gendered Through the Body: Older Women, Their Mothers and Body Image (2007), and Avelie Stuart and Ngaire Donaghue's Choosing to Conform: The Discursive Complexities of Choice in Relation to Feminine Beauty Practices (2005) as examples that contribute to this perspective in the beauty debate. ${ }^{58}$

\footnotetext{
${ }^{54}$ Eldridge, "Afterword: I Want to Look Like You," 314.

${ }^{55}$ Jeffreys, Beauty and Misogyny, 28.

${ }^{56}$ Rice, "In the Mirror of Beauty Culture," 240.

${ }^{57}$ Ibid.

${ }^{58}$ Bonnie Dow, Feminism, Miss America, and Media Mythology," Rhetoric and Public Affairs 6, no. 1 (2003);

Laura Hurd Clarke and Meredith Griffin, "Becoming and Being Gendered Through the Body: Older Women, Their Mothers and Body Image," Ageing and Society 27, no. 5 (2007);
} 
On the other side of the beauty debate are authors who "argue that women are not cultural dupes but active agents. ${ }^{59}$ In 1995, Kathy Davis published Reshaping the Female Body: The Dilemma of Cosmetic Surgery, a controversial text that explores how women who received cosmetic surgery do so with agency and authority over the decision to alter their body. Carol Dyhouse explains that, in Reshaping the Female Body, Davis discussed cosmetic surgery with self-proclaimed feminists; Dyhouse acknowledges that "their motives were complex" and states that Davis "powerfully resists any explanation that would deny the subjectivity or agency of those seeking surgery by presenting them as simple victims of ideological manipulation." ${ }^{\circ 0}$ Linda A. Scott, in her 2005 book Fresh Lipstick: Redressing Feminism and Fashion, also positions herself in opposition to those who subscribe to the idea that beauty practices are always harmful and oppressive. In a review of Fresh Lipstick, Ilya Parkins writes, "The strength of this volume lies in [Scott's] illustrations of what is actually a close relationship between fashion and feminism, through recounting how feminists themselves have used adornment strategically to promote themselves." ${ }^{\circ 1}$ However, Parkins continues by noting that "[ $[$ ]he book features a startling amount of animosity toward feminists. [Scott's] constant use of such adjectives as 'crude' and 'ugly' in relation to feminist activists and projects is a case in point." ${ }^{92}$ Lisa Jacobsen adds to this discussion in a separate review when she states,

Feminists have long criticized mainstream fashion for constraining women's physical movement, glorifying women as sex objects, and encouraging them to invest more in superficial appearances than their intellectual development. Beneath this seemingly

Avelie Stuart and Ngaire Donaghue, "Choosing to Conform: The Discursive Complexities of Choice in Relation to Feminine Beauty Practices," Feminism \& Psychology 22, no. 1 (2012).

${ }^{59}$ Rice, "In the Mirror of Beauty Culture," 240.

${ }^{60}$ Dyhouse, "Glamour for All?," 161.

${ }^{61}$ Ilya Parkins, "Fresh Lipstick: Redressing Fashion and Feminism by Linda M. Scott (Palgrave Macmillan, 2005)," review of Fresh Lipstick: Redressing Fashion and Feminism, by Linda M. Scott, Feminist Theory 11, no. 2/3 (2007): 366.

${ }^{62}$ Ibid. 
liberatory rhetoric, Scott argues, lay a more sinister campaign by feminists to control other women and demean the feminist credentials of fashionable women. ${ }^{63}$

In the beauty debates literature, where Scott differs from many other texts that I have referenced is that Scott looks to the feminist movement as part of the problem. Other writers have more prominently looked to the feminist movement to help guide their critiques of the beauty industry.

The beauty debates in feminist literature have been fraught with divisive discussions; perspectives and arguments were at odds from the beginning. People were often left confused about how they were supposed to behave as feminists. Jo Paoletti recalls this early period in second-wave feminism, when Helen Gurley Brown published Sex and the Single Girl (1962), Betty Friedan published The Feminine Mystique (1963) and Helen B. Andelin published Fascinating Womanhood (1963). Paoletti recalls asking herself, "Which women should I be? Helen Gurley Brown's independent, sexy, young, single girl? Betty Friedan's liberated woman with a career and an equally liberated husband? Or Helen Andelin's domestic goddess, realizing her power by cultivating her femininity?" ${ }^{64}$ The beauty debates in feminist literature are no different. Carla Rice explains in her book Becoming Women: The Embodied Self in Image Culture (2014) that "[t]here is a noticeable groundswell in feminist writing about beauty, both critical and celebratory." ${ }^{65}$ Authors Ana Elias, Rosalind Gill, and Christina Scharff write, "There are many different perspectives on beauty among feminists - by no means can we speak to a singular perspective. Radical feminism, Marxist feminism, black and anti-racist feminisms, and

\footnotetext{
${ }^{63}$ Lisa Jacobsen, "Fashion, Feminism, and the Pleasures and Perils of Consumer Fantasy," review of Fresh Lipstick: Redressing Fashion and Feminism, by Linda M. Scott, Journal of Women's History 22, no. 1 (Spring 2010): 179.

${ }^{64}$ Jo B. Paoletti, "Feminism and Femininity," in Sex and Unisex: Fashion, Feminism, and the Sexual Revolution, ed. Jo B. Paoletti (Bloomington: Indiana University Press, 2015), 36. ${ }^{65}$ Rice, "In the Mirror of Beauty Culture," 240.
} 
postcolonial scholarship all offer contrasting accounts. ${ }^{, 66}$ Just as the diverse values and perspectives of intersectional fourth-wave feminists are part of an ever changing feminist spectrum, the beauty debates cannot be condensed into a binary structure which argue either for or against beauty culture.

\section{“Own Your Beauty": How Feminism Affected the Makeup Industry}

When second-wave feminists began calling for makeup-free lifestyles, beauty companies were sent into a downward spiral ${ }^{67}$ Susan Faludi notes, "Since the rise of the women's movement in the '70s, cosmetics and fragrance companies had suffered a decade of flat-todeclining sales..." ${ }^{98}$ Kathy Peiss also notes that "[ $[$ ] he 'no makeup look' startled cosmetics producers and, according to a CoverGirl publicist, they initially pretended the sweeping attack on beauty products 'wasn't happening.' But the industry soon regrouped. ${ }^{\prime 69}$ Following the decline of the cosmetic industry in the 1970 s, beauty companies swiftly adapted their marketing strategies to suit a demographic of patrons with increasingly political intentions.

When people began to embrace their natural appearances, so did the makeup companies who offered to help achieve a "natural" look with their products. ${ }^{70}$ Faludi explains,

The beauty industry promoted a "return to femininity" as if it were a revival of natural womanhood - a flowering of all those innate female qualities supposedly suppressed in the feminist ' $70 \mathrm{~s} . . .[\mathrm{I}] \mathrm{n}$ the ' 80 s the beauty industry belonged to the cultural look that produced backlash feedback. Inevitably, publicists for the beauty companies would pick up on the warning signals circulating about the toll of women's equality, too-and

\footnotetext{
${ }^{66}$ Elias et al., "Aesthetic Labour," 6-7.

${ }^{67}$ Peiss, Hope in a Jar, 261.

${ }^{68}$ Susan Faludi, Backlash: The Undeclared War Against American Women (New York: Crown Publishing Group, 1991), 213.

${ }^{69}$ Peiss, Hope in a Jar, 261.

${ }^{70}$ Ibid., 262.
} 
amplify them for their own purpose." ${ }^{.11}$

Wendy Chapkis writes, "The daring insistence of early feminists that a woman is beautiful just as she naturally appears has been rewritten in a commercial translation as the Natural Look. The horrible irony of this is, of course, that only a handful of women have the Natural Look naturally." 72 Marlis Schweitzer states "A 'natural' beauty was no longer the woman who eschewed cosmetics, but rather the woman who embraced them."73 Although Schweitzer was referring to an earlier generation, her statement remains relevant in this transplanted context.

This type of targeted campaigning was nothing new. In the first half of the twentieth century, companies cultivated insecurities in single women and stay-at-home mothers. The headline of a prominent 1935 soap ad proclaims, "You've won him—now you must keep him;" this message was intended to give wives the notion that they "can use as much cosmetics as [they] wish if [they] guard [their] skin..." ${ }^{, 74}$ Carol Dyhouse addresses several ads, articles and columns in magazines that promoted sexist intentions with headlines such as "[w]hat makes a girl alluring to men," 75 and "[h]ow to get a boyfriend even when you have pimples on your face. ${ }^{.76}$ As a result of feminism, the industry began preying on cisgender working women. Geoffrey Jones writes,

[B]eauty advertising and marketing did manifest new interest in showing independent professional women and the entry of women into traditionally male occupations. Chanel No.19, launched in 1970, was positioned as appealing to assertive and independent

\footnotetext{
${ }^{71}$ Faludi, Backlash, 212-213.

72 Chapkis, Beauty Secrets, 8.

${ }^{73}$ Marlis Schweitzer, “'The Mad Search for Beauty': Actresses' Testimonials, the Cosmetic Industry, and the 'Democratization of Beauty'," The Journal of the Gilded Age and the Progressive Era 4, no. 3 (July 2005): 292.

74 "50+ sexist vintage ads so bad, you almost won't believe they were real," Click Americana: Memories and Memorabilia, accessed July 2, 2020, https://clickamericana.com/topics/cultureand-lifestyle/50-sexist-vintage-ads-so-bad-you-almost-wont-believe-they-were-real.

${ }^{75}$ Dyhouse, "Glamour for All?," 152.

${ }^{76}$ Ibid., 153.
} 
women in control of their own lives. Estée Lauder and Max Factor advertisements of the 1970s included images of fashionable women getting out of their own expensive sports cars, and well-made-up women as bosses rather than secretaries in offices. There were still plenty of traditional feminine images, but the range of lifestyle choices being offered in the ads had expanded. ${ }^{77}$

Although companies began speaking to professional women, representing them as assertive, liberated and visions of the feminist ideal, these advertisements were not, as Geoffrey Jones concedes, "a step towards equality of sorts." ${ }^{98}$ For example, in a 1988 ad for Nivea Skin Cream, women were asked, "Is your face paying for the price of your success?"79 While the beauty industry wanted to emphasize images of professional women, Susan Faludi argues that they simultaneously made their patrons believe that "equality...create[s] worry lines and cellulite." 80

\section{Language and Gender}

When it comes to the discussion of beauty products and routines in both academic and popular literature, the language overwhelmingly centres on women and is largely heteronormative and Eurocentric. Scholarly writing on this subject is primarily concerned with a gendered exploration of materials and practices in relation to women; she/her pronouns dominate the literature. Cosmetic companies have almost exclusively targeted their marketing strategies towards female consumers, and women's bodies flood the ad campaigns. Slogans and taglines from well-known makeup companies are evidence of these strategies: Avon branded themselves as "the company for women," Revlon advertises that "[t]he most unforgettable women in the world wear Revlon," Elizabeth Arden asserts that "[t]o be beautiful and natural is the birth right

\footnotetext{
77 Jones, "Challenges from New Quarters," 293.

${ }^{78}$ Ibid., 294.

${ }^{79}$ Faludi, Backlash, 213.

${ }^{80} \mathrm{Ibid}$.
} 
of every woman,” Mary Kay is committed to “[e]nriching women's lives," and Charlotte Tilbury states, "Give a woman the right makeup and she can conquer the world." ${ }^{81}$ Nevertheless, just because companies have directed their ads at cisgender-identifying women does not mean that other people are not consuming these advertisements and, subsequently, the beauty products.

To this point, Geoffrey Jones acknowledges that there is "some crossover of products from the female to male markets." 82 Products such as hair dye and skin creams have been marketed towards male consumers, but — as Jones notes - many "companies launched genderspecific brands which made men more comfortable buying them." ${ }^{, 83}$ Analyses of cosmetic use as a commonplace, culturally constructed practice are unfortunately only just beginning to catch up with twenty-first century fourth-wave feminist values, given that more diverse groups (men, women, and genderqueer individuals) use makeup. Rebecca Plante is one author who explores men's relationship to makeup; however, she explains in "Putting on Makeup" that her focus is on “women's everyday acts of 'putting on a face,' not, for instance, men wearing eyeliner ('guyliner') and foundation, [though she does] briefly discuss drag makeup." ${ }^{\circ 4}$ While it is important to acknowledge that she has included men in her discussion, I interpret Plante's statement as a suggestion that associations between cosmetics and men do not contribute to discussions of the "everyday acts of "putting on a face."” Rather, these comparisons are more suited to analyses of the theatricality of makeup — through drag, for example.

\footnotetext{
${ }^{81}$ Jane Andrews, "Can You Name These Makeup Brands from Their Motto?" Howstuffworks Play, accessed July 14, 2020, https://play.howstuffworks.com/quiz/can-you-name-these-makeupbrands-from-their-motto.

82 Jones, "Challenges from New Quarters," 293.

${ }^{83}$ Ibid., 294.

${ }^{84}$ Plante, "Putting on Makeup," 166.
} 
Cosmetics and beauty practices are historically associated with women, cisgender women to be specific, and I do not aim to disassociate gender from cosmetics and beauty practices. In fact, I maintain that this connection to women is critical to understanding the evolution of the cosmetic industry and the ritualized practices that people engage with in their lives. In my research, I draw on my own relationship to cosmetics and adornment to better understand female-identifying artists whose work explores cosmetics and beauty practices with which I connect; however, to maintain intersectional feminist objectives in my writing, I wish to note that I recognize that these female associations with makeup and beauty practices are not an all-encompassing sample of today's society.

In what follows, where possible, I use more inclusive terminology while being mindful of artists' preferred pronouns. The authors that I reference do not tend to use inclusive language; they write as if they are speaking directly to female readers. I do not wish to contribute to the literature that speaks directly to women, as if only women can benefit from discussions of beauty practices. When I reference people more broadly within a discussion of beauty practices, I opt to use they/them, and their pronouns rather than she/her. Ultimately, this is a larger issue that cannot be fully addressed in this thesis and my insistence on inclusive terminology, where applicable, does not remedy the problem; however, by intentionally using inclusive language, I hope that the popular notion that makeup and beauty practices are primarily for women will be re-evaluated. All people who use makeup, frequently or infrequently, should be able to imagine themselves and their own relationships to the materials and the practices, as I have done, while still being aware of the gendered history and industry that has been predominantly concerned with women's relationships to makeup and beauty. 


\section{Feminist Artists 'Makeup' Their Own Rules}

There are many artists throughout history who used makeup in art, and this material has not been exclusive to women artists. In the context of twentieth-century second-wave feminist art, artists who employed makeup have often sought to explore relationships between beauty practices and identity. Cosmetics have served as a tool to investigate the line between the "beautiful" and "ugly, and what this apparent dichotomy means to people's sense of identity.

The exploration of gender, identity, and beauty did not stop with second-wave artists, but continued throughout the twentieth century and remains a topic of interest for feminist artists today. Strategies used to explore cosmetics and beauty practices have varied, ranging from satire and play to the use of the extreme and shocking. Artists have been largely concerned with a critique of beauty practices. Examples of second and third wave artists whose work has been analyzed in relation to cosmetics, decorum, and beauty culture include Martha Wilson, Lynn Hershman, Eleanor Antin, Cindy Sherman, Ewa Partum, Martha Rosler, Lorraine O'Grady, and Orlan.

In my research, I found that artists are not necessarily submissively committing themselves to the act of adornment when they engage in beauty rituals in their art-making; participation in these rituals can, in fact, often be an effective way for artists to critically consider cosmetics and decorum, and guide viewers to understand the issues at hand. When feminist artists discuss their work exploring identity, gender, and beauty, or when critics write about them, many emphasize the importance of regaining control of the culturally constructed practice and redefining it in their own terms. Of course, this is not always the case; for example, Ewa Partum's performance Change concluded when she exclaimed that "she herself was a work of 
art." ${ }^{85}$ On the other hand, Orlan is considered the "creator, not just the creation;" 86 Suzy Lake presents herself as the "beholder and the muse;" 87 and Janine Antoni views herself as the "model and the master." 88 This framework is significant because the artists' positioning of themselves as, for example, the "model and the master" indicates that they are in control of their mark-making despite the fact that they are also the subject of the work. Their mark-making consists of the marks that the artists made on their own bodies with cosmetics. Such a concept defies women's traditional role in art, where they are portrayed by the hand of male artists; it also defies current understandings of beauty where female patrons, in particular, are subject to manipulation at the hand of the male-dominated beauty industry.

Kathy Davis' text “"My Body is My Art': Cosmetic Surgery as Feminist Utopia” on Orlan's work can help us appreciate a key aspect of Lake and Antoni's art. Davis highlights Orlan's acknowledgement that "art has to be transgressive, disruptive and unpleasant to have any sort of social function...[B]oth artist and audience need to feel uncomfortable so that 'we will be forced to ask questions. " 89 Although not as shocking or gruesome as Orlan’s surgical performances, I would posit that many viewers of Suzy Lake's and Janine Antoni’s work feel some level of discomfort when observing their pieces. I do not suggest that discomfort is particularly evident in the visual imagery that viewers see, but rather, it may result from what Lake and Antoni lead viewers to see in themselves.

85 "Ewa Partum," Culture Artists, accessed June 6, 2020, https://culture.pl/en/artist/ewa-partum. ${ }^{86}$ Kathy Davis, "'My Body is My Art': Cosmetic Surgery as Feminist Utopia?" The European Journal of Women's Studies 4 (1997): 30.

87 Zack Hatfield, "Review: Suzy Lake," Arsenal Contemporary Art, accessed June 6, 2020, https://www.arsenalcontemporary.com/press/2020/03/suzy-lake-artforum-zack-hatfield?tag=ny. ${ }^{88}$ Janine Antoni, "Elson Lecture 2018: Janine Antoni," filmed March 1, 2018 at the National Gallery of Art, Washington, DC, video, 10:30, https://www.nga.gov/audio-video/video/elson2018.html.

${ }^{89}$ Kathy Davis, "“My Body is My Art,"” 29. 
Perhaps the most uncomfortable experience is identifying and critically reflecting on one's own life rather than seeing a gruesome image or performance. In the following pages, I argue that Lake and Antoni help people visually identify the conditions that makeup, makeup practices, and the makeup industry have promoted in their lives. By shifting attention to the processes of the adornment routine itself, rather than the finished image of adornment, their works offer a powerful feminist "metaphor" (to use a term of Suzy Lake's) with which those who use cosmetics, or who have direct or indirect experience with varying beauty rituals, can engage. ${ }^{90}$

\footnotetext{
${ }^{90}$ While Lake noted that focusing on herself felt like it "limited the larger context in terms of identity extended beyond the individual," she also explained that "it presents a metaphor that every woman can enter into"; "Suzy Lake Artist Talk," Badischer Kunstverein, Germany, 2013, accessed July 1, 2020, 37:40, https://www.youtube.com/watch?v=1zr19uPBcB4;

Suzy Lake, "Discussing Feminism and Art: A Suzy Lake Interview," interview by Hilary Dow, University of Toronto, accessed June 1, 2020, http://sites.utm.utoronto.ca/historyinternships/blog/03052017-0151/discussing-feminism-and-artsuzy-lake-interview.
} 


\section{Chapter One: Suzy Lake and $A$ Genuine Simulation of... (1973/74)}

\section{Introduction}

Suzy Lake's A Genuine Simulation of... (1973/74) (Figure 1.0) is a series of ninety coloured photographs, arranged in a grid that is 152 centimetres long by 142 centimetres wide, that depict the artist in the act of applying makeup. Each individual portrait presents a moment from what is ostensibly an everyday makeup ritual. Close examination of $A$ Genuine Simulation of..., however, reveals far more than what first meets the eye.

In 1974, a snippet of $A$ Genuine Simulation of ... that had been reduced to only fifteen images was featured on the cover of the exhibition catalogue for Camerart (Figure 2.0). Given the size limitations of the catalogue, the omission of seventy-five images is understandable; interestingly, though, the catalogue showcased a selection of images on the cover rather than a section of images. Not only is Lake's performance reduced significantly, but the implied time that exists between each still frame is also extended and confused. The exclusion of a significant amount of detail from Lake's performance results in the complication of the viewer's interpretation of time and ability to observe Lake's process and visual transformation. In addition, the presentation of $A$ Genuine Simulation of... includes a couple of frames that are out of order-in particular, the first row of images on the exhibition catalogue. The first frame in the catalogue is the twenty-third image in A Genuine Simulation of... and features Lake on the brink of applying cosmetics to her whitened face. This image represents a significant moment in the work because it depicts Lake looking at herself in the mirror after she has applied white pigment to her face; however, rather than showing Lake as she begins to apply makeup, the following image in the exhibition catalogue goes backwards in the artist's process to the eighteenth frame of her original collection, and the third image in the adapted sequence was originally frame 
twenty-one. The first row of images in the exhibition catalogue is completed with two frames that depict Lake using makeup, but the last two images are also out of order. The fourth image of the catalogue cover is frame thirty-one of $A$ Genuine Simulation of... and the fifth image is the thirtieth frame.

Perhaps, by including images from different stages of her performance, these frames were to relay the nature of the ninety-frame, photo-documented performance most effectively; however, the decision to choose a selection rather than a section of images significantly influences understandings of her work. Based on a thorough consideration of the original collection, I would argue that the best way to represent the quality and characteristics of Lake's work would have been to select a sequence of frames that emphasize the slow transition and chronological rigidity of her process. The Camerart exhibition catalogue declares,

The work reproduced on the cover of the catalogue is entitled, "A Genuine Simulation of..." The photos are arranged in sequential order illustrating the process by which the artist, observing a familiar ritual, applied white face make-up and then ordinary everyday make-up. First her own identity is reduced to zero, as it is in mime, a neutral time, a point zero from which a new face can be made. Photography this time as documentation offers this advantage of being able to show a temporal and linear sequence. ${ }^{91}$

This statement indicates that the curatorial team recognized the importance of time and chronology in Lake's piece, though their arrangement does not appear to reflect this recognition.

I begin with this anecdote because, in this chapter, I intend to emphasize the importance of Lake's process. Her presentation of an adornment ritual through process-driven documentation is significant because it allows viewers to engage meaningfully with $A$ Genuine Simulation of .... I also intend to provide a deeper understanding of the work by conducting a close analysis of its individual components. In an exhibition catalogue for Suzy Lake: A Genuine

\footnotetext{
${ }^{91}$ Chantal Pontbriand, "Pontbriand in Translation," in Camerart, ed. Robert Walker (Montreal: Galerie Optica, 1974), Exhibition catalogue, 52.
} 
Simulation..., curator and art historian Chantal Pontbriand writes, "The artist attempts to involve the viewer's response (activity) to this composition of elements through a parallel channel of reading or perceiving the piece." ${ }^{.2}$ Diana Nemiroff further explains that "what we see is not the trace of an earlier 'real' event, but a constructed situation requiring our presence to complete it. ${ }^{" 93}$ Pontbriand and Nemiroff's respective writings were strongly influential for me as I developed this chapter and actively engaged with the work and the ideas that Lake presents.

This chapter is divided into four sections as I explore several poignant questions about the work. Following the introduction, I briefly present the exhibition history and previous interpretations of A Genuine Simulation of.... Next, I consider the history of makeup and its relation to Western feminism in the 1970s; in the same section, I connect this historico-political discussion to Lake's use of miming techniques and whiteface while considering the following questions: how does an understanding of beauty debates in 1970s second-wave feminism contribute to our perception of Lake's work and how does understanding the theory of mime, whiteface, and imitation deepen our perception of $A$ Genuine Simulation of...? Following this exploration, the next section seeks to reveal how a close analysis of the photographic components of A Genuine Simulation of... provides insights that have not been addressed in scholarly literature; to support this assertion, I perform a visual analysis of the work. Close analysis forms an integral part of my engagement with Lake's work as I highlight the importance of the process and address how her process-driven documentation aids in audience engagement. By thoroughly engaging with the piece, I will demonstrate — in the culminating sections - how

\footnotetext{
${ }^{92}$ Chantal Pontbriand, Suzy Lake: A Genuine Simulation of... (Montreal: Galerie Gilles Gheebrant, 1975), Exhibition catalogue.

${ }^{93}$ Diana Nemiroff, Suzy Lake: Political Poetics, eds. Matthew Brower, Carla Garnet and Dot Tuer (Toronto: University of Toronto Art Centre, 2011), Exhibition catalogue, 58.
} 
Lake's work has led to my own personal reflection and how A Genuine Simulation of... can act as a form of empowerment for viewers who recognize and have experience with the adornment acts that she performs.

\section{Exhibition History and Previous Interpretations}

Lake provides a significant amount of information to viewers of A Genuine Simulation of...-a strategy that is not singular in her career. In the 1970s, following Lake's move to Montreal, she began exploring issues of beauty, identity, and decorum. When scanning through Lake's large body of work during her years in Montreal, many visual commonalities arise. Throughout the early to mid-1970s, Lake created photographic images which considered—at varying levels of difference — the idea of a "real" or "genuine self." 94 There are several iterations of Lake playing with cosmetics and whiteface throughout the 70s, including Imitations of Myself $\# 1$ (Figure 2.1) and A Genuine Simulation of... No. 2 (Figure 2.2). ${ }^{95}$ Similarly, serial formations of self-portraits that are rooted in performance and presented through photography were hallmarks of Suzy Lake's work in the 1970s.

Curator and feminist scholar Helena Reckitt explains in the Scotia Bank Photography Award catalogue, Suzy Lake, that audience reception of Lake's early series from the 1970s, On Stage (Figure 2.3), "was not well-received when first shown." ${ }^{96}$ Reckitt continues, "Lake recalls how it provoked criticisms of narcissism and exhibitionism. ${ }^{.97}$ Curator of Canadian Art at the Art Gallery of Ontario and co-curator of the 2014 exhibition Introducing Suzy Lake, Georgiana

\footnotetext{
${ }^{94}$ Heather Davis, Desire Change: Contemporary Feminist Art in Canada (Montreal and Kingston: McGill-Queen's University Press, 2017), 39.

${ }_{95}^{9}$ Uhlyarik, Introducing Suzy Lake, 68.

${ }^{96}$ Helena Reckitt, Suzy Lake (Steidl/Scotiabank, 2017), 170.

97 Ibid.
} 
Uhlyarik notes that On Stage also received "dismissive charges" of "women's work."98 On Stage is a series of eighty images that Lake presented through a slideshow. Lake explains, "It was an early foray into identity and gender. But it was also my introduction to the problems of gender in the art gallery." 99 She continues by explaining that " $[\mathrm{t}]$ he slideshow was intended to be a critique of women's representation in the media. I had hoped that the mimic was a strategy to invert the imposition of who we were, and we were supposed to be." ${ }^{100}$ As Helena Reckitt observes, “[p]erhaps her approach was too subtle and her self-reflective critique of femininity as a commodity ahead of its time." ${ }^{101}$ In 1972, the critiques Lake received led her to remake On Stage three times. ${ }^{102}$ She altered how it was displayed and added didactic material with the intent that it would offer more clarity to her viewers and make the mimicry of femininity more obvious. ${ }^{103}$

After a few years of trying to rework On Stage so that the piece would be received as she had envisioned, Lake continued to explore these issues of identity, gender, and decorum while pursuing a new project. In 1973, prior to A Genuine Simulation of ..., Lake created a photodocumented performance entitled Imitations of Myself \#1. This series of photographs can be read as the foundation of $A$ Genuine Simulation of..., a conceptual and technical starting point from which A Genuine Simulation of... would develop. ${ }^{104}$ In the first frame of Imitations of Myself \#1,

\footnotetext{
${ }^{98}$ Uhlyarik, Introducing Suzy Lake, 68.

${ }^{99}$ Lake, "Big Ideas in Art \& Culture: Suzy Lake,", 9:30.

100 Ibid., 9:45.

${ }^{101}$ Reckitt, Suzy Lake, 170.

${ }^{102}$ Lake, "Big Ideas in Art \& Culture," 10:50.

103 Ibid., 12:05.

${ }^{104}$ Uhlyarik, Introducing Suzy Lake, 44.
}

Uhlyarik explains that these related works were produced early in Lake's professional career and, during the process of shooting Imitations of Myself \#1, the artist came across unexpected technical issues. She ended up casting Imitations of Myself \#1 aside due to the harsh effects of photographing herself under fluorescent lights. ${ }^{104}$ Nearly a year after Lake discarded this piece, she decided to recreate the work and call it A Genuine Simulation of.... Forty years later, after the advent of digital technology, Lake re-printed Imitations of Myself \#1. 
Lake holds up a paper in front of her face that says "a genuine simulation of...." When Imitations of Myself \#1 and A Genuine Simulation of... are read next to each other, their difference in overall scale is significant; A Genuine Simulation of ... portrays Lake's narrative in a sequence of ninety still images whereas Imitations of Myself \#1 is spread out over the course of forty-eight images.

As her career developed, Lake began to achieve some critical success in the art world in Canada - not as a feminist artist who questioned constructs of gender and identity but as an artist who contributed to the development of photography in Canada. A Genuine Simulation of... appeared in the 1974 Camerart exhibition in Montreal and was featured on the cover of the Camerart exhibition catalogue. In the same year, it was exhibited at Art Basel and highlighted in the contemporary magazine Flash Art. ${ }^{105}$ The four essays which were included in the exhibition catalogue for Camerart focused almost exclusively on contributing to emerging theories of photography in 1970s art and illuminating how the artists who were part of this exhibition fit into that discussion. Paul Heyer explains in his essay Image: Product or Proposition that many of the artists in Camerart, including Suzy Lake, create work that is "conceptual, propositional, and cerebral." ${ }^{106}$ Heyer concludes by noting, "If there is a lesson to be learned from Camerart, it must not derive from what the artist has made, but from the activity associated with the making." ${ }^{107}$ Unfortunately, Heyer does not explore the meaning of Lake's activities and how they are "associated with the making." Chantal Pontbriand later directly addresses $A$ Genuine Simulation of..., but she does not acknowledge the feminist social and political meaning of the

105 Reckitt, Suzy Lake, 170.

106 Paul Heyer, "Image: Product or Proposition," in Camerart, ed. Robert Walker (Montreal: Galerie Optica, 1974), Exhibition catalogue, 36.

107 Ibid., 40. 
work. Rather, she explains, "Photography this time as documentation offers this advantage of being able to show a temporal and linear sequence."108

In a 1978 publication of ARTnews, called Canada's Artists with Cameras, writer William E. Ewing also avoids addressing Lake's important exploration of identity and gender when he explains, "Suzy Lake puts her own face and body through transformations. Lake's earlier work used her face as a blank canvas to be manipulated before the camera or in the dark room. She thus plays on the photographic portrait's ability to capture the character of the subject." 109 These quotes demonstrate that Lake's emerging recognition in the mid-to-late 1970s arose because of her use of photography to document transformations and movements.

In recent years Lake has spent time reflecting on her early pieces; she explains that she experienced critiques of narcissism and dismissals of traditional "women's work" and attributes them to the fact that "the artist being female and seen as the subject matter in the work obscured the content." ${ }^{110}$ In 2017, following her first solo exhibition in New York at Arsenal Contemporary Art, writer Zack Hatfield noted that "[p]eers misinterpreting or uncomfortable with Lake's self-centeredness_—with her role as beholder and muse—accused her of narcissism." 111 During an artist talk in 2017, Lake recalled that "women's work" was said between clenched teeth and acted as "an accusation, not an adjective." 112 The artist further explained,

108 Pontbriand, "Pontbriand in Translation," 52.

109 William E. Ewing, "Canada's Artists with Cameras," ARTnews, April 1978, 84.

${ }^{110}$ Lake, "Big Ideas in Art \& Culture," 11:00.

${ }^{111}$ Hatfield, "Suzy Lake."

112 Lake, "Big Ideas in Art \& Culture," 10:40; Suzy Lake, "New Kind of Beauty in Bloom," interview by Leah Sandals, National Post, April 29, 2011, accessed June 10, 2020, https://artmuseum.utoronto.ca/wpcontent/uploads/2016/11/29-04-11-National-Post.pdf. 
Without realizing the persistence of the male gaze, I wondered what I had actually done to mislead my audience. After all, Vito Acconci had just jacked off underneath a gallery floorboard and nobody called it man's art. So why is my identity art 'women's art'? ${ }^{113}$

After decades of reflection, Lake has ultimately answered this question for herself, arguing that “it was read as women's work because makeup is a signifier of women or girls."114

Lake's work has resurfaced in the twenty-first century as a significant part of Western feminist art history. Writer Sky Goodden states, "Despite her important initiations in the 1970s and 80 s, Lake has only recently been subject to international recognition and canonical placement. Her acknowledgement has arrived, in part, with a wave of feminist-art-related exhibitions that sprung up." 115 After some of Lake's early pieces were included in monumental feminist exhibitions such as WACK! Art and the Feminist Revolution (2007), the artist began to receive greater recognition. The curators of $W A C K !$ mounted $A$ Genuine Simulation of... at the entrance of the exhibition, positioning Lake and $A$ Genuine Simulation of... not just at the forefront of this feminist exhibition but also at the forefront of the feminist art movement. Lake highlights that "[m]any years later, when this work was brought forward again, it was the first time that we were, women were, hearing writers, critics and historians talking about the work with a language that was really familiar to how we made it in the first place." ${ }^{116}$ During an interview in 2015, Lake further discussed the reception of $W A C K !$, addressing the male audience in particular:

As the show toured each American city, and Vancouver, men-professional men in the community - would say to me, "I cannot believe how much work in this show contributed to the development of new choices in media, materiality, the sense of scale;

\footnotetext{
113 Lake, "Big Ideas in Art \& Culture: Suzy Lake," 11:10.

${ }^{114}$ Lake, "Artist Talk," 27:45.

115 Suzy Lake, “The Difficulty of Distilling Suzy Lake," interview by Sky Goodden, Momus, March 23, 2015, accessed January 19, 2020, https://momus.ca/interview-the-difficulty-indistilling-suzy-lake/.

${ }^{116}$ Lake, "Artist Talk," 32:00.
} 
the duality of the work; the thoroughness of its thinking." So many of them sounded like they were apologizing for overlooking the work. In other words, we were doing our job, we just weren't in a position where people were citing it. ${ }^{117}$

Since then, Lake's early work—including A Genuine Simulation of ... - has toured around Canada and abroad, being prominently featured in shows.

Lake's recognition, although overdue, has prompted more people to acknowledge the connections between Lake and renowned feminist photographer Cindy Sherman. Suzy Lake and Cindy Sherman are certainly in dialogue with each other; their works have appeared in several of the same exhibitions, including A Bigger Splash: Painting After Performance Art at the Tate Modern in 2012/13 and the 2017/18 exhibition Feminist Avant-Garde of the 1970s at the ZKM | Center for Art and Media. Works by Lake and Sherman are not only shown in many of the same exhibitions, but they also often appear in the same sections of these exhibitions. For example, in Feminist Avant-Garde of the 1970s, both artists are included in the section on roleplay, where "clichés and stereotypes are scrutinized." 118 In the context of role play in this exhibition, it is said that Sherman "examines everyday and historic clichés," while Lake "questions ideals of beauty and flawlessness." ${ }^{119}$ In a review of the exhibition, Thomas Micchelli highlights that "Cindy Sherman has all but owned costume self-abnegation for decades," but, while she was a student at Buffalo State College, Lake was a direct influence on her. ${ }^{120}$

Lake's influence on Cindy Sherman's career cannot be overlooked. Holly Meyers boldly states, “one begins to suspect that Sherman's ascendancy had less to do with quality or rigor...

${ }^{117}$ Lake, "The Difficulty of Distilling Suzy Lake."

118 "Feminist Avant-Garde of the 1970s," ZKM Center for Art and Media Karlsruhe, accessed June 7, 2020, https://zkm.de/en/exhibition/2017/11/feminist-avant-garde-of-the-1970s.

119 Ibid.

120 Thomas Micchelli, “The Feminist Avant-Garde, Now More than Ever," Hyperallergic, May 20, 2017, accessed June 7, 2020, https://hyperallergic.com/380348/woman-feminist-avant-gardeof-the-1970s-sammlung-verbund-mumok-2017/. 
than with her living in New York and her work being cleaner, easier to package and, frankly, sexier." ${ }^{121}$ Lake clearly influenced the development of Sherman's oeuvre, and works such as $A$ Genuine Simulation of... were particularly influential. Robert Longo, a friend of Cindy Sherman, revealed the relationship that he perceived between the pair, recounting an experience shared by him and Sherman when they saw A Genuine Simulation of... on the cover of the Camerart exhibition catalogue. He states,

[We] both thought it was really wonderfully funny and striking in the way [A Genuine Simulation of ...] attacked femininity with its step-by-step, gridded transformation. Its humour was disarming, and the nuances of the detail were extraordinary... I believe Suzy's work aided in the development of both our emerging visions: it reinforced and gave solidarity to Cindy's practice. ${ }^{122}$

Lake has also spoken to the comparison between herself and Cindy Sherman, addressing her thoughts on why Sherman has ultimately become better known around the world:

Oh, the Suzy-Cindy thing? Cindy has always, right from the beginning, gone out of her way to give Eleanor Antin and I credit for being her influences...I went to New York too early: my work that influenced her was thought of as being narcissistic and uninteresting- - "women's work" as an accusation, not an adjective... ${ }^{123}$

Of course, while there are certainly parallels between Lake and Sherman — their use of makeup and decorum, their performance-based photographs, and the way they both seek to critique constructs of gender, femininity, and identity — there are also significant differences that separate their work.

A critical aspect of Lake's work is serial documentation and the process that can be read through it. The self-portraits for which Sherman is more widely known do not follow a

${ }^{121}$ Holly Meyers, "Time to Analyze the Roles We Play," Los Angeles Times, June 8, 2007, accessed June 10, 2020, https://www.latimes.com/archives/la-xpm-2007-jun-08-et-theft8story.html.

${ }^{122}$ Uhlyarik, Introducing Suzy Lake, 51.

${ }^{123}$ Lake, "New Kind of Beauty in Bloom." 
composition that employs a process/progress-driven framework. Sherman did, however, incorporate this structure in some of her early works, notably drawing from works like $A$ Genuine Simulation of... in her 1975 photographic piece Untitled \#479. Art historian Hilary Dow argues that " $[\mathrm{b}]$ oth works comment on constructions of beauty, gender, and appearance, although Lake's treatment of the subject is far more nuanced than Sherman's." ${ }^{24}$ Carla Garnet also addresses major differences that exist between Lake and Sherman in her essay "Contradiction and Oscillation in Suzy Lake's 'Choreographed Puppets,'” explaining,

In Sherman's case, this implied gaze functions as a strategy to absent herself from her work, while in Lake's case it dramatizes the process of revealing herself incrementally. Envisioning a more progressive model than the underlying hierarchy of activity and passivity that supports the dominant power structure, Lake attempts to do more than just repeat normative representations of woman within an existing historical framework. ${ }^{125}$

Garnet further notes that, "while both Lake and Sherman create representations of women as signifiers of a male-dominated commodity culture, presence is essential to Lake's work while absence is a central theme in Sherman's." ${ }^{126}$ Where these two works differ is that Lake shows a process and the rituals of cosmetic adornment, while Sherman does not let viewers observe her in the act of applying makeup. Untitled \#479 documents a visual transformation in her appearance- her progress_-whereas $A$ Genuine Simulation of... emphasizes the process.

${ }^{124}$ Hilary Dow, "Suzy Lake vs. Cindy Sherman: Americanism and the Forgotten Canadian Feminist Art of the 70s," University of Toronto, accessed June 8, 2020, http://sites.utm.utoronto.ca/historyinternships/blog/11282016-0157/suzy-lake-vs-cindy-shermanamericanism-and-feminist-art-70s.

${ }^{125}$ Carla Garnet, "Contradiction and Oscillation in Suzy Lake's 'Choreographed Puppets,"” Carla Garnet, accessed June 10, 2020, https://www.carlagarnet.com/suzie-lakes-puppets.

${ }^{126}$ Ibid. 


\section{Makeup and Miming}

"Really, I look like something from Madame Tussaud's."127 - Suzy Lake

In regards to cosmetics, makeup has had a tumultuous relationship with both feminist movements and Western culture more broadly; early feminist perspectives in Western beauty debates have been subjected to much critical analysis and explored by many contemporary feminist scholars. Nonetheless, when second-wave feminism emerged in North America during the 1960s and 1970s, feminists looked to the beauty industry as "the cornerstone of women's oppression." 128 The anti-cosmetics movement in second-wave feminism was sustained by the notion that makeup was a form of objectification and sexualization. ${ }^{129}$ Angela Smith explains in the introduction of the text Twenty-First Century Feminism: Forming and Performing Femininity that,

The Second-Wave feminists of the 1970s had largely followed Simone de Beauvoir's description of female fashion as a form of 'bondage' which effectively subjected women to lives as sexualized beings who were governed by the sexual desire of men. ${ }^{130}$

As an artist working during the height of this movement, Lake was driven to create a body of work that explored issues of beauty and identity, and A Genuine Simulation of... was produced out of this political context. Thus, understanding the beauty debates that occurred in 1970s

${ }^{127}$ Murray Whyte, "Suzy Lake at the Art Gallery of Ontario: Enduring Beauty, Up Close and Very Personal," The Star, November 12, 2014, accessed January 19, 2020, https://www.thestar.com/entertainment/visualarts/2014/11/12/suzy_lake_at_the_art_gallery_of_o ntario_beauty_and_determination_up_close.html.

128 Peiss, Hope in a Jar, 260.

129 Anna Walker, “The Evolution of: Makeup,” Reader's Digest, accessed January 14, 2020, https://www.readersdigest.co.uk/lifestyle/fashion-beauty/the-evolution-of-makeup.

${ }^{130}$ Angela Smith, "Introduction," in Twenty-First Century Feminism: Forming and Performing Femininity, eds. Claire Nally and Angela Smith (Houndsmill; New York: Palgrave Macmillan, 2015), 4. 
feminism will give context to Lake's practice in the early 1970 s and to the creation of $A$ Genuine Simulation of....

With the insistence that cosmetics and the beauty industry were culprits of oppression, feminists began to reevaluate their relationship to them in the late 1960s and early 1970s. Whether people displayed their resistance through public protests or private, personal activism, the goal was to proudly assert their unadorned natural appearances, thus defying the various aesthetic standards that beauty companies had promoted for many years following the industry's expansion. Throughout the 1960s, the Miss America Pageant was a coveted program that Americans indulged in annually. Feminist art historian Bonnie Dow noted that feminism's "attacks on a cherished American institution would be the event that 'marked the end of the movement's obscurity." ${ }^{, 131}$ Historian Geoffrey Jones notes, "Feminists staged ritual protests at events regarded as demeaning to women. A demonstration against the Miss America pageant in 1968 culminated in the crowning of a live sheep." ${ }^{132}$ Carol Hanisch, known for popularizing the feminist slogan "The Personal is Political," explained that feminists used the highly anticipated televised event, which would be watched in homes across the United States, to assert their “presence as a group and/or media to make women's oppression into a conscious social issue."133 Many writers cite the Miss America Pageant demonstrations in 1968 as a defining moment for the feminist movement, clearly showcasing the movement's engagement with beauty politics.

While political demonstrations were popular among second-wave feminists, many activists began participating in and experimenting with other forms of protest during this time.

\footnotetext{
${ }^{131}$ Bonnie Dow, "The Movement Meets the Press: The 1968 Miss America Pageant Protest," in Watching Women's Liberation 1970: Feminism's Pivotal Year on the Network News (Ubrana; Chicago: University of Illinois Press, 2014), 30.

132 Jones, "Challenges from New Quarters," 292.

133 Dow, "The Movement Meets the Press," 29.
} 
The 1968 Miss America protest — one of many public protests conducted throughout the 1960s and 70s — was a way for feminists to be seen and heard by the general public, but feminists' political concerns were also reflected in their everyday lives. Geoffrey Jones states that "[m]any educated young women in Western countries expressed their resistance by no longer wearing make-up or plucking or shaving body hair, and instead proudly displaying hairy legs and armpits." ${ }^{\prime 34}$ Historian Kathy Peiss also notes,

Beautifying became highly politicized in a climate where social movements recast personal matters as public issues. The counterculture promoted an ideal of the "natural body," evident in men growing long hair and beards and women rejecting makeup. The natural body was considered authentic, real, erotic, and beautiful, a challenge to the artifice and repression of postwar society. ${ }^{135}$

In rejecting beautification rituals in their own lives, feminists aimed to attack the beauty industry on two fronts; their personal protests served to highlight their dissatisfaction with the sexist industry while also ensuring that these businesses faced economic repercussions for their exploitation of women.

As mentioned in the introduction, many feminist artists who were active during this period turned to their studio practices to explore issues related to beauty, cosmetics, and identity. Georgiana Uhlyarik explains in the exhibition catalogue Introducing Suzy Lake that feminists also used similar strategies to broach these topics in their work: "The aesthetic strategies [Lake] deployed — staging, mimicry, masquerade — were common to many of her peers exploring the same issues, foraging a visual language of feminist critique."136 Lake explains in the artist statement for her series Portraits as an Issue of Identity, of which A Genuine Simulation of... is a part, that "artists performed and recorded visualizations of questions we were asking, using the

134 Jones, "Challenges from New Quarters," 293.

135 Peiss, Hope in a Jar, 260.

136 Uhlyarik, Introducing Suzy Lake, 68. 
ordinances at hand." ${ }^{" 137}$ Furthermore, as Lake later explains, the questions that she was exploring in the identity series "rest[ed] in the struggle between true identity, decorum, and role-playing at a time of social and political change." ${ }^{\prime 138}$ Lake poses these questions by participating in the acts that she seeks to critically consider. She does so in a way that does not advocate for beauty and cosmetics but, instead, helps viewers understand the complex issues entangled in beautification practices.

In $A$ Genuine Simulation of ..., the title represents the sole textual element that viewers observe in the piece. The title is a puzzling juxtaposition between two contradictory terms: "genuine" and "simulation." Merriam-Webster defines genuine as "actually having the reputed or apparent qualities or character...sincerely and honestly felt of experiences...free from hypocrisy or pretense," and "actual" or "true." 139 Simulation, on the other hand, is defined as "counterfeit, [and]...the imitative representation of the functioning of one system or process."140 The title of Lake's work encourages viewers to begin thinking about what is "genuine" and what is a "simulation" in the piece.

Lake notes in her artist statement that "[d]evices such as role-playing and make-up were regularly used as masks to metaphorically conceal and reveal." ${ }^{\text {141 }}$ Her choice to use the words "conceal" and "reveal" suggests that, in works where she was using makeup (such as in $A$ Genuine Simulation of...), she is concealing her natural appearance with cosmetics. This

${ }^{137}$ Suzy Lake, "Portraits as an Issue of Identity: Artist Statement," Suzy Lake, accessed September 10, 2019, http://www.suzylake.ca/artist-statement\#1.

138 Ibid.

139 “Genuine,” Merriam-Webster, accessed October 13, 2020, https://www.merriamwebster.com/dictionary/genuine.

140 "Simulation," Merriam-Webster, accessed October 13, 2020, https://www.merriamwebster.com/dictionary/simulation.

${ }^{141}$ Lake, "Portraits as an Issue of Identity." 
explanatory choice may reveal to viewers the issues that exist as a result of the beauty industryan industry which was seen to promote the masking or effacing of individuality through the use of makeup. In Introducing Suzy Lake curator Gabriele Schor also states that Lake's use of whiteface "double-functioned as a mask — to hide behind and reveal.""142 Together, the use of whiteface, the contradictory title, and the meticulous documentation of Lake's adornment process help to uncover the artist's questions regarding beauty, identity, and decorum.

Extensive research on this topic has shown that scholarly literature on the artist's early work with whiteface often includes a discussion of why this practice is significant to the piece. While an interrogation of whiteface is critical to any discussion of works such as $A$ Genuine Simulation of..., this chapter will also acknowledge the theory and technique involved in the artistic practice of mime; an understanding of these elements can deepen viewers' understanding of the artifice and mimicry involved in A Genuine Simulation of.... Lake studied mime when she moved to Montreal in the late 1960s. Curator at the Art Gallery of Ontario, Sophie Hackett explains that whiteface "became the perfect vehicle for exploring individual identity in relation to social expectations, and formed the basis for several important works." ${ }^{\text {"143 }}$ Incorporating the theory and techniques used in mime allowed her to align her performances with the dialogue of gender and identity that she was exploring.

Whiteface and miming help advance Lake's position by further emphasizing the idea of masking — or concealing - her natural appearance. Lake notes that "whiteface was applied to denote mask." 144 Whiteface in miming translates to "position zero" or, as Sophie Hackett

\footnotetext{
${ }^{142}$ Uhlyarik, Introducing Suzy Lake, 44.

143 Ibid., 68.

${ }^{144}$ Lake, "Portraits as an Issue of Identity."
} 
explains, "a neutral, non-individual state from which the story begins." ${ }^{145}$ In the 1988 exhibition catalogue for Suzy Lake: Point of Reference, curator Martha Hanna explains that, with respect to A Genuine Simulation of..., "the whiteface represented a blank canvas which the artist could manipulate; and in the daily ritual of a woman, applying make-up was the foundation for a representation of the self." ${ }^{" 146}$ Lake further explains,

In my artworks, to apply the makeup on the white face, just a normal amount that women would use to enhance themselves, but on top of the white layer it becomes a mask. That way, I can talk about that imposition as a mask to identify with culture-as opposed to identifying with the self... ${ }^{147}$

The first sequence of actions documented in this performance presents the artist in the process of covering her individual facial features. She moves towards neutrality before constructing her altered appearance with cosmetics - a series of actions that spectators witness in later frames. The artist's use of whiteface as a means of exploring identity, femininity, and cosmetics emphasizes that Lake is not striving to make herself pretty or attractive. Lake recounts that she "looked like something from Madame Tussaud's"-referencing the iconic wax museum franchise — which suggests that applying cosmetics atop the whiteface gave her an artificial appearance. ${ }^{148}$

The use of whiteface in A Genuine Simulation of... also positions Lake as the actor-mime in this ninety-image sequence. Miming refers to imitation, particularly imitations that are

\footnotetext{
${ }^{145}$ Uhlyarik, Introducing Suzy Lake, 68.

${ }^{146}$ Martha Hanna, ed. Suzy Lake: Point of Reference (Ottawa: Canadian Museum of Contemporary Photography, National Gallery of Canada, 1988), Exhibition catalogue, 6. 147 "In Conversation: Suzy Lake," interview by Anna Kovler, Arsenal Contemporary Art, November 2019, accessed January 19, 2020, https://www.arsenalcontemporary.com/press/2019/11/in-conversation-suzy-lake?tag=ny. ${ }^{148}$ Whyte, "Suzy Lake at the Art Gallery of Ontario."
} 
recognizable to the mime artist. ${ }^{149}$ Imitation is not singular to the world of mime and acting; mimicry is part of life and appears everywhere around us. Children learn from imitation, mimicking through their own actions what they see and hear. ${ }^{150}$ Imitation is, of course, not always a deliberate act; it is picked up over time and through association with other people and experiences. ${ }^{151}$ According to performance art historian and theorist Richard Schechner, like most daily rituals, acts, performances, observation, mirroring, and repetition are all components of "learning appropriate culturally specific bits of behaviour, of adjusting and performing one's life roles in relation to social and personal circumstances." ${ }^{\prime 52}$ Routines such as cosmetic adornment — among other gender roles and rituals not explored in this thesis — are a learned process. ${ }^{153}$ Nancy Ann Rudd more specifically notes, "Makeup is a learned process that changes over a woman's lifetime, generally beginning in adolescence, increasing during high school, then dropping and leveling off." "154 Lake uses whiteface and makeup in A Genuine Simulation of... to expose the "masquerade of femininity that women have learned to imitate."155

When Lake applies whiteface in the first two rows of $A$ Genuine Simulation of..., viewers witness her becoming the actor-mime. Everything following this section, when Lake uses beauty products, is the artist mimicking the adornment process. Actor, mime, and director Jacques Lecoq explains that mimes imitate what they know; Lake — as a trained mime - is able to

\footnotetext{
149 Jacques Lecoq, "Mime, the Art of Movement," in Theatre of Movement and Gesture, ed. David Bradby (London: Routledge, 2006), 68.

150 Jacques Lecoq, "Imitation: From Mimicry to Miming," in Theatre of Movement and Gesture, ed. David Bradby (London: Routledge, 2006), 1.

${ }^{151}$ Ibid., 2.

${ }^{152}$ Richard Schechner, "What is Performance?" in Performance Studies: An Introduction, ed. Richard Schechner (New York; London: Routledge, 1997), 28.

${ }^{153}$ Nancy Ann Rudd, "Cosmetic Consumption and Use Among Women: Ritualized Activities that Construct and Transform the Self." Journal of Ritual Studies 11, no. 2 (Winter 1997): 63. 154 Ibid.

155 Wark, Radical Gestures, 159.
} 
perform the act of adornment because of her personal experience with cosmetics, and her recognition of the movements and what they signify. Jacques Lecoq further clarifies that "there are several levels of quality in the act of imitating...[Mimes] create the illusion that the person [they] imitate is present in [their] gestures, and will be likewise in all of life's activities." ${ }^{156}$ In $A$ Genuine Simulation of..., Lake creates this illusion because she is performing herself; she imitates her own gestures. Lecoq addresses this concept, elaborating that "[a]ny actor imitates some of the time, and if he is also the author, he performs himself in the role of the one who is imitated." 157 This seems to be what Lake is doing with her art; she is the author but also the one who is being imitated. This concept is highlighted in the title of Imitations of Myself, the piece which predates $A$ Genuine Simulation of.... Lake explained, during a 2013 artist talk at the Badischer Kunstverein in Germany, that "applying makeup on top of the whiteface creates such a strong thick mask quality that I basically felt that I was performing, doing an imitation of myself." ${ }^{158}$ In the photographs that make up A Genuine Simulation of ... viewers can see the thick mask-like quality created through Lake's combination of whiteface and makeup. However, understanding this concept of Lake performing an imitation of herself is not as easily observed in the visual imagery; it requires an understanding of the art of mime and whiteface.

The artist's interest in miming brings to mind the act in which a performer dramatizes being stuck in an invisible box. Even without having to perform the recognizable gestures of repeatedly pressing one's hands up against a firm, flat and imaginary surface while searching for a way out, Lake echoes this act in A Genuine Simulation of... Given that each frame is reminiscent of a box, the artist seemingly uses the shape of the photograph to capture herself

${ }^{156}$ Lecoq, "Mime, the Art of Movement," 68.

157 Ibid., 69.

${ }^{158}$ Lake, "Artist Talk," 31:00. 
constricted in a confined space. In the catalogue for the 2002 exhibition Attitudes et

comportements, Suzy Lake at Musée Regional de Rimouski, the author explains that "[t]o present one's self as a specimen to everyone's gaze and judgement demands a lot more than temerity and courage, it implies a desire to be free of oneself." 159 Instead of motioning to the presence of the box, the process of applying cosmetics in a self-constructed, enclosed space asserts the idea that Lake is trapped within the frame. For people who use cosmetics this can be read as a metaphor for feeling trapped within the repetitive beautification rituals that Lake performs in $A$ Genuine Simulation of... and that makeup users participate in their own lives.

During an artist talk in 2017, Lake stated that—in her early works which explored identity, gender, and decorum — she was "looking for a language and a means for an audience to experience an issue. Not just look at it but experience an issue and a concept more internally." 160 Lake has noted that she was "trying to redefine the representation of what women were. We knew we weren't housewives or mothers, but everything was so new; what was it we were going to be?"161 When she begins to construct a new image for herself on top of the whiteface, Lake is “asking questions about the resistance."162 She explains, "Cosmetics can become a mask to hide behind or to advance a desired image." ${ }^{\prime 63}$ What was it that Lake was going to be? What was it that women were going to be? Moving forward and interacting with A Genuine Simulation of... from a fourth-wave feminist perspective in 2020, I want to consider Lake's question as if she is

159 Jocelyn Fortin, ed., Attitudes et comportements, Suzy Lake (Rimouski: Musée Regional de Rimouski, 2002), Exhibition catalogue, 31.

${ }^{160}$ Lake, "Big Ideas in Art \& Culture," 8:00.

161 Whyte, "Suzy Lake at the Art Gallery of Ontario."

162 Ibid.

${ }^{163}$ Uhlyarik, Introducing Suzy Lake, 77. 
asking me directly.

\section{Taking a Closer Look: A Visual Analysis of $\boldsymbol{A}$ Genuine Simulation of...}

My work is directed by performance strategies, with the intent of having the audience identify their own emotions through the figure. A metaphor is constructed to represent a social dynamic that the audience may be familiar with in their own lives. With luck, they will understand the dynamic to see an empowerment in its resolve. ${ }^{164}$ - Suzy Lake

Art historians have not been concerned, by and large, with offering a detailed visual analysis of this work. My engagement with A Genuine Simulation of ... begins through a close looking exercise; such an exercise is important for developing my analysis of the work while also contributing to the literature on Lake and $A$ Genuine Simulation of... in a manner that has yet to be explored. A Genuine Simulation of ... is not about Lake per se. Rather, as curator of the Sammlung Verbund in Vienna and co-curator of the 2014 exhibition Introducing Suzy Lake Gabrielle Schor explains, it speaks more broadly to "how the individual act of painting one's face can have larger implications, or as a slogan of the women's movement of the 1970s put it: 'The personal is political."" 165 While recognizing how the act of "painting one's face can have larger implications," my engagement with Lake's ideas has also shown that the work can have personal implications for the viewer.

In A Genuine Simulation of ..., Lake invites her audience to witness her private routine; she stages herself as the subject of her performative portraits and captures particular moments of adornment as she applies cosmetics. This work is made up of ninety portraits of the artist, which are arranged in a gridded structure that measures ten photos across by nine down. A Genuine

${ }^{164}$ Suzy Lake, "An Interview with Suzy Lake," interview by Becky Rynor, National Gallery of Canada, February 3, 2015, accessed June 8, 2020, https://www.gallery.ca/magazine/artists/aninterview-with-suzy-lake.

${ }^{165}$ Uhlyarik, Introducing Suzy Lake, 44. 
Simulation of... 's composition is a storyboard-like format that results in a crowded construction of self-portraits lacking in clarity or distinction from image to image. The thick, white lines that are present outline the performative portraits and separate the individual images, helping to control the composition so that the portraits do not bleed into one another and form one large picture of indistinguishable components. While keeping the images disconnected, these borders simultaneously hold all of the frames together within the gridded structure, connecting the images as a compositional whole. This organization emphasizes the gridded structure, which helps to prevent viewers' attention from moving quickly around the series without pause.

Excluding the first and final frame, there is a serial sameness to each image in $A$ Genuine Simulation of..., and Lake does not draw focus to a particular image or section of images. This design choice suggests that no hierarchy exists between images; as a result, process takes precedence in the configuration of photos. Daniel Baird explains, "Although Lake has made videos of performances, like Choreographies of the Dotted Line and Box Concert, 1978, her work has never been fully time based; duration manifests itself in her art in a process of transformation." "166 Lake explains,

I do think of my photographs as having much more of a performance vocabulary no matter how much I love photography and the inherent qualities of the medium. So often times I call them performances and my interest is to actually create an image where there's a sense of duration or sense of performance that the photograph is still performing for you even though it's a still image. ${ }^{167}$

Lake further notes, "I've made a lot of single images, but sequencing and time come back to haunt me a lot." 168 Ninety frames allow for the narrative and visual transformation to unfold

${ }^{166}$ Daniel Baird, "Self-Inventions: The Photography of Suzy Lake," Border Crossings 30, no. 3 (Fall 2011):103.

167 “Suzy Lake: Artist Talk,” Ryerson University, filmed June 9, 2017, accessed June 8, 2020 , video, 14:30, https://ryecast.ryerson.ca/48/Watch/11447.aspx.

168 Baird, "Self-Inventions," 103. 
slowly; the application of cosmetics does not feel rushed. ${ }^{169} \mathrm{New}$ information that was not available in the previous frame is constantly being revealed to the viewer. In this sense $A$ Genuine Simulation of... is reminiscent of a cartoon strip or stop-motion animation. The significance that each of the ninety still images hold is enhanced when they exist all togetherespecially when they are composed in the story-board-like format.

Lake did not simply sit down and begin to apply makeup. A Genuine Simulation of... is conceptual, and Lake's stage is methodically produced to reveal information to the viewer about the artist's adornment process. The artist is seated at a table in her kitchen - a private, domestic setting. The presence of a checkered pattern on the tablecloth, which is mirrored on the artist's shirt, accentuates Lake's stage. This staging, along with the piece's overarching colour palette of blue, red, green, and white, implies that Lake thoughtfully engaged with the adornment process and was concerned with designing a scene that was not disjointed. A Genuine Simulation of... also has many objects placed throughout the space that coordinate with the colour story that the artist has arranged. Including these seemingly mundane objects highlights the everyday nature of Lake's adornment process and establishes it as a normalized set of actions that she performs. The objects remind viewers that, while this is a stage she set and a performance she produced, Lake is nonetheless performing commonplace actions in an otherwise unremarkable house; viewers could be doing the same thing as Lake, and many likely have. Objects include a green teapot, a mirror that rests against the teapot, a hair brush (the most foregrounded object) that is slightly blurred, a white teacup that peers out from the right side of the teapot from time to time, and various cosmetic products that are shuffled around during Lake's process.

${ }^{169}$ Uhlyarik, Introducing Suzy Lake, 44. 
These objects are everyday items that could be found in the home, yet they carry strong associations with stereotypical feminized activities, domesticity, and gender roles. Lake's inclusion of these objects is characteristic of feminist artists in the 1970s. Many artists took up and adapted feminized and domestic tools as a tactic of subversion and parody. They frequently renegotiated their relationships to items like those found in A Genuine Simulation of... - the teacup and teapot, the makeup, and the hairbrush — and transformed them into feminist iconography, objects of liberation and agency. Lake's objects are no different. They also serve a function for the artist; not simply placeholders, the objects are practical tools that Lake uses at various points throughout her private performance. Their functions are revealed to the audience as they advance through the images.

Lake begins this private performance by applying a thick layer of white pigment to her face (Figure 2.4). Upon looking at the first row of images, her application of whiteface seems like it could simply be makeup foundation or concealer. This observation is reasonable at the outset because, in typical adornment routines, the first step is to apply a base layer to one's skin with foundation or a primer gel; however, after viewers progress through the first row of photographs, this interpretation can no longer be justified. The white pigment that covers Lake's entire face is shown to be thick and paint-like, and it does not mimic the effect a makeup foundation and concealer would create. By the twenty-fifth image, Lake has finished applying white paint to her face. Following this sequence of images, which occupies the first quarter of the performance, Lake begins to apply makeup atop the mask of white pigment that conceals hermakeup that starkly contrasts with the whiteface.

When she begins applying conventional cosmetics at approximately frame twenty-six, Lake starts with what looks like foundation, using a shade that closely matches her skin tone. 
The third row presents Lake carving out the contours of her face with lines of makeup that stretch down her cheeks and across her forehead. This technique brings some definition to the artist's facial structure, which was initially concealed with whiteface. Having previously concealed the natural characteristics of her face, it is as if Lake is working to recreate the facial scaffolding that lies beneath the white paint. The performance continues with Lake applying makeup to her eyes, and she finishes the entire process by drawing on eyebrows. In the end, Lake appears artificial and ghost-like. As her individual facial features are nearly completely hidden beneath the dense white pigment, the cosmetics cannot fully override the whiteface. The addition of more artificial materials to the already dense layer of white paint makes it looks like the artist had used copious amounts of cosmetics when, in fact, this was not the case. ${ }^{170}$

In A Genuine Simulation of ..., Lake's frontal position within the frame emphasizes the viewer's positioning across the table; the audience is situated as if they are looking directly at the artist. Viewer/artist engagement in performance art is not a rare occurrence; however, in $A$ Genuine Simulation of ..., this relation is complicated by Lake's absence during the viewing experience. The staging of the images at first appears to suggest that Lake is trying to distance herself from her viewers by performing in a private setting. It is undeniable that her private location in a kitchen is tied to her dialogue with femininity and identity. Similarly, her actions in performance are fitting for the location in which she performs. Rather than emphasize distance between her 'self' and her viewer, however, I maintain that $A$ Genuine Simulation of... creates the opportunity to engage with the concepts and issues that Lake presents in a way that is intimate and more comfortable for the viewer.

170 "In Conversation: Suzy Lake," interview. 
Lake has constructed a scene that is easily recognizable, which leads me to imagine my own experiences of sitting with someone and having a conversation with them as they applied makeup. This reflection translates to how I perceive Lake's work; however, when I engage with Lake in this looking exercise, the artist does not interact with me. Her focus is on her adornment, though — in some instances_-Lake peers towards the camera lens as if it is a surrogate for the viewer's eyes. ${ }^{171}$ As the performance unfolds, and the audience follows along with her, there are moments where she gazes outwards, pausing from her cosmetic routine (Figure 2.5). The first time that she looks up is when she has finished applying whiteface and the next stage of adornment is about to take place. Starting at the twentieth frame and continuing through to frame twenty-two, Lake's eyes are momentarily drawn away from the mirror as she purses her lips together. Following the moments where she looks out towards the viewer, Lake sips a drink, pulls her hair back and begins to apply makeup. She is focused again, consumed by her changing appearance that she sees in the mirror. Lake does not look outwards again until more than halfway through the performance. The viewer, however, engages with her the whole time. Although it does not occur frequently, when Lake does look up, it is as if to acknowledge the viewer's presence.

It is at the end of the performance where the audience is inclined to feel truly includednot simply viewers anymore but participants in the artist's intellectual process. We have remained present across from Lake on the opposite side of the table throughout the entirety of the artist's adornment process; however, the end of the performance is the point at which Lake invites us closer. A Genuine Simulation of ... concludes with the artist fully adorned in cosmetics and her facial appearance is subsequently fully altered. Lake does not, however, present her

${ }^{171}$ Uhlyarik, Introducing Suzy Lake, 44. 
newly formed appearance to spectators directly through the lens of the camera. Instead, in the final frame, spectators gaze upon Lake through a photograph of the artist's reflection in the mirror, which reveals only a portion of her face. Not only does the placement of the camera change for the final frame, but the mirror complicates the way in which viewers engage with Lake; we are now positioned behind Lake, and it is as if we are peering over her shoulder. At first, this effect feels inappropriate, as though we are intruders spying on the artist from a position where she cannot see us. It feels like we are crowding Lake's personal space. Yet in lieu of the intrusion that we experience, we are also in a familiar position. We are no longer simply viewers of Lake's adornment routine, a collection of subjects on the other side of the table; instead, we are positioned in Lake's position.

This is an intriguing shift in perspective, and the change is made clear by writer Daniel Baird when he explains that "Lake is more interested in process and revision, the way roles are inhabited by living bodies, than in maintaining anything like an illusion." ${ }^{172}$ Rather than view her finished work, she invites viewers to her side of the table where we view her through the mirror; we cannot see Lake now without seeing ourselves. Surveillance of the artist from this new perspective is not just about Lake but about the viewer as well. Her routine, her adornment, and her gestures are now a reflection of our routines, our adornment, and our gestures. Perhaps, as Lake is miming, she offers an imitation of our own personal adornment routines.

As a viewer, my feelings of recognition and relatability towards Lake's routine are continuously complicated by the theatricality and exaggeration of her performance. Given that Lake's performance begins with the artist applying whiteface, it would be reasonable to assume that viewers are instantly made aware that this is more than a regular adornment routine. In $A$

172 Baird, "Self-Inventions," 101. 
Genuine Simulation of..., Lake constantly vacillates between the exaggerated and natural, the ordinary and the extraordinary. The artist goes to great lengths to make sure that this performance is an honest portrayal of cosmetic adornment. Lake's process is identifiable; she constructs a recognizable scene, and her use of the cosmetics seems natural. Lake emphasizes the ordinary in her performance with the cosmetics that she uses, including blush, eye makeup and lipstick. These materials are common to me and likely to people who use cosmetics daily. Her actions display verisimilitude; the way that she dabs makeup on her eyelids or lips does not veer from the traditional, Western techniques in which I have taken part. The way in which she moves her body to apply the pigment in different areas of her face is an authentic representation of an average, able-bodied person's natural reflexes during cosmetic application. Furthermore, there are several instances where Lake pauses her makeup routine to fix her hair, have a drink, smoke a cigarette, and engage with her emerging image by posing in the mirror. Had she not applied whiteface, there would be no indication that this series of images was anything more than some personal photographs of Lake in the process of getting ready. These small acts affirm this performance as an ordinary process, one that many individuals participate in on a frequent or even daily basis.

At the same time, any attempt to relate to A Genuine Simulation of... is constantly contradicted by the fact that Lake is simultaneously striving to remind audiences that this is a performance and that she is the performer. Is there anything in the teacup from which she sips and does she inhale smoke from the cigarette that is in her hand, or are all of the gestures and "natural" objects featured in this adornment process part of Lake's acting as well? As I grapple with my personal relation to the piece, what I realize is that I relate to Lake as the performer in $A$ 
Genuine Simulation of ... because I am the performer too.

\section{Reflection and Empowerment}

“... the search for one's voice and one's self often takes place in the dynamic of resistance." ${ }^{173}$ - Suzy Lake

Through my close looking exercise, I am reminded of theory put forth by German playwright and director Bertolt Brecht—particularly Verfremdungseffekt, which is otherwise known as the Alienation Effect. The Alienation Effect is the basis of Brechtian theory. Elin Diamond explains that it is "the technique of defamiliarizing a word, an idea, a gesture so as to enable the spectator to see or hear it afresh: 'a representation that alienates is one which allows us to recognize its subject, but at the same time make it seem unfamiliar." ${ }^{174}$ The Alienation Effect was a common strategy used in feminist theatre of the 1970s. Karen Laughlin notes that second-wave feminist theatre in the United States is indebted to Brechtian theory as his work "played a significant part in shaping emergent feminist theatre." 175 Elin Diamond further recognizes that "[f]eminist practice that seeks to expose or mock the structures of gender usually uses some version of the Brechtian A-effect. That is, by alienating (not simply rejecting) iconicity, by foregrounding the expectation of resemblance, the ideology is exposed and thrown back at the spectator." ${ }^{176}$ A Genuine Simulation of... is not a theatre performance; however, Lake's emphasis on process and the dismantling of illusion in performance-based photography recalls Brechtian theory.

${ }^{173}$ Lake, "Big Ideas in Art \& Culture," 12:50.

${ }^{174}$ Elin Diamond, "Brechtian Theory/Feminist Theory: Toward a Gestic Feminist Criticism," TDR 32, no. 1 (Spring 1988): 84.

${ }^{175}$ Karen Laughlin, "Brechtian Theory and American Feminist Theory," in Brecht Sourcebook, eds. Henry Bial and Carol Martin (London; New York: Routledge, 2000), 213.

${ }^{176}$ Diamond, "Brechtian Theory/Feminist Theory," 84. 
In Jane Wark's chapter "Roles and Transformations," taken from Radical Gestures:

Feminism and Performance Art in North America, Wark explores the idea of Brechtian theory when discussing artists who incorporate makeup, decorum, and role-play in feminist performance art, including Lake in this analysis. She describes the Alienation Effect and its connection to feminist art thusly:

[It is an effect] whereby the feminist performer in art or in theatre can simultaneously inhabit herself (as woman/character) and stand beside herself (as actor/agent) in order to show or mimic how the reiteration of stylized acts produces gender, rather than the other way around. ${ }^{177}$

Following this quote, I am reminded of the sensation that Lake experienced when she incorporated makeup and whiteface into her work, the feeling that she was doing an imitation of herself. Lake is the actor/mime and she is herself simultaneously; "the Brechtian "performersubject disappears neither into a representation of the character nor into a representation of the actor: each remains processual, contingent, incomplete." ${ }^{178}$ In doing this in A Genuine

Simulation of..., Lake pulls back the curtain on the private act of cosmetic adornment. As curator of Attitudes et comportements, Suzy Lake Jocelyn Fortin explains,

By revealing the tricks of makeup, hairstyle, clothing, and posture- essential female assets, according to many-Lake broaches some of the issues brought up in the fervour of the feminist movement so present in the seventies. Lake sheds light on a certain female captivity: a disposition to use one's body as a factor of esteem and recognition, rather than highlighting one's intellectual and personal qualities. ${ }^{179}$

By making this act public and allowing viewers to peer into her adornment routine, Lake does not shine a positive light on the act but rather allows viewers to see it "afresh," as Elin Diamond writes.

177 Wark, Radical Gestures, 126.

${ }^{178}$ Ibid., 127-128.

${ }^{179}$ Fortin, Attitudes et comportements, Suzy Lake, 32. 
Brechtian theory in feminist theatre requires an engaged spectator "ask[ing] the audience to be more mentally active." ${ }^{180}$ But more than an engaged spectator, Josette Feral notes that the Alienation Effect "requires participation from an informed spectator." 181 Diamond further explains that Brechtian theory in performance "invites the participatory play of the spectator, and the possibility for which Brecht most devoutly wished, that significance (the production of meaning) continued beyond play's end, congealing into choice and action after the spectator leaves." ${ }^{\prime 182}$ The title of this piece is the first indication for viewers that Lake is seeking an audience that engages with the ideas that she presents; while she is the main subject presented in the work, the title is not $A$ Genuine Simulation of...Suzy Lake. The ellipsis in the title welcomes viewers to involve themselves in the piece, emphasizing that this work is not only about Lake. Martha Hanna cites Gail Fisher-Taylor's 1990 essay At the Epicenter in the exhibition catalogue for Suzy Lake: Point of Reference, highlighting that "[i]t is...one of [Lake's] intentions to create work that can be actively experienced rather than just passively observed." 183 In the exhibition catalogue for the 2004 exhibition Point \& Shoot: Performance and Photography, curator Diana Nemiroff discusses Suzy Lake's work, and - although her discussion does not directly reference A Genuine Simulation of...-Nemiroff explains that the drama in Lake's work lies in the "fundamental exchange between artist and audience or, more generally, between self and other." ${ }^{184}$ As Fisher-Taylor continues, "In order for the work to function in this way, the viewer

${ }^{180}$ Philip Glahn, "Brechtian Journeys: Yvonne Rainer's Film as Counterpublic Art," Art Journal 68, no. 2 (2009): 92.

${ }^{181}$ Josette Feral and Jon Bermingham, "Alienation in Multi-Media Performance," Theatre Journal 39, no. 4 (December 1987): 462.

${ }^{182}$ Diamond, "Brechtian Theory/Feminist Theory," 86.

${ }^{183}$ Hanna, Suzy Lake: Point of Reference, 9.

${ }^{184}$ Diana Nemiroff, Point \& Shoot: Performance and Photography, eds. France Choinière and Michèle Thériault (Montreal: Dazibao, 2004), Exhibition catalogue, 43. 
must have prior experience to fuel an emotional response." ${ }^{185}$ As this chapter has demonstrated, when I view A Genuine Simulation of..., I do so as an engaged and informed spectator. Lake's performance of an adornment routine leads me beyond the visual aspects of $A$ Genuine Simulation of... and towards my own personal reflection.

I have been a patron of the beauty industry since I was thirteen. My makeup skills today are adequate; I found a routine that suited me and products that I was comfortable using when I was a teenager, and my adornment has not drastically evolved in the ensuing time. Looking back, I recognize that the reason that I started using cosmetics was because I viewed beauty products as a tool to make myself appear more attractive. Analyzing this further, my inclination to make myself more aesthetically pleasing with cosmetics was because I felt like I was supposed to be beautiful. This internalized obligation to be attractive masqueraded itself as personal desire, and the frequent wearing of makeup by the women around me normalized its use. Reflecting on these feelings, I found that I was experiencing a desire to control how others perceived me, and makeup provided a means of achieving this goal. Writer and sociologist Rebecca Plante effectively conveys her feelings when she wears no makeup, which align with my own. She writes,

Even on the rare days when I do not apply any makeup, I look in the mirror, attempting to imagine what others will think of me. How will they read the impression I am trying to make? Am I managing that impression effectively, actively creating a storyline or narrative for my self-presentation? ${ }^{186}$

And so, I recognized why I began using cosmetics, but it was still unclear to me why I continued to wear makeup as an adult.

${ }^{185}$ Hanna, Suzy Lake: Point of Reference, 9.
${ }^{186}$ Plante, "Putting on Makeup," 165. 
I have never been compelled to wear a lot of makeup and I never experiment with cosmetics by trying new products or playing with colours; however, there was a period in my life where I felt more comfortable wearing makeup than going without it. Allison Vandenberg explains a related phenomenon when she writes,

[S]omeone who generally wears very little makeup, whose hairstyle requires very little use of product, and whose clothing does not require complicated undergarments, may experience a similar moment of misrecognition if given a makeover with the techniques and products she does not ordinarily employ. She may feel weighed down..."187

Building upon Vandenberg's earlier argument, in my experience, I have found that wearing more makeup than usual or trying different looks produced less discomfort for me than wearing no makeup at all. This discomfort came from an acute awareness that my face was unadorned during school, work, and social gatherings. I also suffered because I sincerely believed that everyone else noticed my insecurities when I was not wearing makeup.

What is it about makeup that makes me feel confident? Why was I more comfortable wearing layers of product on my face and body? How could the weight from mascara on my eyelashes or foundation on my skin be less of a burden then the idea of wearing no makeup at all? Maintaining the illusion became easier than confronting the process that created the illusion. It is the concept of not feeling like myself without makeup that sticks out to me as an important takeaway from my engagement with $A$ Genuine Simulation of.... Lake asserts that "[e]mpowerment can come from understanding the elements of resistance. Once you see the power dynamic that you're caught in you have the beginning understanding to dismantle it."188 Sociologist Rebecca Plante also affirms that "[p]utting on makeup involves playing a part and

${ }^{187}$ Allison Vandenberg, "Toward a Phenomenological Analysis of Historicized Beauty," Women's Studies Quarterly 46, no. 1/2 (Spring/Summer 2018): 172

188 “Suzy Lake: Artist Talk," 21:00. 
using cosmetics to create an illusion." ${ }^{189}$ In A Genuine Simulation of ..., Lake emphasizes this notion of "playing a part," but—rather than create an illusion—she breaks it down through her presentation of the process. By representing the duration of her performance through meticulous documentation, she also gives viewers the opportunity to recognize the impact that such illusions have on their own lives.

\section{Conclusion}

In Lake's photo-documented performance, the artist is not literally present, but the viewer is. Art historian Frazer Ward notes that "distantiation and mediation is centrally characteristic of much performance art and suggests that presence is not straightforward, and that the body is not given." ${ }^{190}$ Experiencing A Genuine Simulation of... as a performance is not straightforward, because viewers can see Lake but know that they are not physically with her. Still, Lake explains that she seeks to create the "sense that the audience could actually almost walk into the photograph or that they could identify with the figure as another person." 191 This gives spectators the opportunity to form their own connections to Lake's performance. In the 1975 article Suzy Lake Par Suzy Lake: Images et Metaphores, Laurent Lamy writes, "Ce moi, la photo lui permet de le tenir à distance...Ce moi, coupé d'elle-même comme s'il s'agissait d'une autre personne, est en même temps aussi près d'elle qu'il se peut." 192 What Lamy is suggesting is that Lake's use

189 Plante, "Putting on Makeup," 165.

${ }^{190}$ Frazer Ward, "Introduction: Reimagining the Audience," in No Innocent Bystanders: Performing Art and the Audience, ed. Frazer Ward (Hanover: Dartmouth College Press, 2012), 10. 191 "Suzy Lake: Artist Talk," 20:50.

192 Laurent Lamy, "Suzy Lake par Suzy Lake: image et métaphores," Vies des Arts 20, no. 78 (1975), 32 . 
of photography keeps the viewer at a distance while the acts that she performs bring the viewer closer.

As a person viewing $A$ Genuine Simulation of... nearly fifty years after it was created, from a fourth-wave feminist perspective, this work still resonates with me. Similarly, during an interview with Suzy Lake in 2020, artist and writer Anna Kovler mentioned that viewing Imitations of Myself \#1 and \#2 - a series of images that act as a conceptual starting point for her later piece, A Genuine Simulation of... - made her suddenly aware of her own makeup rituals. ${ }^{193}$ Whether viewed in Montreal in the 1970s, when it was created; in Toronto, at Suzy Lake's retrospective at the Art Gallery of Ontario in 2014; or ten years from now, perhaps in a virtual setting, audiences can connect with Lake's work. Viewers follow along with Lake throughout the stages of her meticulously documented performance, engage with the work and the ideas presented, and are led towards personal reflection regarding their experiences with beauty rituals.

193 "In Conversation: Suzy Lake," interview. 


\section{Chapter Two: Janine Antoni and Butterfly Kisses (1996-99)}

\section{Introduction}

Janine Antoni's Butterfly Kisses (Figure 1.1) is a set of drawings created in 1993 and was revisited by the artist between the years of 1996 and 1999. The black lines which make up Butterfly Kisses are created from CoverGirl Thick Lash Mascara. The title of the piece references the actions that the artist performed to create the resulting image; Antoni applied mascara to her eyelashes and then transferred the pigment to paper through the act of "butterfly kissing"—an innocent, intimate, and playful gesture involving someone gently brushing their eyelashes on another's skin. Antoni takes this intimate and fleeting show of affection and subverts the act by putting its material traces on display. Put differently, Antoni transforms the butterfly kiss into an image for people to view - the exact opposite of the standard practice of butterfly kissing, which leaves no visible traces. Butterfly kissing in this work becomes a purposeful aesthetic technique. Through intentional, laborious actions, Antoni paradoxically evokes an air of playfulness while questioning beauty and femininity as it is interpreted in art history and popular culture. She also provides her audience with a novel opportunity to question beautification practices.

The way Antoni activated her body during the creation of Butterfly Kisses is significant; her creative process is often driven by the way her body interacts with materials and spaces. Antoni explains, "I begin with the idea of an experience I want to give myself. The meaning reveals itself to me through the experience, through the process." 194 Visualizing and understanding the performance that created Butterfly Kisses can ultimately help in understanding the still image on view. The performance, the creation of the object, and audience interaction-

194 Cottingham, “Janine Antoni: Biting Sums Up My Relationship to Art History,” 105. 
among other elements - all contribute to understanding the artist's process. However, when the artist removes herself from the viewing experience and the performance aspect is hidden, viewers must fill in the gaps that are missing. Antoni explains,

By removing myself, I allow the viewer to have a relationship to the object. Inevitably, through the traces, the viewer is brought back to the process I went through to make the work. The viewer is left to fill in the story within that gap - the space between process and object. Thus, I create a space for the viewer to exist, to participate in the work. If I'm performing, it is much more difficult to create that circumstance because the focus is on me. ${ }^{195}$

When viewers engage with Butterfly Kisses in this way, they gain insight into the creation of the work wherein Antoni's exploration of beauty culture is not only revealed but draws the viewers attention towards their own relationship to beauty culture as well.

In The Art of Janine Antoni: Labor, Gender and the Object of Performance art historian Stephanie Karamitsos explains, "the object of performance is not simply a case of things that are created but of situations and relationships. ${ }^{196}$ In this chapter I will emphasize relationships: relationships between artist and viewer, between artist and cosmetics, between viewers and cosmetics, and I will also consider my own relationship to Butterfly Kisses. Antoni explains, "The key word for me is empathy." 197 I aim to articulate how Butterfly Kisses can affect the viewer in a meaningful way if they are able to establish a relationship to Antoni and the acts that she performed in the making of Butterfly Kisses.

Keeping in mind Antoni's key word, “empathy," this chapter is divided into seven separate sections which lend to my overall discussion of Butterfly Kisses. Following the introduction, I will briefly discuss exhibition history and existing interpretations of Butterfly

\footnotetext{
${ }^{195}$ Martha Buskirk, The Contingent Object of Contemporary Art (Cambridge: MIT Press, 2003): 139.

196 Stephanie Ann Karamitsos, "The Art of Janine Antoni: Labor, Gender and the Object of Performance," (PhD Diss., Northwestern University, 2006), 342.

${ }^{197}$ Ibid., 341.
} 
Kisses. I will then move into the section called "Covered, Girl: Beauty Practices and Materiality of Cosmetics." In this section I will explore Antoni's application of consumer products as fine art materials. Next, I will provide a detailed visual analysis of Butterfly Kisses. I seek to examine and understand the subject matter of Antoni's work before moving beyond what I can see in the static image and exploring the mystery of making Butterfly Kisses. In the following section, "Understanding the Mystery of the Making: A Phenomenological Exploration of Butterfly Kisses," I will recount my engagement with this work, my pursuit to solve the mystery, and in effect how this engagement led to experiencing empathy towards Antoni and what she was presenting in Butterfly Kisses. Before concluding, I will discuss audience engagement more broadly and consider how viewers can achieve empathy in their viewing experience as well.

\section{Exhibition History and Previous Interpretations}

Antoni's extensive and impressive curriculum vitae shows that, since 1993, she has regularly exhibited her work around the world in a wide variety of shows that foreground a range of themes. Butterfly Kisses (1993) appeared in PerForms: Janine Antoni, Charles Ray, Jana Sterbak, at the Institute of Contemporary Art in Philadelphia in 1995. ${ }^{198}$ Butterfly Kisses (199699), was included in several exhibitions between 1996 and 2020, including; Drawing from the Modern, 1975-2005, in 2005/06; the 2006/07 exhibition, Out of Time: A Contemporary View at the Museum of Modern Art; the 2011 Dance/Draw exhibition at the Institute of Contemporary Art in Boston; and the 2016 exhibition This is a Portrait if I Say So: Identity in American Art,

\footnotetext{
198 Judith Tannenbaum, PerForms: Janine Antoni, Charles Ray, Jana Sterbak, Edited by Judith Tannenbaum (Philadelphia: Institute of Contemporary Art University of Pennsylvania, 1995), Exhibition Catalogue, 21.
} 
1912 to Today, held at the Bowdoin College Museum of Art. ${ }^{199}$ Most recently, in 2020, Butterfly

Kisses could be seen in the Bodyscapes exhibition at the Israel Museum in Jerusalem. ${ }^{200}$ These exhibitions situate Antoni's work in various narratives to which Butterfly Kisses can speak: minimalism and experimentation in performance, "a labor-intensive response to time," "drawing's ability to encode movement," "a portrait of the artist...through the evocation of intimate contact," and "the body as a means of marking and delineating physical and symbolic territories and boundaries..."201

Aside from Butterfly Kisses' presence in exhibitions and recognition from galleries and curators, this work has not been the subject of much scholarly research or critical discussion in comparison to some of Janine Antoni's other, more popular works. In academic literature, Butterfly Kisses is certainly one of Antoni's under-appreciated pieces from the 1990s. When

${ }^{199}$ Drawing from the Modern, 1975-2005, Museum of Modern Art (MoMA), accessed May 27, 2020, https://www.moma.org/calendar/exhibitions/105;

Out of Time: A Contemporary View, Museum of Modern Art (MoMA), accessed May 27, 2020, https://www.moma.org/calendar/exhibitions/5?locale=en; Dance/Draw, Institute of Contemporary Art Boston, accessed May 27, 2020, https://www.icaboston.org/exhibitions/dancedraw; This Is a Portrait If I Say So: Identity in American Art, 1912 to Today, Bowdoin College Museum of Art, accessed May 27, 2020, https:/www.bowdoin.edu/artmuseum/exhibitions/2016/this-is-a-portrait-if-i-say-so.html.

${ }^{200}$ Yael Edelist, "Innovative Exhibition Exploring the Body, Nature, and Knowledge Across Time and Media To Premiere at The Israel Museum, Jerusalem in February 2020," Resincow and Associates, January 7, 2020, accessed May 27, 2020, https://resnicow.com/clientnews/innovative-exhibition-exploring-body-nature-and-knowledge-across-time-and-mediapremiere.

201 Tannenbaum, PerForms, 3, Exhibition Catalogue;

Janine Antoni, Butterfly Kisses, 1996-99, Museum of Modern Art (MoMA), accessed December 19, 2020, https://www.moma.org/collection/works/82074;

Scott Roben, "Dance/Draw," Freize, March 20, 2012, accessed May 27, 2020, https://frieze.com/article/dancedraw;

Anne Collins Goodyear et al., This Is a Portrait If I Say So: Identity in American Art, 1912 to Today (New Haven: Yale University Press, 2016), 108;

Edelist, "Innovative Exhibition Exploring the Body, Nature, and Knowledge Across Time and Media." 
Antoni's work is analyzed, one of the key themes that arises is her application of the body and the hidden performance that creates her work and captivates viewers with its allusiveness. Her choice of materials and how she interacts with them is also a major focal point among scholars. In most cases, analyses of Butterfly Kisses occur as secondary discussions that are intended to provide context for other works by Antoni.

For example, what Antoni does in Butterfly Kisses is essentially create art with her hairher eyelashes, to be specific; however, what is more frequently discussed in relation to Antoni creating art with her hair is Loving Care, a performance from 1993 (Figure 3.0). Butterfly Kisses has been described as the drawn equivalent of Loving Care. ${ }^{202}$ In Loving Care, the artist dips her hair in black hair dye and mops the gallery floor, leaving behind expressive black strokes of hair dye. Despite parallels between these works, Loving Care has received more significant scholarly attention than Butterfly Kisses. This imbalance is especially interesting because the material product of the 1993 performance has long since been washed away from the gallery floor; all that remains is photographic imagery of the performance. Yet, Butterfly Kisses is a piece that remains as it was two decades ago.

One could also consider her 1992 work Gnaw (Figure 3.1); just as Loving Care is the painting equivalent of Butterfly Kisses, Gnaw can be viewed as a sculpted analogue. Gnaw and Butterfly Kisses are perhaps more closely related than Loving Care because both were created through a hidden process during the artist's private performance. Sculpting massive cubes of chocolate and lard with her teeth, Antoni took the remnants of the material that she had chewed and made heart-shaped packages for chocolates_recalling a cliché gift one might receive on

202 Antoni, “Elson Lecture 2018: Janine Antoni," 10:43. 
Valentine's Day — and tubes of lipstick made from lard. ${ }^{203}$ As with Butterfly Kisses, what exists today of Gnaw are the objects that Antoni created through her intimate interaction with the materials. Stacie M. Lindner explains, when discussing Gnaw, that there is an expectation to "see the artist feasting on chocolate...; in lieu of such dramatics, they must examine the relics more closely for meaning." 204 While the acts that the artist performed in Gnaw and Butterfly Kisses are different, the visceral objects which these ritualized and repetitive acts created drives the viewer to understand the mystery of the making.

Alongside commentary on how Antoni activates her body and engages with materials in performance, another significant area of interest for historians is Antoni's response to modern art and her desire to critically engage with art trends that are dominated by male artists. ${ }^{205}$ At first glance, Butterfly Kisses appears to evoke Abstract Expressionist techniques while also reflecting the Minimalist styles of the 1960s and 70s. Antoni explains, "I feel attached to my artistic heritage and I want to destroy it: it defines me as an artist and excludes me as a woman, all at the same time." ${ }^{206}$ Antoni continues, "I am absolutely conscious of the fact that every gesture I make has some roots in patriarchal art history. I want the work to let the viewer know that I am conscious of the history." ${ }^{207}$ During an artist talk at the National Gallery of Art in Washington, D.C. in 2018, Antoni further explains that she is thinking about "aesthetics that have been passed down to us through art history. But also, ideas of women and beauty and how, if I work with

203 “Gnaw,” Janine Antoni Immaculate Conception Inc, accessed May 2020, http://www.janineantoni.net/\#/gnaw/.

${ }^{204}$ Stacie M. Lindner, "Janine Antoni: Finding a Room of Her Own," (MA Diss., College of Arts and Design, Georgia State University, 2006), 20.

205 Patrick Jones, “The Mythical Speech of Janine Antoni," (MA Diss., West Virginia University, 2006), 46-47.

${ }^{206}$ Cottingham, "Biting Sums Up My Relationship to Art History," 104.

207 Janine Antoni/Matrix 129, 6. 
those in parallel ways, I could call them both into question." ${ }^{208}$ Antoni pays homage to these art forms while simultaneously critiquing, not the aesthetics of the Modernist movements, but its masculine form through parody. ${ }^{209}$ Art historians have argued that Antoni does this by using her body as a tool in a way that empowers her as the master and the model. ${ }^{210}$

When historians discuss Antoni's work in relation to Minimalism, the commentary tends to focus on how her work is often created through her interaction with consumer products, agitating traditional notions of Minimalism by inserting her female body into the work. The artist herself confirms this connection to Minimalism, highlighting in an interview in 1993 that she "feel[s] Minimalism has influenced and defined [her] as an artist." ${ }^{211}$ Curators at MoMA note that Antoni developed Butterfly Kisses to exhibit the "impersonal repetitions of serial Minimalism." ${ }^{212}$ Minimalist artists commonly worked with industrial materials and fabrication and, as MoMA staff aptly put it, "showed us our new 1960s world of industrial, mass producedbeauty." 213 Antoni's awareness of and interest in minimalist strategies aligns with Butterfly Kisses as the artist quite literally explores 'mass-produced beauty' - that is, the mass-production and consumption of beauty products.

In relation to Abstract Expressionism, Antoni's work has been almost exclusively analyzed in connection to Jackson Pollock. Of course, these comparisons tend to focus on Loving

\footnotetext{
208 Antoni, "Elson Lecture 2018," 11:05.

${ }^{209}$ Karamitsos, "The Art of Janine Antoni," 204.

${ }^{210}$ Judith Findlay, "Press Me, Push Me, Feel Me, Find Me," Women's Art Magazine 64, MayJune 1995, 16;

Antoni, "Elson Lecture 2018," 10:30.

${ }^{211}$ Cottingham, "Biting Sums Up My Relationship to Art History,” 104.

212 MoMA, "Janine Antoni, Butterfly Kisses, 1996-99."

213 “Minimalism," MoMA Learning, accessed May 26, 2020, https://www.moma.org/learn/moma_learning/themes/minimalism/.
} 
Care and Pollock. Antoni has said herself on numerous occasions that Loving Care was influenced by a desire to respond to Pollock. The dramatic black and white photo documentation of the artist at work sparks discussions of connections between Antoni’s Loving Care and Pollock. ${ }^{214}$ Given that there is no documentation of Antoni in the process of creating Butterfly Kisses, it is the artist's active methods that form the connection between Butterfly Kisses and Pollock. ${ }^{215}$ Where many have discussed Abstract Expressionism and Pollock more prominently in relation to Loving Care, art historian Stephanie Karamitsos contributes to this association as one of the only writers to directly reference Butterfly Kisses, describing it as a "miniaturized Jackson Pollock painting." ${ }^{216}$ Karamitsos also addresses the presence of "Pollock's 'concept of the overall painting, the painting seemingly without beginning or end"' in Butterfly Kisses. ${ }^{217}$

The body, hidden performances, non-traditional materials, and critiques of maledominated artistic legacies are prevalent avenues of discussion for historians who analyze Antoni's work. Ideas of gender and femininity are simultaneously woven into these discussions. Building on this research, I intend to develop an analysis of cosmetics and the beauty practices that the artist engages in during the creation of Butterfly Kisses. Aside from the paper that she leaves her marks on, the only other material that Antoni uses is mascara. Beautification rituals and beauty ideals play a significant part in Butterfly Kisses-more so, I would argue, than in most of Antoni's other pieces. In this chapter, I will contribute to the limited literature on Butterfly Kisses by focusing on Antoni's interaction with mascara and her engagement with

${ }^{214}$ Robert Enright and Meeka Walsh, “The Beautiful Trap: Janine Antoni’s Body Art,” Border Crossings, March 2010, 39.

${ }^{215}$ Karamitsos, "The Art of Janine Antoni," 87.

216 Ibid.

217 Ibid., 88. 
beauty practices, and by demonstrating how these elements contribute to viewers' overall understanding Butterfly Kisses.

\section{Covered, Girl: Beauty Practices and the Materiality of Cosmetics}

Throughout the 1990s, Antoni frequently explored issues surrounding Western beauty standards — specifically in relation to consumerism. Many of her performative objects tended to embody narratives related to women and the beauty industry, but, more than that, they were created through her participation in the ritualistic, feminized labour which such industries promote. ${ }^{218}$ Gnaw, for example, highlights Antoni's interest in performance and the process of repetitive labour. Gnaw further reflects Butterfly Kisses and Antoni's interest in cosmetics and beauty products. In Gnaw, Antoni uses non-traditional materials to fabricate lipstick through a non-traditional process. Given Antoni's absence from the viewing experience in Gnaw, the hope is that viewers are able to observe the lipsticks that she made, which the artist describes as "a cliché of women and beauty," and take their viewing experience a step further by imagining how these beauty products were made. ${ }^{219}$ In imagining Antoni in the process of creating Gnaw, viewers would likely feel disgusted or appalled by the idea of using the lipsticks that the artist created with the remnants of her chewed up lard. The same goes for Butterfly Kisses; when viewers engage with the eyelash drawing and understand the tedious labour that produced the work, it can be overwhelming and prompt them to question their own beauty practices.

The substances that Antoni uses in her work are often consumer products that could be found in a grocery store or drugstore. Mascara, hair dye, soap, lard, and chocolate are examples

${ }^{218}$ Nancy Spector, "Slumber: A Fairytale," Janine Antoni, ed. Cristina Bechtler (Küsnacht: Ink Tree, 2000), 14.

${ }^{219}$ Lindner, "Finding a Room of Her Own," 19. 
of materials with which Antoni has worked. In Loving Care, Antoni's materials also held personal significance; she not only opted to use a popular brand of hair dye but also chose it because it was the hair dye that her mother used. ${ }^{220}$ The choice to use generic consumer products as a means of creating art was commonplace for artists in the 1990s. Art historian Martha Buskirk explains,

One striking feature in the work of several younger generations of artists who came to prominence in the 1980 and 1990s, and whose work incorporates allusions to art of the proceeding decades, has been a careful attention to formal and material decisions not as an end in themselves, but as a means of addressing a wide range of cultural as well as personal references. ${ }^{221}$

Antoni recognizes that these substances are not traditional fine art materials and, as such, do not always withstand the making process. In certain scenarios, her performative objects have a limited lifespan because the consumer products that she uses can disintegrate or fall apart over time. While discussing Lick and Lather (1993) (Figure 3.2) during an interview, Antoni addresses her materials and how she accepts the changes that her objects experience. She states, When I sold Lick and Lather I made a contract saying that the person buying it understands that the transformation of the material is conceptually part of the meaning of the work. And of course many people said, "Thank you very much but I guess we won't get it." All the time I'm getting letters from collectors saying, "My soap is cracking," and I say, "Well if you have any old soap around, that's what it does. That's the piece." Then all of a sudden the piece starts to be about something else in the collectors' relationship to it, which is great. ${ }^{22}$

\footnotetext{
${ }^{220}$ Ewa Lajer-Burcharth, “Antoni's Difference," in Janine Antoni, ed. Cristina Bechtler (Küsnacht: Ink Tree, 2000), 44.

${ }^{221}$ Buskirk, The Contingent Object of Contemporary Art, 137.

${ }^{222}$ Janine Antoni and Adrian Heathfield, "Touching Remains," in Perform, Repeat, Record: Live Art in History, ed. Amelia Jones, and Adrian Heathfield (Bristol; Chicago: Intellect Books Ltd, 2012), 523.
} 
This transience is most prevalent in her sculptures. However, in much of her work Antoni's materials possess agency and the artist acts with them rather than simply using them. ${ }^{223}$ In Butterfly Kisses, Antoni's chosen material—CoverGirl Thick Lash Mascara—carries with it an overwhelming set of cultural associations and meanings which she uses to connect with her audience, ${ }^{224}$ I would posit that Antoni emphasizes the consumer product's brand name in Butterfly Kisses for this reason. She could have simply noted that she used mascara as a medium, but the type of mascara that Antoni uses means something; I maintain that the brand is significant to the artist's dialogue with consumer culture and Western beauty, and it contributes to an audience's overall understanding of the eyelash drawing. Butterfly Kisses strongly contradicts CoverGirl's famous slogan "Easy, Breezy, Beautiful."225 When Antoni created Butterfly Kisses, she proved that her adornment was anything but easy or breezy; instead, Antoni compares her process to "masochism." 226 In recent years, CoverGirl has changed their recognizable slogan, "Easy, Breezy, Beautiful," to "I Am What I Make Up," adding more meaning to Butterfly Kisses twenty years later. ${ }^{227}$ CoverGirl maintains that their slogan change is "designed to challenge cultural perceptions around makeup... giving its target consumers permission to do whatever they want with makeup." 228 Meanwhile, I perceive this quote as suggesting that Antoni, or whoever uses CoverGirl products, become 'themselves' when they are made up with cosmetics. While the brand of mascara that the artist used in Butterfly Kisses could

${ }^{223}$ Petra Lange-Berndt, ed., Materiality: Documents of Contemporary Art (Cambridge: MIT Press, 2015), 13.

${ }^{224}$ Buskirk, The Contingent Object of Contemporary Art, 7.

${ }^{225}$ Tanya Dua, "CoverGirl is ditching its iconic slogan," Business Insider, October 10, 2017, accessed May 29, 2020, https://www.businessinsider.com/cover-girl-has-ditches-its-signatureeasy-breezy-slogan-2017-10.

${ }^{226}$ Antoni, "Elson Lecture 2018," 11:00.

${ }^{227}$ Dua, "CoverGirl is ditching its iconic slogan."

${ }^{228}$ Ibid. 
have had personal associations, just like the Loving Care hair dye had, the product's "CoverGirl" branding is a reference that Antoni ultimately exploits. I argue that using CoverGirl boldly points to the fact that Antoni is covering herself. So, if "I am what I make up," then what I am is covered-like Antoni during the creation of Butterfly Kisses.

In her pursuit to critique the material, she makes use of it; she consumes the product but does not let it consume her. Antoni does not use mascara purely for the sake of adornment but as a means of communication. This use is emphasized by the fact that Butterfly Kisses has no ending, no point in which Antoni's adorned self is the culmination of the performance. Instead, the work is concerned with the meaning and cultural implication associated with the act itself, privileging "act over object." 229 With every flutter of her eyelashes, Antoni is signaling her position in this adornment routine and performance; the act becomes a feminist version of Morse code, in a sense. As artist Cildo Meireles explains, "material makes more than one language possible. ${ }^{" 230}$ Antoni employs this material to speak to the social and cultural history of cosmetics and places it into a new context by shedding light on its material impact and on the contemporary gendered expectations which associate cosmetics with femininity.

\section{Visual Analysis of the 1993 and 1996-99 Versions of Butterfly Kisses}

Before creating Butterfly Kisses in 1996-99, Janine Antoni created a separate iteration of Butterfly Kisses (Figure 3.3) as a diptych in 1993; the 1996-99 version is the one that Antoni chose to document on her personal website. The 1993 version maintains several distinctions that

${ }^{229}$ Paul Schimmel, "Leap into the Void: Performance and the Object," in Out of Actions: Between Performance and the Object, 1949-1979, ed. Russell Ferguson (New York: Thames and Hudson, Inc, 1998), 17.

${ }^{230}$ Lange-Berndt, Materiality, 6. 
separate it from the 1996-99 iteration; however, as the pieces do not have two separate artist statements, it is likely that the context in which Antoni created both iterations of Butterfly Kisses was the same. Furthermore, there is no prominent research or writing that focuses on comparing the two Butterfly Kisses, and-since 1993, when the first iteration of Butterfly Kisses was created - there evidently has been little interest in crafting a detailed visual analysis of the work. Creating a comprehensive visual analysis for a work like Butterfly Kisses is important because it is the first step towards understanding the performance that created the piece. We must analyze the gestural markings first before we can look beyond the visual qualities and imagine the artist in action. In this section, I will be positioning myself as the viewer and I will describe the eyelash drawings in detail from my perspective. Although I will address the earlier eyelash drawing in my visual analysis to further contextualize the 1996-99 work, my focus throughout this chapter is the 1996-99 Butterfly Kisses.

Both the 1993 Butterfly Kisses diptych and the 1996-99 Butterfly Kisses work are, at surface value, simple compositions. The composition of both pieces is crowded and appears chaotic, but it is a controlled chaos. Analysis of these two works, side by side, suggests a development in the composition of Antoni's Butterfly Kisses series; formal qualities in the 199699 version exhibit greater balance, symmetry, movement, and unity. The sophisticated and effective composition of the 1996-99 iteration of Butterfly Kisses suggests that Antoni was not impulsively or thoughtlessly winking across the paper. She methodically produced Butterfly Kisses so as to create a strong, visual experience, keeping in mind the earlier version from 1993.

The most prominent difference between the two Butterfly Kisses is that the 1993 version is a diptych; there are two sides of the eyelash drawing that are separated by the narrow gap of literal space that exists between them. The gestural lines throughout the left and right side of the 
1993 Butterfly Kisses diptych are not in sync. In other words, each side of Butterfly Kisses complements the other, but they are ultimately quite different. The left and right sides of the diptych do not exhibit a pattern, which suggests that Antoni did not have a predetermined composition in mind during the performance component that created to object. Antoni's butterfly kiss traces in this earlier version appear more spontaneous; the placement of each line, as well as the varying angle of the eyelash strokes, lend credence to theory. The composition in the diptych appears to be less structured, less aesthetically pleasing, and less powerful. Furthermore, due to the varied placement and direction of each eyelash stroke, the 1993 diptych gives less weight to the movement of the lines; the gaze is not pulled in a direction that follows the dominant current of the accumulated eyelash strokes. In fact, overall, the diptych lacks a sense of direction and the gaze is left to wander around the composition. In the Butterfly Kisses diptych, there are areas that are more densely covered with mascara, and these sections act as islands across which the gaze jumps. If viewers look between the more densely covered areas, the lighter, barely touched sections of the Butterfly Kisses diptych weave around the paper like a maze or a beaten-down path on which the eye can manoeuvre.

In the 1996-99 version of Butterfly Kisses, there is a clear centre that divides the work in two, separating the left and right sides. Both sides of the 1996-99 eyelash drawing are relatively equal in size and have approximately the same amount of eyelash strokes (specifically, 1254 winks made with either eye). ${ }^{231}$ Though extremely abstract and expressive, most of the lines are angled in towards the centre of the composition. This draws the spectator's gaze towards the prominent line that runs through the middle of her image. While the composition of the 1996-99

231 “Janine Antoni. Butterfly Kisses. 1996-99," Museum of Modern Art (MoMA) Kids, accessed February 2, 2020, https://www.moma.org/audio/playlist/224/2895. 
Butterfly Kisses piece differs from the 1993 diptych, the latter version certainly mimics the earlier piece; in both, the artist has created two distinct sides. The curation of the Butterfly Kisses diptych is echoed in the composition of the 1996-99 Butterfly Kisses; the clear centre line of the 1996-99 Butterfly Kisses work is mirrored in the narrow gap offered by the gallery wall for the 1993 diptych.

In the 1996-99 iteration of Butterfly Kisses, the subject matter—gestural lines which make up the abstract composition — creates a more cohesive visual experience. Every individual line is distinct within the composition; the bottom right corner in Butterfly Kisses is different from the top right corner, but, together, the marks create an effect of uniformity. This latter Butterfly Kisses also depicts a tighter composition of repetitive gestural lines, which emphasizes the serial sameness throughout the work. This sameness creates symmetry, which is accentuated by the prominent line of untouched space that runs through the middle of the image and which acts as an axis. The empty space in the middle is like a crease in the paper, which would have resulted if the image had been folded. It is possible to imagine Antoni butterfly kissing one side of the paper and then proceeding to fold the paper in half, pressing her already existing marks on to the opposite side. Although this was not the case, Butterfly Kisses' distinct sides seem to paradoxically mirror each other despite the uniqueness of each line and its placement.

As with the 1993 diptych, there is no one way to view the 1996-99 Butterfly Kisses. The possibility to explore the imagery in either version is as varied and undefined as the spectators who make up Antoni's audience. At the same time, there is a greater fluidity to the 1996-99 version of Butterfly Kisses, depending on the path that spectators chose to follow. If viewers follow the direction in which the lines naturally flow, they can progress through the image with relative ease. The movement is reminiscent of rushing water or a waterfall; viewers' eyes are 
pulled downwards by the strong current of the lines that are working together; however, following the tide of cascading lines is not the sole viewing strategy that audiences could employ. There is potential for audiences to go against the current when viewing Butterfly Kisses; this approach, like paddling upstream or against the current, offers the most resistance. This sensation seems unsurprising because, in the latter scenario, the viewer's gaze is climbing up the composition rather than flowing down.

\section{Understanding the Mystery of the Making: A Phenomenological \\ Exploration of Butterfly Kisses}

I want the viewer to feel it in their body. To register their own eye blinking and then imagine how many times it would take to reach 1,124 . I also want them to feel the accumulation that that number provides... (those) who have the experience of putting on mascara can also bring that ritual to the work. ${ }^{232}$ - Janine Antoni

There is a mystery to the making of Butterfly Kisses - a gap in the story. The application of cosmetics can be a step-by-step process. Yet, Antoni denies spectators the opportunity to observe her process in its entirety. Butterfly Kisses challenges audiences to interpret the marks left by the artist as an embodiment of Antoni's performance. Essentially, what we witness is the artist asserting her presence through the traces of herself that she leaves behind. These visceral traces stand as markers for the artist's touch which, in turn, symbolizes the artist's presence in the performance that created Butterfly Kisses. ${ }^{233}$ They also stand as a record of her actions. Butterfly Kisses tracks the movements of the artist's body without the body being present. The

232 Goodyear, This is a Portrait if I Say So: Identity in American Art, 1912 to Today, 212.

${ }^{233}$ Buskirk, The Contingent Object of Contemporary Art, 7. 
signs of having "been made" correlates to a body "having been in motion." 234 The frequency at which lines are inscribed across the paper varies and signals this trajectory of motion. None of these drawings are overly large on their own, but I would argue that their size highlights Antoni's need to move around during the performance aspect of this work. She would likely not have been able to remain still during its creation. Not only would she have had to move her head around as she winked across the paper, but her body would also have had to be activated to ensure that her eyelash traces reached the far corners of the performative drawings.

Rather than continuing to imagine how Antoni’s process would have looked and felt, I decided to recreate the work and further my own interpretation of Butterfly Kisses. I applied the mascara to my eyelashes, and I butterfly-kissed a piece of white paper, performing twenty winks per sitting at three different times throughout the day. While Antoni conducted this process for many months, I did it for one day. I struggled to cover a $20 \times 25 \mathrm{~cm}$ piece of paper, while Antoni's Butterfly Kisses (1996-99) is 81.92 x $81.92 \mathrm{~cm}$.

I did not veer from Antoni's arrangement of actions. I used my right eye to leave traces on the right side of the paper and my left eye on the left side of the paper. I also used CoverGirl Thick Lash Mascara to achieve greater consistency between my work and the original. The preparation for the re-performance was minimal; I taped a piece of white paper to the wall so that the top of the paper was slightly below eye level. This placement ensured that I could easily move around the paper, reaching the entire surface. As I began to butterfly-kiss the paper, I realized that, like Antoni's, my eyelash traces were also angling downwards. While this could have been an unconscious decision, based off of analysis of Antoni’s Butterfly Kisses, I would

${ }^{234}$ Amelia Jones, "Material Traces: Performativity, Artistic 'Work', and New Concepts of Agency," Power Publication, June 2, 2015, Audio, 13:05, https://www.powerpublications.com.au/podcast-material-traces/. 
argue that it was a result of the physical limitations of the act. I could not approach the paper straight on and press my eyelashes on to it; my nose became an obstacle around which I needed to manoeuvre. As a result, my eyelashes could not reach the surface of the paper unless my head was tilted, and my cheek bone was firmly pressed against the paper on the same side (Figure 3.4). My recreation of Butterfly Kisses also includes an untouched centre. Whereas Antoni's empty space in the middle of the composition is straight and precise, mine is more fluid. I knew that I wanted to include an empty space in the middle, like in the original, because I saw that it would act as a guideline to follow as I butterfly-kissed the blank page. As I became involved with the performance, I grew more concerned with how each eyelash trace looked and where I put them in relation to each other; the untouched space in the centre became less of a priority to maintain for the purpose of this experiment.

Through this exercise, I have re-embodied Antoni's movements and, now more than ever, I recognize the artist's labour during the creation of Butterfly Kisses. In creating my own interpretation of Butterfly Kisses, I became more aware of the different levels of Antoni's process and of the time that Antoni must have dedicated to creating the work. This undertaking ultimately consumed my entire day. During the exercise, it took about twenty to thirty minutes to finish one interval; however, because of the labour of this performance, I extended the duration between engagements and I finished my final interval nearly eight hours after I started the work. The act of performing one butterfly kiss takes just seconds, but the continued re-application of cosmetics was required for me to leave my trace. This aspect of the private performance consumed the largest amount of my time, but it was also the part that I had to consider the least. I stood in front of a mirror and, like I have done many times before, I applied mascara to my eyelashes (Figure 3.5). Knowing when I had applied enough pigment and was ready to butterfly 
kiss the paper was instinctual; I knew exactly how many times I needed to brush the mascara wand through my eyelashes in order to thoroughly coat them. Interestingly, even though I was applying mascara only to butterfly-kiss it away moments later, I continued to feel the urge to make my eyelashes look aesthetically pleasing every time that I returned to the adornment stage of the performance.

Sometimes jagged and sometimes seamless, almost every eyelash trace is connected to the trace of another in Butterfly Kisses. This creates long black strokes or short fragmented pieces. Some lines are thicker than others and sometimes lines appear as misshapen spots of heavy black mascara. Before my re-performance, I inferred that these dark spots throughout the work were likely the result of Antoni's heavy application of makeup. In my experience, though, I found that the best way to control the amount of mascara transferred from my lashes to the paper was to alter my proximity to the paper. In general, I applied the same amount of mascara every time. In my re-performance, I also experimented by sometimes quickly fluttering my eyelashes and, at other times, slowly and firmly closing my eyes to change the effect of each trace. Based on my findings, I would suggest that-while Antoni could control how much mascara she applied to her eyelashes and how and when she fluttered them across the paper- the way that the pigment dispersed on to the surface of Butterfly Kisses would have been difficult to regulate. In my own performance, it was hard for me to predict what each eyelash mark was going to look like. Eventually, I realized that I needed to get as close as I could and slowly close my eye if I wanted to make a dark stroke on the paper; I found that the closer that I placed myself in relation to the paper, the harder I had to press my face into the wall (Figure 3.6). I could feel my eyelashes trail across the paper with some resistance as the pigment dispersed. I put so much force and thought into this one seemingly simple movement, and there was so much anticipation 
that built during the one second that it took to leave my mark. I would wonder: what would this eyelash trace look like? Would it be as dark as I hoped? Sometimes, butterfly kissing would result in my desired outcome- - whether it was thick black lines or not. In other scenarios, the effort that I exerted would feel like it was for nothing; the heavy coating of mascara would unevenly smear on the paper or not enough mascara would be transferred. When this happened and the marks being left were not what I had hoped I felt frustration but, more than that, I felt the motivation to leave my next eyelash trace and make it better.

Whether or not Antoni controlled her mark making through the amount of mascara she applied to her eyelashes, it is important to consider that a quicker turnover between application and action allows for a greater amount of pigment to be pressed into the paper. Mascara, as a medium, is complicated because it dries quickly. I imagine that, from the time Antoni applied wet mascara to the moment she butterfly-kissed the paper, she would have been limited to the amount of times she could perform the act of butterfly kissing before having to apply more makeup. I was able to transfer pigment from my own eyelashes by butterfly kissing the page approximately one or two times before having to return to the adornment phase. As a result of the material's limitations, Antoni would likely not have been able to veer from this particular arrangement of actions; if she waited too long, the mascara would become dry and no traces would be left behind on the medium's surface, but if she started too early, before enough mascara was applied to her lashes not enough pigment would transfer on to the paper. ${ }^{235}$

This tedious and unpredictable process was further complicated by the physical demands of the piece. Every time that Antoni made a mark on the paper, her eyes would have to have been closed. This requirement, along with her proximity to the paper, meant that Butterfly Kisses was

235 MoMA, "Janine Antoni, Butterfly Kisses, 1996-99." 
largely developed through an aleatoric approach to art making. When constructing Butterfly Kisses, Antoni would have likely visualized the entire composition; however, the individual strokes which make up the composition were dependent on chance. She would have been able to observe where she wanted to leave a mark, but the act of butterfly kissing means that every time she made traces of her eyelashes, she would have to close her eyes. There were several times where I pulled away from the paper, ready to observe my new mark, and would find nothing. At first, I thought that no pigment was being left on the paper-which was sometimes the case, early on when I was just getting used to the process-but I eventually learned that the traces were just blending in with each other and I was no longer going to be able to identify each mark immediately after I left it. The fact that I could not see exactly where I was leaving each mark exacerbated this issue. As a result, I started more thoroughly documenting my re-performed Butterfly Kisses and noticed that each mark that I left contributed to the development of my image, though the progress was slow. From the first interval of twenty butterfly kisses to the second and then the third, there was an undeniable difference in the density and darkness of some of the areas on which I focused (Figure 3.7 and figure 3.8).

After my re-performance, I am left wondering why Antoni endured this process for so long. I only re-performed Butterfly Kisses for one day, and — after a single day-my eyes were sore from forcefully blinking and my face hurt from being firmly pressed against the wall. The process of applying mascara, something that I had done many times over and was never particularly bothered by, became irritating and tedious - something that I resented during my reperformance. One could suggest that Antoni continued to perform the tasks that Butterfly Kisses demanded until she was pleased with the results of the performative drawings, but I would maintain that the desire to create an aesthetically pleasing visual was not the driving force; 
though aesthetics were certainly relevant, given the evolution from the 1993 Butterfly Kisses diptych to the 1996-99 version, this consideration does not appear to have been paramount to the artist. If the importance of how the work was made is significant, perhaps it is more suitable to ask not why she endured the process for so long but what her commitment to this process and her materials mean.

To further explore the question of what Antoni's labour and process means, it is also useful to perform Antoni's gestures in a manner that does not simply re-enact the artist's movements — as I have done_-but instead responds to them with one's own movements. ${ }^{236}$ Antoni sheds a light on what cosmetics look like when they are no longer on one's body when she accumulates her material traces into this image. Antoni adorns herself only to remove the mascara moments later. This is a curious practice that does not align with typical cosmetic adornment routines that people partake in in their own lives, and it suggests that Antoni is actively rejecting uninterrogated cosmetic adornment. In this sense, Antoni's practice recalls the act of removing makeup as much as it represents the application of makeup. In the case of Butterfly Kisses, though, Antoni accelerates the removal process. People who adorn themselves in cosmetics tend to stay that way for extended periods of time, throughout the day. Antoni not only almost instantly rubs away the makeup from her eyelashes through the act of butterfly kissing but also denies a viewer the ability to see her adorned with mascara as well.

In Butterfly Kisses, cosmetics do not seem to serve vain purposes. After re-performing the work, it became clear that mascara in this context is not a tool that Antoni utilizes to enhance her appearance and boost her own self-confidence. Speaking from my own experience with the procedure, the mascara did not completely transfer when I butterfly-kissed the paper. While most

${ }^{236}$ Findlay, "Press Me, Push Me, Feel Me, Find Me," 16. 
of the pigment was removed during the butterfly-kiss process, there was some residual mascara that remained. This left-over mascara made the work more meaningful to me because, even though I was trying to get as much pigment from my eyelashes on to the paper as I could, I ultimately could not rid myself of the mascara completely. Consequently, I had to apply new mascara to the dried pigment left on my lashes. The first couple of intervals of application were unremarkable; my lashes were full and natural, and - if I had stopped the re-performance during this early phase- - I could have gone about my day looking appropriately adorned; however, every time I applied more product, my eyelashes became thicker, messier and more unwieldy. Butterfly-kissing paper with wet mascara did not help matters. My lashes became deformed and were squished with each stroke on the paper. Moreover, every time that I pressed my lashes on to the paper, mascara would press itself on my skin and leave black pigment smudged all over my eyelids (Figure 3.9). These undesirable cosmetic outcomes further suggest that Antoni's work is concerned with the act and cultural implications of adornment rather than straightforward beautification.

Removing mascara in a quotidian, non-performance environment also mimics Antoni’s butterfly kissing; in many ways, Butterfly Kisses resembles the accumulation of makeup removal wipes over the course of several months (Figure 3.10). In everyday life, I have created an innumerable amount of 'butterfly kiss'-like compositions on makeup removal wipes. Spread across the surface of the wipes are the traces of my own eyelashes, and each marking is uniquelike the lines in Antoni’s series. After analyzing Butterfly Kisses, I started to observe the cosmetic traces that I regularly leave behind, engaging with these lines as I would with Antoni's eyelash drawing. My engagement with Butterfly Kisses has directly translated to a deeper consideration of my own personal experiences with the adornment process. 
Had I not disposed of the wipes or washed my traces away, I imagine I would be faced with an emotional experience parallel to what Butterfly Kisses elicits. In this sense, Antoni constructs a powerful dialogue about Western beauty standards and consumer culture. Historian Allison Vandenberg explains,

The acts we engage in on a regular basis not only shape what we can do as a result of repetition; they also affect our perceptions of ourselves...The notion, which varies between individuals and changes over time, is strongly connected to our reiteration of acts; the same repetition that renders work invisible also has the capacity to alter the ways we see ourselves in everyday life. ${ }^{237}$

I experience pieces that are similar to Antoni's performative drawings on a regular basis, but I come into contact with these markings through a single makeup wipe, which is capable of representing a single adornment routine that is washed away or disposed of almost immediately; this repetition renders my own adornment seemingly invisible or, at the very least, transient. Facing a single makeup wipe was never enough to indicate the extent of my own labour. Seeing the gestural strokes of Antoni's eyelashes all at once and at this overwhelming frequency, for extended periods of time, forces me to confront my own position within a dialogue of consumerism and feminine beauty standards.

\section{Viewer Engagement and Empathy}

I want to position the viewer in a particular relationship to the object, one of empathy toward my process. That's very different from the way we normally approach a conceptual work of art, where we remain very objective and go through a process of decoding information. ${ }^{238}$ - Janine Antoni

${ }^{237}$ Vandenberg, "Toward a Phenomenological Analysis of Historicized Beauty Practices," 171.

${ }^{238}$ Judith Olch Richards, Inside the Studio: Two Decades of Talks with Artists in New York (New York: Independent Curators International, 2004), 227. 
Spectators are not meant to simply view Butterfly Kisses but, rather, to imagine themselves as active participants. Viewers must closely examine the object on view and thoughtfully engage with the subject matter as a means of understanding the elements of Butterfly Kisses that are inferred but not seen. To achieve this, it is important to consider all aspects of Butterfly Kisses, including the private performance, its documentation, and spectator engagement — all of which are significant factors in Antoni's eyelash drawing. Dynamic engagement with the object can help spectators to recognize the labour-intensive actions that are intertwined in Butterfly Kisses, thereby filling in the story within the gaps. As a result, Butterfly Kisses becomes both about the artist's actions and the audience's reception of the work, including the memories of the audience as they recognize and relate to it and its creator. Through stimulating thoughtful engagement, Butterfly Kisses can draw people towards empathy in their viewing experiences.

There are different types of empathy that a person could experience-emotional, cognitive, and compassionate. ${ }^{239}$ When viewers feel empathy when they engage with Antoni's work, I would argue that it often manifests in the form of cognitive empathy (sometimes called "perspective taking"). This type of empathy "means putting yourself in someone else's shoes" and involves thinking more than emotional feeling, referring to one's ability to identify and understand a person's emotions or experiences. ${ }^{240}$ It also becomes possible for viewers to experience self-empathy when they engage with Butterfly Kisses. Lidewij Niezink and Katherine

239 "What is Empathy," Greater Goods Magazine, accessed November 25, 2020, https://greatergood.berkeley.edu/topic/empathy/definition.

${ }^{240}$ Kate Miller-Wilson, "Genuine Examples of Showing Empathy," Your Dictionary, accessed November 25, 2020, https://examples.yourdictionary.com/genuine-examples-of-showingempathy.html;

"What is Empathy." 
Train explain "[s]elf-empathy means that an aspect of yourself observes, in an empathic manner, the aspect of your self that experiences... Self-empathy simply requires you to notice and recognize what is happening to you."241 Thus, when viewers experience empathy towards Antoni's adornment routine, towards themselves, or others who endure a similar process, it allows viewers to identify what is happening and recognize the effects that cosmetics can have in one's life. To generate such sentiment when observing Butterfly Kisses, it is necessary to conceive of the work as a process.

The trajectory of the artist's body in motion is unclear and viewers will not be able to pinpoint where Antoni began and how she progressed through the image; each viewer will recognize various starting and ending points. What can be determined is that each eyelash trace represents the artist registering another moment. Like numbers on a clock that indicate the time in a day, the gestural marks in Butterfly Kisses indicate moments in Antoni's adornment process/performance. Robin Le Poidevin explains in The Images of Time: An Essay on Temporal Representation that,

Another method of representing time and change is illustrated by those Futurist paintings in which representations of non-simultaneous states are superimposed on each other: Duchamp's Nude Descending a Staircase, Balla's Dynamism of a Dog on a Leash, or Malevich's The Knife Grinder. And a familiar technique in photography is the longexposure photograph...All these are static representations of motion, and hence intervals of time. $^{242}$

${ }^{241}$ Lidewij Niezink and Katherine Train, “The Self in Empathy: Self-Empathy," Psychology Today, July 13, 2020, accessed November 26, 2020, https://www.psychologytoday.com/us/blog/empathic-intervision/202007/the-self-in-empathyself-empathy.

242 Robin Le Poidevin, "Image and Instant: The Pictorial Representation of Time," in The Images of Time: An Essay on Temporal Representation, ed. Robin Le Poidevin (Oxford: Oxford University Press, 2007), 8-9. 
Similar to Duchamp's Nude Descending a Staircase, which depicts a figure in motion, Antoni captures her body's movements during particular stages; however, unlike Duchamp, Antoni registers movements that are non-sequential and, thus, cannot be read in a linear fashion. Le Poidevin further explains that,

...the answer to the question of what time span a static image represents depends on the level of cognitive sophistication involved in responding to the features of that image. At the most basic level, static images may depict part of an event, whatever could be taken at a single glance. ${ }^{243}$

The "part of an event" that is registered in Butterfly Kisses - the static image on view-is the act of butterfly kissing, but what it represents is a larger, more involved process.

Stephanie Karamitsos explains that "this hidden aspect of [Antoni's] artistic process offers a unique opportunity for the viewer to empathize with [the artist's] activities through a mind's eye reconstruction of his or her own." 244 During an interview with Stuart Horodner, Antoni also notes, "Imagining the process is so much more powerful than watching me do it. Imagining is so much more provocative and makes each viewer's experience slightly different. By imagining me, the viewer's experience turns out to be about their own wish fulfilment."245 Engagement with the traces in Butterfly Kisses leads viewers beyond the static image; audiences no longer view Butterfly Kisses as an object made through a performance but instead start to imagine the performance itself.

When speaking about Antoni's work, curator and art historian Judith Tannenbaum explains that "what is exhibited is the effect of performance, the tense, negotiated 'contract' that is established between viewer and actor in performance... Such contracts are the product of time

${ }^{243}$ Le Poidevin, "Image and Instant: The Pictorial Representation of Time," 14.

${ }^{244}$ Karamitsos, "The Art of Janine Antoni," 112.

245 Ibid., 341. 
and ritual repetition." 246 As a contract, Butterfly Kisses is a document that holds information and inscribes both social and temporal relationality. Antoni explains, "I'm trying to produce more than a relic. I want the object to hold the information;" ${ }^{247}$ however, Antoni is only interested in disclosing enough information to intrigue the viewers and, as Wendy Vogel states, in "creating work that bears the traces of its making while leaving room for speculation about its backstory." 248 Vogel's supposition echoes art historian Jan Hogan's description of the ability of documents to "inhale(s) the touch of everything it comes into contact with, retaining traces of a memory of an encounter across space, time, matter." ${ }^{249}$ Of course, when artist and viewer negotiate Butterfly Kisses, only Antoni is in literal, physical contact with the paper. Nevertheless, as I will address, Hogan's quote still applies when discussing Butterfly Kisses, even though no viewers actually touch the work.

Presence, social dynamics, and time are key qualities that exist in the performance art genre; Frazer Ward explains that "[t]he specifically art-historical reception of performance art circles three main elements: presence, the activation of the viewer, and duration." ${ }^{250}$ The assumption is that these facets are more easily conveyed in temporary live performances, but this does not mean these qualities cannot be accessed through imagining the actions that gave rise to Butterfly Kisses. Karamitsos emphasizes that it is Antoni's desire to imagine how her audience will understand her experience and encounter it themselves. ${ }^{251}$ Of course, this engagement is rendered most effective because of Antoni's absence. Patrick Jones argues that “Antoni's

\footnotetext{
246 Tannenbaum, PerForms: Janine Antoni, Charles Ray, Jana Sterbak, 20.

${ }^{247}$ Enright and Walsh, "The Beautiful Trap," 52.

${ }^{248}$ Vogel, "Turning Inside Out: Janine Antoni's New Perspective on Sculpture and Dance," 43.

249 Jan Hogan, "A Touching 'Contract,"” in Touch, ed. Caterina Nirta et al. (London: University Westminster Press, 2020), 91.

${ }^{250}$ Ward, "Introduction: Reimagining the Audience," 9.

${ }^{251}$ Karamitsos, "The Art of Janine Antoni," 16.
} 
absence serves as an important part of the work, because it is the point of entry for the viewer to become the participant." 252 Although Jones' remark is made in reference to Gnaw, I maintain that it is also applicable when discussing Butterfly Kisses.

If the artist was physically present, as she would be in temporary live performances, spectators would not be driven to understand her experiences because her presence would offer more clarity (not complete clarity but certainly more of it). Additionally, viewers would not have to work to interpret the process's temporal or spatial dimensions because a live performance would present greater transparency in both regards. Rather than being literally present, Antoni provides clues for the audience through her traces. The traces of her eyelashes signal her past presence when she engaged in the making of Butterfly Kisses; "the physical presence of the subject who made these markings is denied [and the] work insists on the presence of the author and in doing so carries the viewer beyond a representation of the body and into a world governed by the artist's personal experience." ${ }^{253}$ Similarly, time and the labour of her adornment are also imposed by the markers of her touch. For the artistic qualities of these performances to come to fruition, they must be read accordingly.

As closeness is an essential element of performance art, with the artist — in real time and space - situated alongside spectators in a fleeting moment, the emphasis of Antoni's physical touch as a form of mark making establishes a closeness between artist and viewer. ${ }^{254}$ Art historian Kathy O’Dell explores touch and how it simulates closeness between artist and viewer by using photo-documented performances as her primary subject of analysis. She posits that "the

252 Jones, "The Mythical Speech of Janine Antoni," 27.

${ }^{253}$ Anthony Innacci, “Janine Antoni,” Kunst Bulletin, June 1994, 18.

${ }^{254}$ Kathy O'Dell, "Displacing the Haptic: Performance Art, the Photographic Document and the 1970s," A Journal of the Performing Arts 2, no. 1 (1997): 77. 
reception of performance art - which is to say, the reception of photographic documents from which performance art is inseparable - is not exclusively dependent on visual experience, but relies heavily on the experience of touch." ${ }^{255}$ Touch for O’Dell, however, corresponds to a viewer's ability to actually hold the performance document in their hands. While audiences may not literally touch Butterfly Kisses, I would like to expand O'Dell's argument in reference to Antoni's work.

During a conversation with Janine Antoni, Joshua Reiman asks, "Is it possible to touch something with sight, to feel something deeply in a total state of awareness?"256 Reiman continues, "For Janine Antoni, creative process takes on a psychological disposition. She creates objects with an intense admiration of life, in which her body is your vehicle, a fulcrum of perception, in which senses are enabled through corporeal textures." ${ }^{257}$ Touch is one of the most intimate sensations that a person can experience; to touch is to be touched. ${ }^{258}$ According to philosopher Maurice Merleau-Ponty, as explained by Jan Hogan in Touch, "the sense of touch involves a reciprocal arrangement...[Touch is] a double sensation: the hand embodies both the agency of touching and the receptivity of being touched." 259 Building on this idea, I will apply Merleau-Ponty's notion to Butterfly Kisses and explore how audiences experience touch when viewing Antoni's visceral material trace drawings.

Butterfly kissing is a fleeting expression of affection and carries with it many recognizable referents. Depending on context, the act can be read as a flirtatious cliché or an act

255 O’Dell, "Displacing the Haptic," 74.

256 Janine Antoni, "My Body is Your Vehicle: In Conversation with Janine Antoni," interview by Joshua Reiman, Sculpture, May 2015, 23.

${ }^{257}$ Ibid.

${ }^{258}$ Findlay, "Press Me, Push Me, Feel Me, Find Me," 15.

${ }^{259}$ Hogan, "A Touching 'Contract'," 95. 
of tenderness between individuals. ${ }^{260}$ This interaction requires a physical, and arguably emotional, closeness, and it requires touch. The history of Antoni's touch is all over the performative drawing. In touching the surface of Butterfly Kisses, Antoni effectively felt her touch reciprocated by the paper. Though it is an inanimate object, Antoni uses the paper as a tool to get close to those who encounter her work. She states, "The objects act as surrogates for my own body and my desire to be in contact." ${ }^{261}$ By touching her objects in a way that records her own body, Antoni begins to cultivate a connection between artist and viewer in spite of their physical and temporal separation. Antoni notes, "Sometimes I feel that if I am intimate enough with the object it will come alive." 262 Judith Findlay also explains this dynamic, stating that "[i]n our minds we are getting close to Antoni's body."263 This quote by Findlay is key to understanding the tension between closeness and distance that Butterfly Kisses elicits. It is "in our minds" that we interact with Antoni. Through a combination of visual and haptic relations to Butterfly Kisses, viewers can feel a connection to the artist. Given that no entity - other than the paper-is literally receiving Antoni's butterfly kisses, viewers can begin to experience Antoni's touch by imagining that they are her intended recipients.

With other pieces by Antoni, her audience has, in some scenarios, felt compelled to literally touch her work - sometimes mirroring her actions and sometimes trying to kinaesthetically understand how the object was made. During an interview in 2015, Antoni discussed her 1993 work, Lick and Lather, and noted that viewers have taken bites out of her chocolate self-portrait busts. Whether or not they were driven by a desire to indulge in the

\footnotetext{
${ }^{260}$ Karamitsos, "The Art of Janine Antoni," 88.

261 Antoni, "My Body is Your Vehicle," 25.

262 Antoni and Heathfield, "Touching Remains," 527.

${ }^{263}$ Findlay, "Push Me, Press Me, Feel Me, Find Me," 15.
} 
chocolate cast or by the yearning to know what it is like to sculpt with one's teeth, Antoni is not offended by the varying physical responses that her viewers experience. The artist explains, "I am trying to elicit desire within the viewer, so if someone succumbs to that desire and bites the chocolate image of me, how can I be upset?"264 She recognizes that the viewers' experiences with her objects - and, in effect, their experiences with her — are at the core of her artistic productions.

Antoni playfully explains that her work "is like coming in on the scene of a crime and the viewer [is] slowly figuring out what happened."265 Nonetheless, this engaging quality in Butterfly Kisses that drives viewers to solve the mystery of the making is felt more strongly by some than it is by others. Karamitsos maintains that spectators can re-create the development of the image in their minds just by looking at it, leaning upon the closeness between Antoni and viewers. ${ }^{266}$ Robert Enright similarly states that "the effect of the materials she uses, and what she does with them, resonates in her audience like memory and blood." ${ }^{267}$ Joshua Reiman also notes that "[p] henomenologically speaking, Antoni would like you to feel her body and to understand where your body is in relation to the gestures frozen into forms." ${ }^{268}$ Reiman further explains that Antoni "hopes the body feels before the mind takes over;" 269 however, depending on the viewer, some may require time to contemplate Butterfly Kisses before they are able to engage with the work. Personally, I find that the work induces a strong urge to follow along with Antoni's motions, blinking with Butterfly Kisses and imagining that I am adding to the accumulation of

\footnotetext{
264 Antoni, "My Body is Your Vehicle," 25.

265 Bonnie B, "Janine Antoni, in person at BU," Big Red and Shiny, November 22, 2013, accessed June 3, 2020, http://bigredandshiny.org/14661/janine-antoni-in-person-at-bu/.

${ }^{266}$ Karamitsos, "The Art of Janine Antoni," 16.

${ }^{267}$ Enright and Walsh, "The Beautiful Trap," 40.

268 Antoni, "My Body is Your Vehicle," 23.

${ }^{269}$ Ibid.
} 
eyelash strokes in these performative drawings. Understandably, however, this kind of engagement might not be shared among all of the work's viewers. In one instance, someone may read the title, observe the subject matter and then instinctively begin to move their eyes around the paper, fluttering their eyelashes along as they go. Meanwhile, in another scenario, a viewer may observe Butterfly Kisses and have no bodily response to the work or not understand how their body is supposed to engage.

One's experience of Butterfly Kisses can also be enhanced by one's encounters with other viewers who are simultaneously engaging with the work. This mode of interaction is generative because experiencing art among an audience is quite different from experiencing it as a single viewer. When attending a live performance, groups of people tend to congregate around the exhibit—-sometimes in large numbers. This collection of people creates a shift from the viewer/artist relationship to a series of audience/artist relationships. As a result, a collective understanding among the audience tends to develop based on everyone's respective body language. If there is a group of people viewing Butterfly Kisses, those who are not completely sure how they can engage with the work (beyond passively viewing it) can feed off of those around them. In this sense, viewers not only engage with the artist but also with those who are present around them, accessing the social dynamism that is key to the performance art genre. Alternatively, if viewers are surrounded by other people, they may feel uncomfortable immersing themselves in a thoughtful engagement with Butterfly Kisses, and, as a result, their understanding of the piece will be affected.

To those viewing the work, Antoni only offers insight into the making of Butterfly Kisses through the indeterminate formation of recorded butterfly kisses. That being said, butterfly kissing is only one aspect of the performance; it is not just this act that bears recognition. In 
Allan deSouza's "What It Is, Now," taken from a special issue of Representation, the author explores the "possibilities that would open up within each media if we consider all media as material form and time-based?" 270 While deSouza's focus is on photography, this text indicates that viewers can also narrativize Antoni's performative drawing “by imagining what might happen before or after the moment documented. This is not literally (or literarily) a narration, but a recognition of its performativity as a prescripted reiteration of, for example, gender coding." 271 By engaging with Antoni's traces, viewers can develop their connection to the artist. To deepen their understanding of her private performance and Butterfly Kisses in its material form, viewers should also imagine what happened before the moments were documented. This means also addressing what cosmetics do in this work. In the case of Butterfly Kisses, the process exists almost solely because of Antoni's use of cosmetics.

Antoni was aware of the feminized connotations associated with the act of butterfly kissing and sought to emphasize these connections by mixing a feminized material with the feminized act. When viewers observe Butterfly Kisses and imagine that they are contributing to the accumulation of eyelash strokes, they also need to recognize that the black lines would not be visible without the use of mascara. Thus, when Antoni says that she wants viewers to "register their own eye blinking and then imagine how many times it would take to reach 1,124 ," they cannot complete the process in their minds without also imagining Antoni's use of cosmetics, her labour and her dedication to the adornment process. ${ }^{272}$ All viewers can engage with Butterfly Kisses, but those who understand and have experienced cosmetic adornment - whether through

${ }^{270}$ Weihong Bao et al., "Reflections on Durational Art," Representations, no. 136 (Fall 2016): 140.

${ }^{271}$ Ibid., 141.

272 Goodyear, This is a Portrait if I Say So: Identity in American Art, 1912 to Today, 212. 
personal experience or by association — are likely to have an easier time interpreting the piece's temporal and labourious aspects. If viewers have experience with cosmetic adornment, the thought of applying enough mascara to accommodate 1,124 butterfly kisses might seem unimaginable. Yet, if a viewer — on average — applies mascara once a day, then they have already coated their eyelashes enough times to create several Butterfly Kisses-like compositions through their daily routines.

Antoni strives for an emotional response that demands a thoughtful engagement with the performance. While the variables of each viewing experience cannot be anticipated, Butterfly Kisses yields the potential for viewers to imagine that their own eyelashes are creating the lines which fill the composition. Furthermore, they can explore how their movements, their participation and engagement with this work contributes to a larger discussion of cosmetic adornment or, otherwise, how their traces exist in relation to Antoni's marks. The artist explains that she has a desire for spectators to have empathy towards her process. This desire translates to empathy towards a set of feminine beauty rituals that are inscribed into societal codes as gendered female acts. Antoni further explains that her work "may provoke an empathic response from its audience - the viewer having a sense of the experience of the artist's labor." ${ }^{273}$ When spectators experience empathy in response to a work like Butterfly Kisses, the image becomes a mirror of the self. ${ }^{274}$ By establishing a closeness to Butterfly Kisses and engaging with the work in such a way that viewers can relate - through both the recognition of Antoni's movements as well as their own - viewers are able to discover the adornment process that is embedded in the still imagery. This discovery is possible when we no longer only recognize time and the

${ }^{273}$ Karamitsos, "The Art of Janine Antoni," 312.

${ }^{274}$ Dictionary.com, s.v. "Empathy," accessed January 1, 2020, https://www.dictionary.com/browse/empathy?s=t. 
adornment process that exists in the making of Butterfly Kisses but also make connections to the time and adornment process that exists in our own lives.

\section{Conclusion}

The artist's simultaneous absence and presence ensure that spectators look beyond the physicality of the work and instead visualize both the artist's and their own experiences. Judith Findlay explains that "the spectators' appreciation is not dependent on analytical comparisons nor on any empathy with Antoni as an artist or as a personality, but rather it is based on an empathic experience with her body (a body). ${ }^{275}$ Recreating the private process that took Antoni several months to complete, through my phenomenological exploration, has given insight into the creation of Butterfly Kisses. As a viewer, I have become empathic to her process and to what her body endured during the making of Butterfly Kisses; however, throughout this chapter, I have also taken into account the material used (mascara), the repetitive act of adornment, and the gendered, feminized histories to which these materials and acts are associated. While considering these elements, I found that I experienced empathy for more than just what her body endured but why her body endured it. By engaging with Butterfly Kisses through the activation of my body, I have been able to reflect on my own experiences with the materials used by Antoni, and on beauty standards and adornment more broadly.

${ }^{275}$ Findlay, "Press Me, Push Me, Feel Me, Find Me," 16. 


\section{$\underline{\text { Conclusion }}$}

Throughout this thesis, I have sought to consider the use of cosmetics in feminist art. Since the beginning of the feminist art movement, artists have incorporated beauty products and beauty rituals into their practice. My primary analysis has focused on works that do not illustrate the artist as adorned but instead present the artist's body in the process of adornment. The process which the artist engages in and their willingness to allow viewers to peer into that process are what I believe creates a meaningful viewing experience. Suzy Lake and Janine Antoni create work that emphasizes the artists' bodies, their movements, and the process of cosmetic adornment.

In the first chapter, I analyzed Suzy Lake's 1973/74 photo-documented piece $A$ Genuine Simulation of.... My intent was to engage with Lake's work through a close looking exercise and discuss how A Genuine Simulation of... acts as a form of empowerment for viewers who have experience with the actions that she performs. In the second chapter, I discussed Butterfly Kisses, the 1996-99 work of Janine Antoni. I explored how this piece yields the potential to lead viewers towards empathy: empathy for themselves or for those who endure adornment in their own lives and empathy for the acts the artist performed.

Both artists have their own perspectives on what cosmetics and beauty rituals signify. Through different mediums, photography and drawing, they raise awareness about cultural attitudes towards gender, identity, and beauty. At the same time, their works of art do not fixate on the negative impacts of beautification; rather, they investigate the impact that these traditions have on identity and, consequently, on one's life. As a result, Lake and Antoni create pieces that allow viewers to draw their own conclusions. Going beyond the artists' actions in A Genuine 
Simulation of... and Butterfly Kisses, this body of work encourages thoughtful audience engagement which, in effect, enables viewers to see the beauty traditions from a new perspective. When viewing these works and engaging with the process of adornment that the artists perform, empowerment and empathy can be achieved in the form of awareness.

\section{A Call to Action}

In the 1960s, Suzy Lake spoke of the "social and political unrest" which drove her to move to Canada, where she would pursue a career as an artist. Today, we continue to exist in a world of unrest, with political demonstrations occurring all over the world; women's marches, Black Lives Matter rallies, union strikes, and other forms of protest push for changing politics, policies and public opinion. People across the globe continue to demand change in the face of social injustice and systemic oppression, and — even amid a global pandemic — people are being urged to use their voices to call out injustice. To write during this time, to contribute my own voice through my thesis, was a deeply empowering experience for me. Just as Suzy Lake sought to make sense of "what was happening in the studio and what was happening in the street," I drew from what was going on around me - the momentum and inspiration of so many passionate people - and I applied it to my work. During the course of my research on Lake and Antoni, I also found myself turning the lens upon myself; I began seeing what these artists were presenting in a way that was immediate and current to the issues that I was seeing in the world and in my own life. 


\section{Makeup Your Own Feminism}

In my research, I have sought to shed light on the history of cosmetics and the beauty industry in relation to feminism and feminist art. While this history has had a complicated —and often ugly—relationship to the feminist movement, it cannot be read as all encompassing, especially with current feminist ideologies which intersect concerns of racism, classism, ableism, transphobia, rape culture, media representation, cultural appropriation, domestic violence, and missing and murdered Indigenous women and girls. ${ }^{276}$ As the MoMA succinctly puts it, "Both feminism and feminist art continue to evolve;"277 from one generation of feminism to the next, the topic of beauty has been subject to criticism and protest. As I mentioned in Chapter One, in the 1960s and 70s, feminists saw cosmetics as the cornerstone of women's oppression. My research complicates this notion; people turn to makeup for reasons that stem from a variety of motives - all of which are dependent on the individual and their life experiences, as well as the priorities and various demographics of the time.

Recognizing the cultural obligations that pressure people into beautification rituals is fundamental to understanding the turn to cosmetics and beauty practices, but it is also important to look beyond this. As Ana Elias asserts, when analyzing cosmetics and beauty practices, we must “...think more ambivalently about beauty politics, retaining an openness to multiple readings." ${ }^{278}$ Allison Vandenberg also notes that, "[i]n addition to the oppression and negative

276 “About FAC," Feminist Art Collective, accessed October 27, 2020, https://www.factoronto.org/mandate.

277 "Feminist Art," Museum of Modern Art, accessed October 27, 2020, https://www.moma.org/collection/terms/168.

${ }^{278}$ Elias et al., "Aesthetic Labour: Beauty Politics in Neoliberalism,” 21. 
sensations beauty practices often entail, pleasure must also be considered, for beauty practices are quite frequently sources of enjoyment.... as well as means for self-expression...."279

Nancy Ann Rudd further explains:

The nature of women's makeup use history and her dominant style of use are tied to her identity construction and reflection, allowing her to explore and define multiple aspects of herself such as the real versus the artificial self, the day versus night self, the work versus fun self, the feminist versus the nonfeminist self. ${ }^{280}$

Natalie Halvin and Jillian M. Báez also contribute to this discussion, explaining that "women of colour feminists, particularly black and Chicana feminists...acknowledge the significance of beauty—not only as personal adornment but also as a mode of survival." ${ }^{281}$ As I conclude, I want to end on an important note; engagement, empowerment, and empathy will look different for each viewer who experiences $A$ Genuine Simulation of ... or Butterfly Kisses because viewers all have different relationships with cosmetics and adornment.

In 2006, Rita Felski—critiquing Sheila Jeffreys' Beauty and Misogyny — detailed the double bind faced by women when they make personal choices about their own adornment:

When women describe their discomfort around fashion and beauty, they are treated as reliable native informants; when they testify to their enjoyments, their words are read symptomatically and diagnosed as clear-cut evidence of misrecognition and selfdeception... Jeffreys's decision to stop dying her hair is portrayed as authentic choice, whereas another woman's decision to reach for a bottle of Clairol can only be a pseudochoice steered by larger forces beyond her grasp and control. ${ }^{282}$

Conclusions drawn by scholars that maintain that beauty practices are exclusively oppressive are, I suggest, as oppressive as the culturally constructed beauty practices that they discuss. I

${ }^{279}$ Vandenberg, "Toward a Phenomenological Analysis of Historicized Beauty," 171.

${ }^{280}$ Rudd, "Cosmetic Consumption and Use Among Women," 63.

${ }^{281}$ Natalie Halvin and Jillian M. Báez, "Introduction: Revisiting Beauty," Women's Studies Quarterly 46, no. 1/2 (Spring/Summer 2018): 14.

${ }^{282}$ Rita Felski, “'Because it is Beautiful': New Feminist Perspectives on Beauty,” Feminist Theory 7 no. 2 (2006): 274. 
maintain this perspective because they invalidate a person's right to enjoy cosmetics and establish healthy relationships to the products and related practices.

Division in the makeup debates makes it difficult for people to navigate their own beauty rituals and identify their significance. Rebecca Plante writes,

At some point in high school I began to think I'd call myself a feminist, and at my alternative, somewhat counterculture college, I got into heated debates about whether my makeup was a symbol of my own and other women's oppression. I struggled to reconcile my feminism and my perceived individuality with cosmetics and the invented stories they help me tell. ${ }^{283}$

I believe that it is important to challenge notions of beauty in a way that does not simply discount practices of self-fashioning and adornment. Carla Rice affirms that "[w]omen's actual beauty practices don't fit neatly into either frame of this debate." 284 The roles that these beautification rituals inhabit must extend beyond oppression and sexualization. In 2018, Allison Vandenberg noted that "what is perhaps more significant to understanding the significance beauty practices hold in the lives of the subject are the myriad feelings that lie somewhere between and outside the limited binary of pleasure and pain." 285 In "Aesthetic Labour: Beauty Politics in Neoliberalism," Ana Elias writes that "[m]uch popular third wave feminism also calls on feminism to engage with beauty and fashion in terms of playfulness and pleasure rather than coercion... Debbie Stroller for example states that 'painting one's nails expands notions of what a feminist is allowed to do or how she might look." ${ }^{\prime 286}$ Debbie Stroller's quote is an important reminder that not all feminists need to look and act alike; Stroller validates those who identify

\footnotetext{
283 Plante, "Putting on Makeup," 168.

${ }^{284}$ Rice, "In the Mirror of Beauty Culture," 240.

${ }^{285}$ Vandenberg, "Toward a Phenomenological Analysis of Historicized Beauty Practices," 171.

${ }^{286}$ Elias et al., "Aesthetic Labour: Beauty Politics in Neoliberalism," 21.
} 
with feminist values but also find pleasure or enjoyment in beauty practices, or other acts and lifestyles, which feminism has long opposed.

I now recognize more clearly the oppressive histories of which cosmetics have been part, and I continue to learn, but I am also a person who continues to wear cosmetics on occasion. While some may see this as contradictory or espouse the belief that I am willingly participating in harmful, sexist, and culturally constructed practices, I maintain that — after working very hard to develop a healthy relationship with my adorned and unadorned appearance-my makeup use no longer negatively affects me. I think that the key is being aware of the history and the "harmful cultural practices" to which Sheila Jeffreys refers, and then redefining one's relationship to cosmetics based on this awareness. 


\section{$\underline{\text { List of Figures }}$}

Figure 1.0 Suzy Lake, A Genuine Simulation of..., 1973/74. Ninety chromogenic prints. (C) Suzy Lake; Courtesy of the artist.

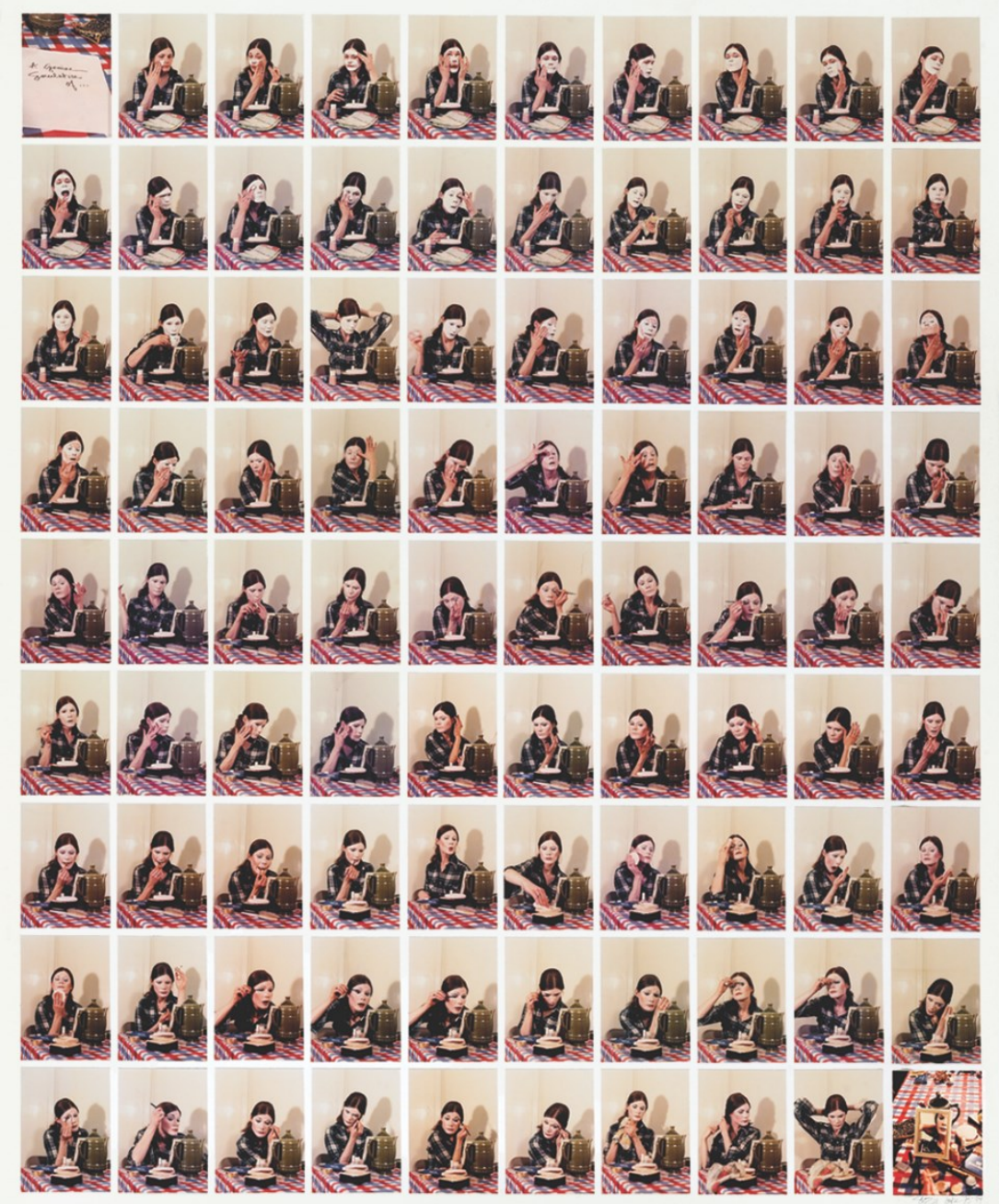


Figure 1.1 Janine Antoni, Butterfly Kisses, 1996-99. CoverGirl Thick Lash Mascara on paper. (C) Janine Antoni; Courtesy of the artist's website.

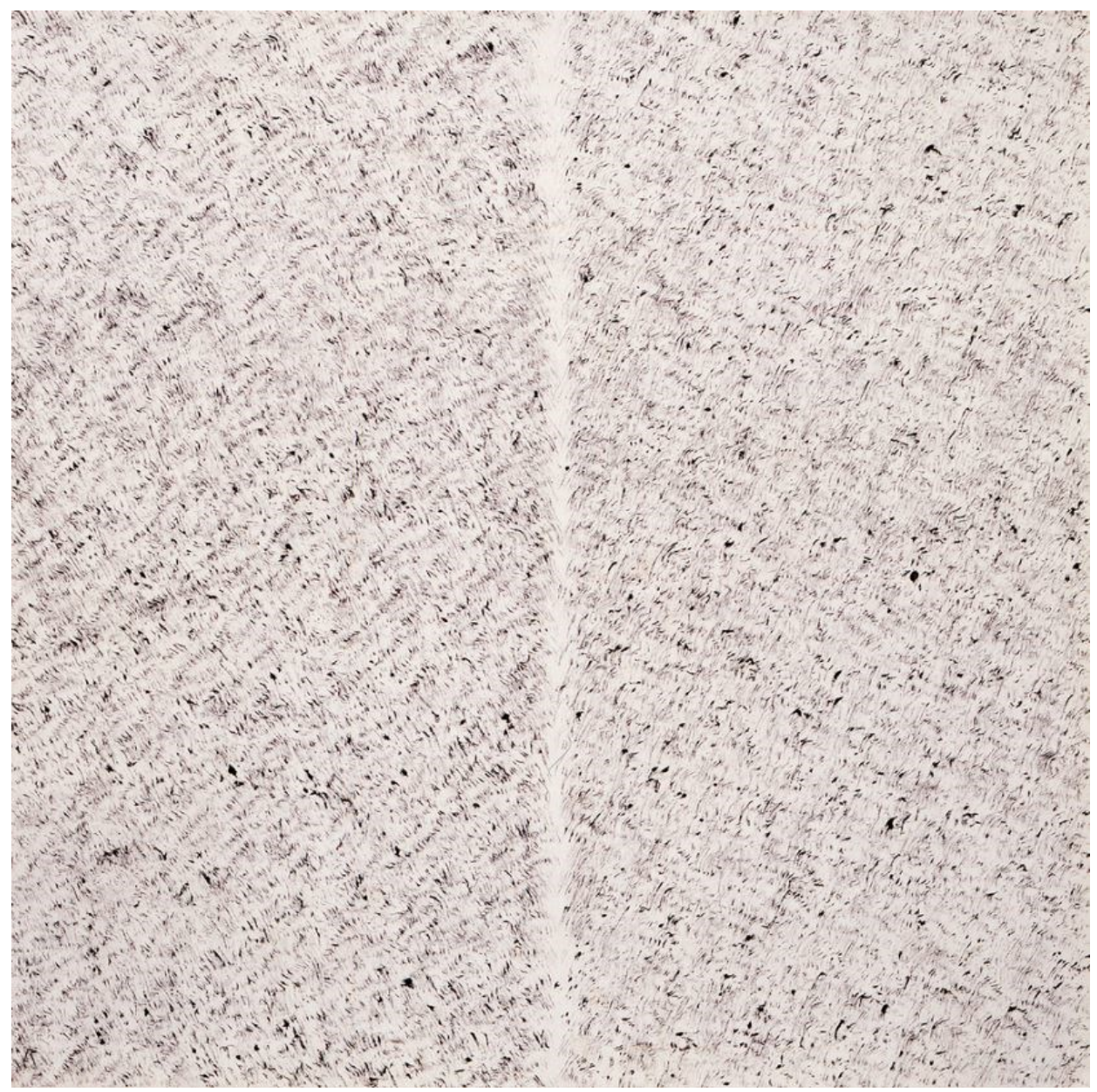


Figure 2.0 Suzy Lake, A Genuine Simulation of... on the cover of the Camerart exhibition catalogue, 1974. Galerie Optica, Montreal.

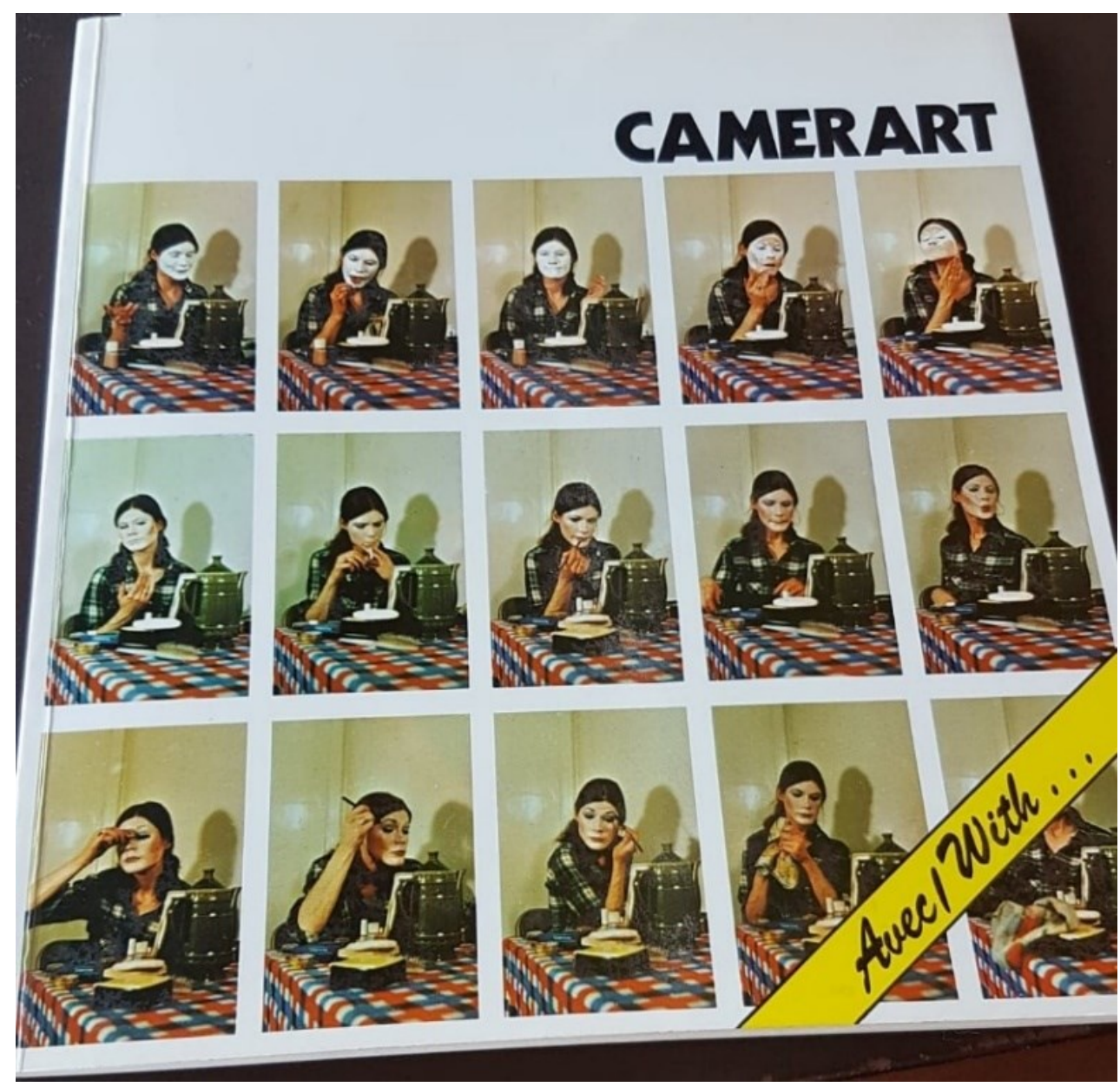


Figure 2.1 Suzy Lake, Imitations of Myself \#1, 1973/2012. Forty-eight chromogenic prints. (C) Suzy Lake; Courtesy of the artist.

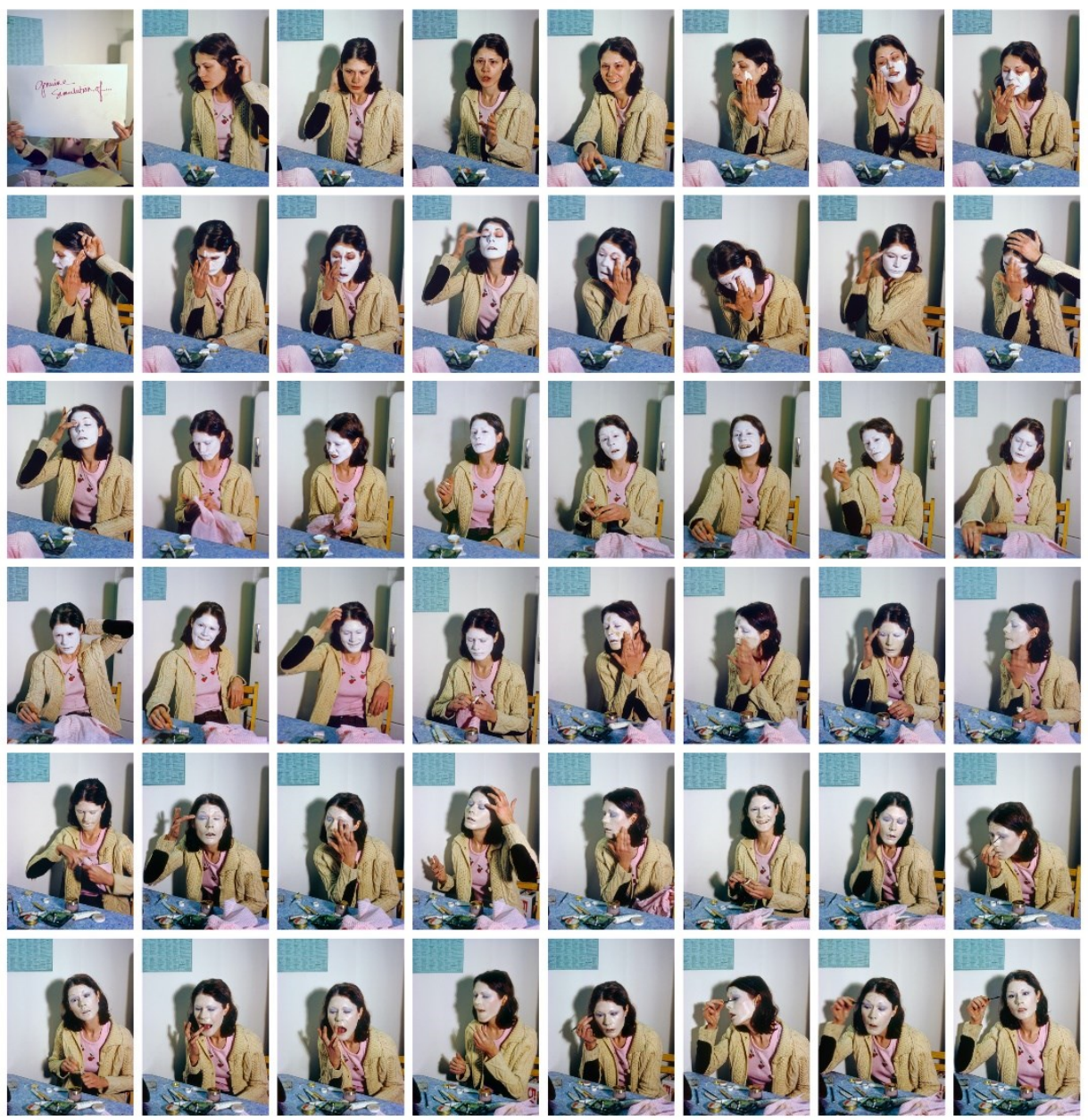


Figure 2.2 Suzy Lake, A Genuine Simulation of ... no. 2, 1973/74. Six gelatin silver prints and makeup. (C) Suzy Lake; Courtesy of the artist.

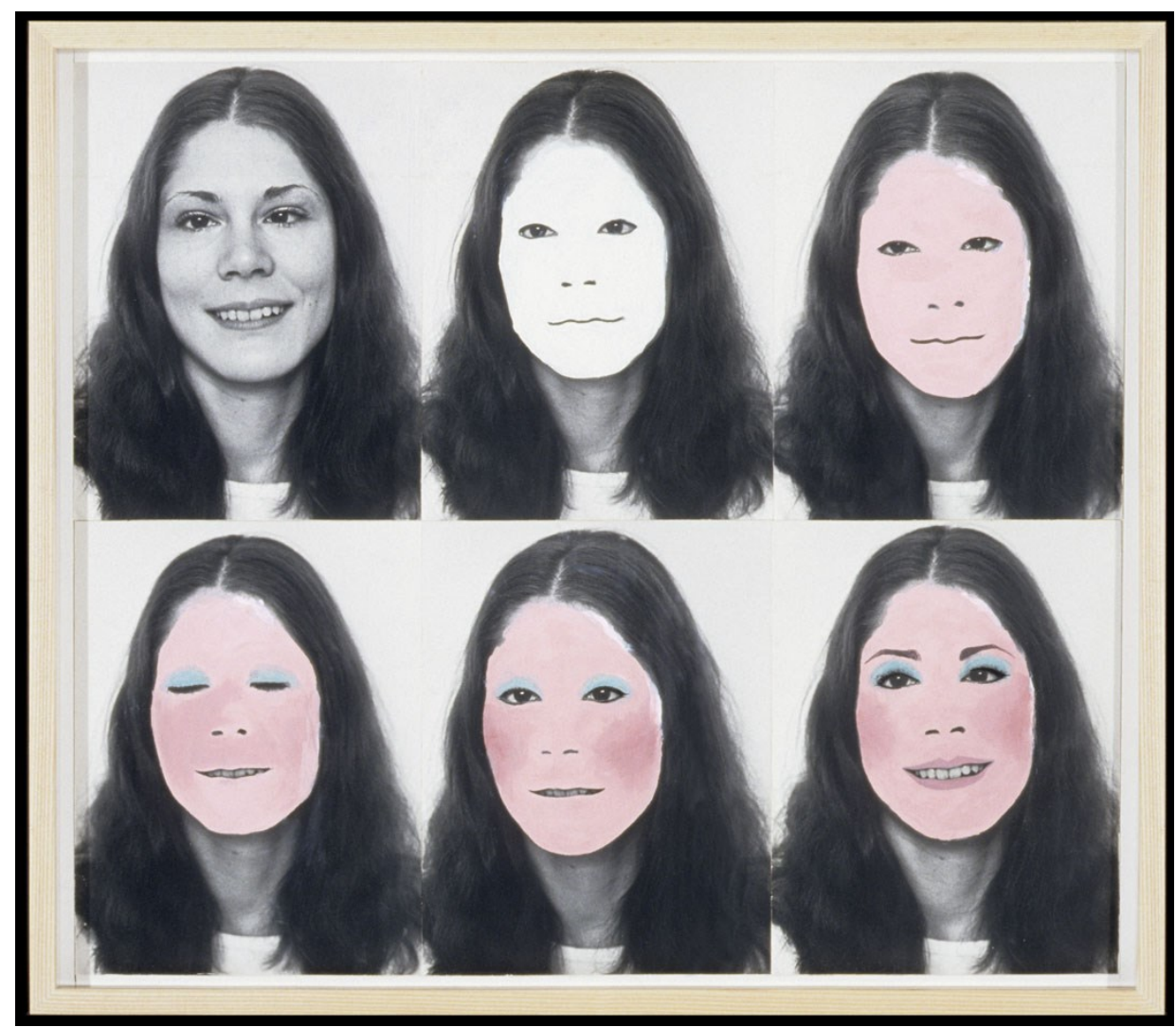

Figure 2.3 Suzy Lake. On Stage, 1972, reprinted 1996. Gelatin silver print, selenium toned, 40.1 x $91.3 \mathrm{~cm}$. Art Gallery of Ontario. Gift of Carol and Morton Rapp, 2009. (C) Suzy Lake. $2009 / 290$.

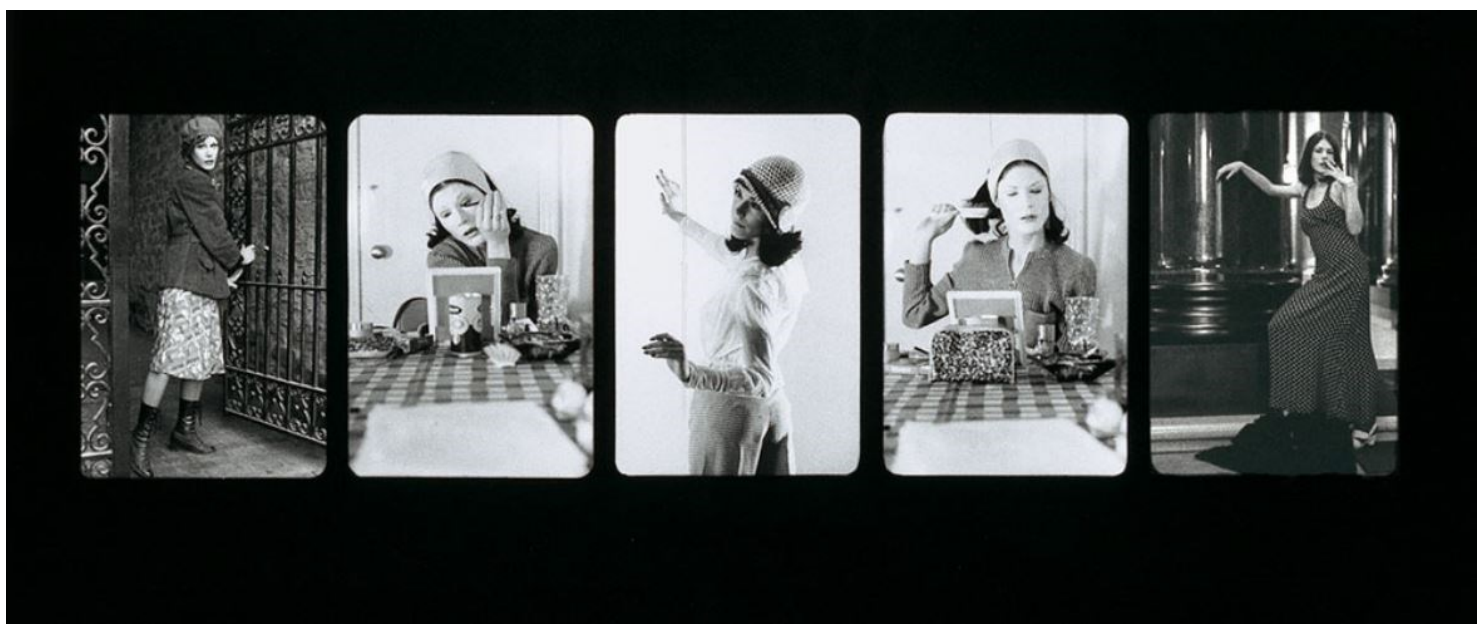


Figure 2.4 A Genuine Simulation of... detail \#1. Photo taken from the Introducing Suzy Lake exhibition catalogue.

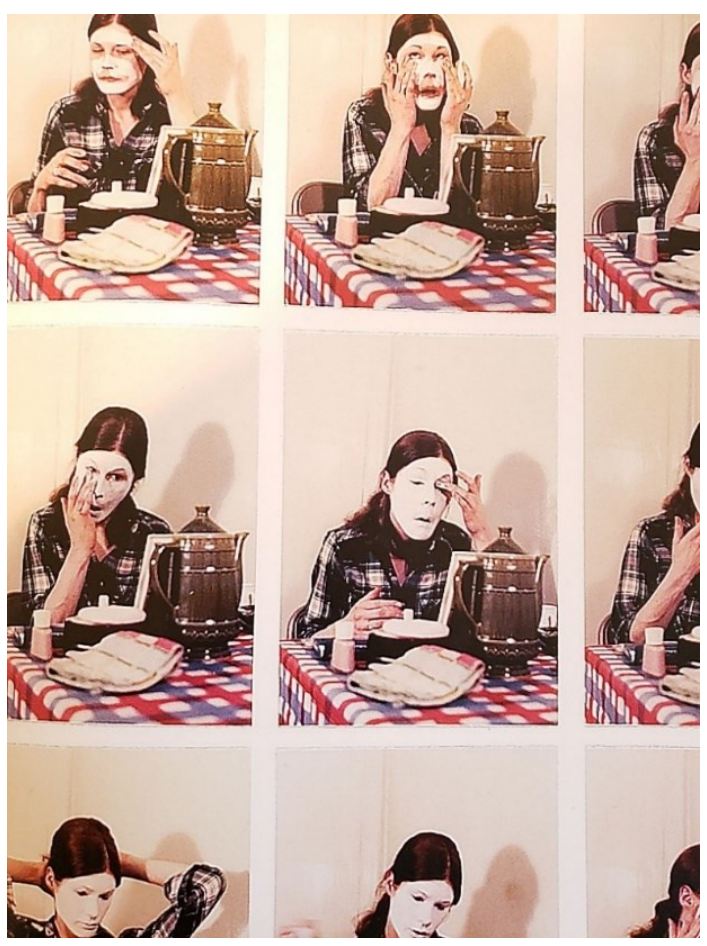

Figure 2.5 A Genuine Simulation of... detail \#2. Photo taken from the Introducing Suzy Lake exhibition catalogue.

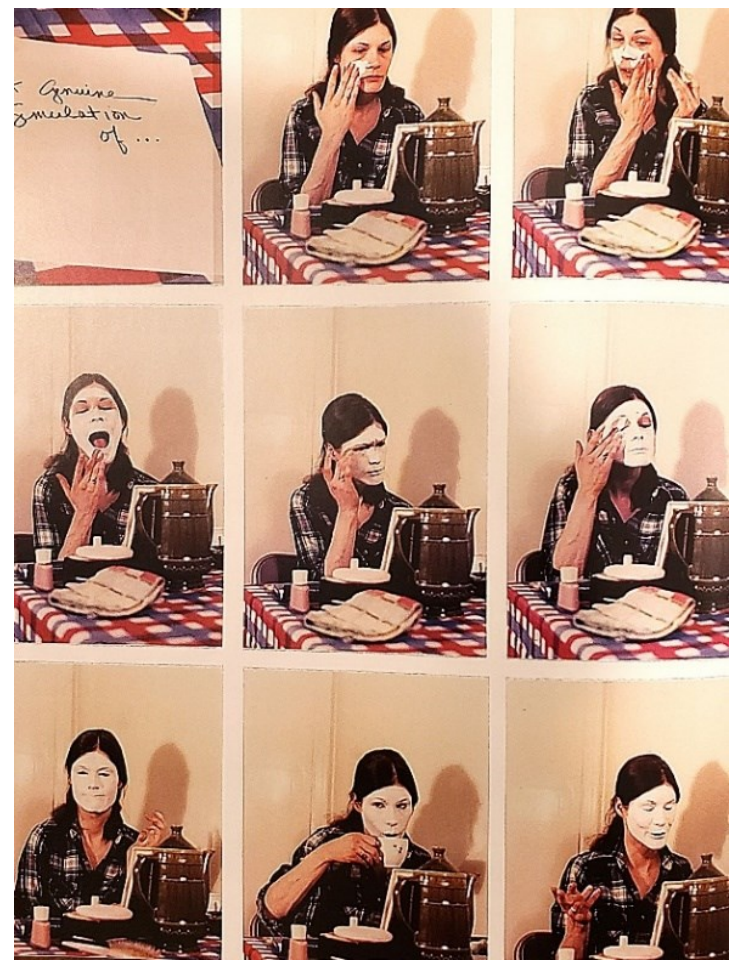


Figure 3.0 Janine Antoni, Loving Care, 1993. Performance with Loving Care hair dye, Natural Black, Dimensions variable. Photographed by Prudence Cumming Associates at Anthony d'Offay Gallery, London, 1993. (C) Janine Antoni; Courtesy of the artist and Luhring Augustine, New York.

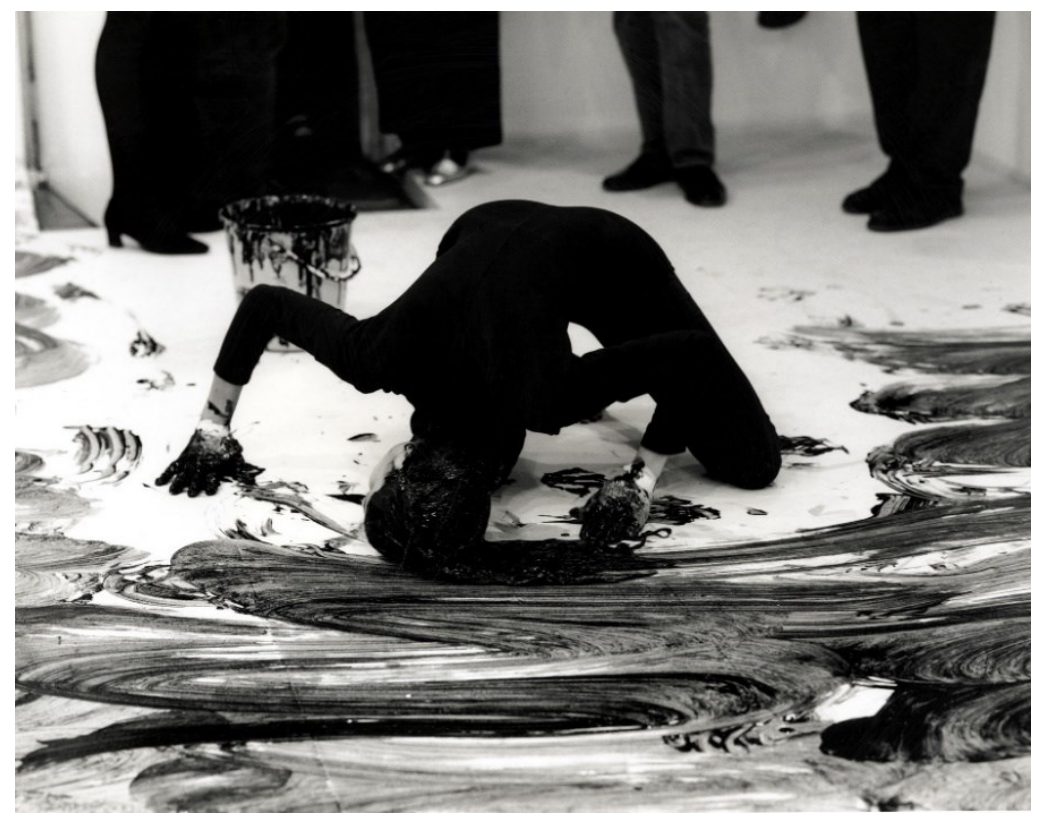


Figure 3.1 Janine Antoni, Gnaw, 1992. $600 \mathrm{lb}$ chocolate cube and $600 \mathrm{lb}$ lard cube gnawed by the artist, 45 heart-shaped packages of chocolate made from chewed chocolate removed from the chocolate cube, and 150 lipsticks made with pigment, beeswax, and chewed lard removed from the lard cube. Each cube: $24 \times 24$ x 24 inches (60.96 x $60.96 \times 60.96 \mathrm{~cm})$; installation dimensions variable. Installation view: The Museum of Contemporary Art Los Angeles. (C) Janine Antoni; Courtesy of the artist and Luhring Augustine, New York.

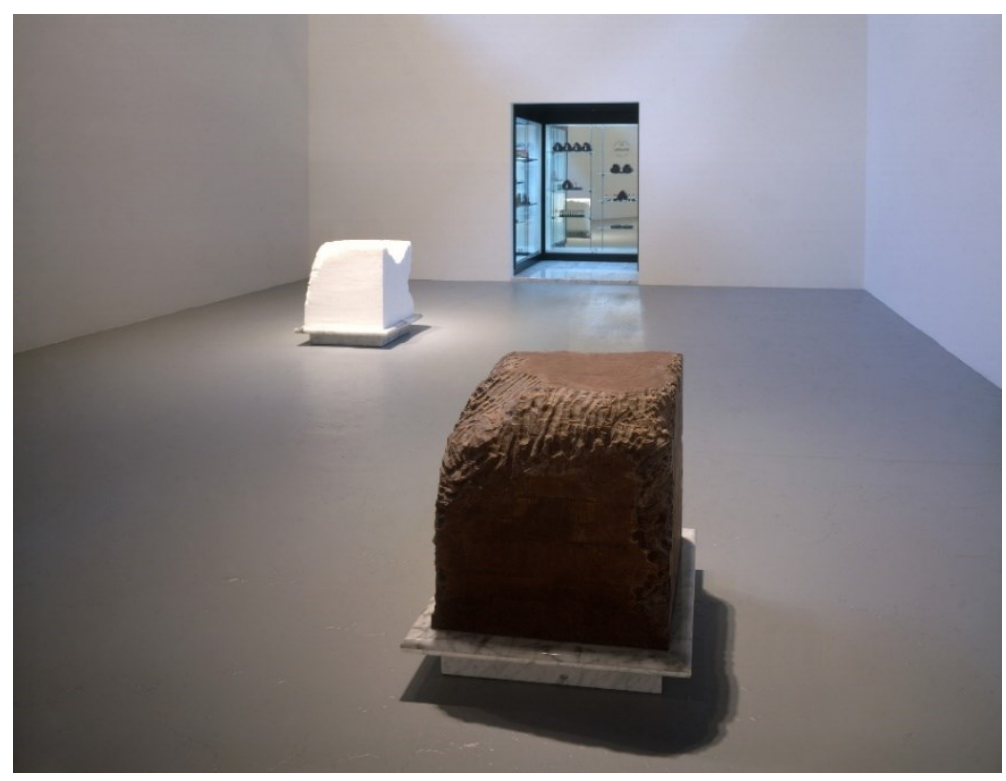


Figure 3.2 Janine Antoni, Lick and Lather, 1993. One licked chocolate self-portrait bust and one washed soap self-portrait bust on 14 pedestals, addition of $7+2$ Aps + TP. Bust: 24 x 16 x 13 inches (60.96 x 40.64 x $33.02 \mathrm{~cm})$ (each approximately), Pedestal: 45 7/8 x 16 inches (116.01 x $40.64 \mathrm{~cm}$ ) (each). Collection of the Carla Emil and Rich Silverstein and the San Francisco Museum of Modern Art (John Caldwell, curator of Painting and Sculpture, 1989-93, Fund for Contemporary Art Purchase). Photo: Ben Blackwell. (C) Janine Antoni; Courtesy of the artist and Luhring Augustine, New York.

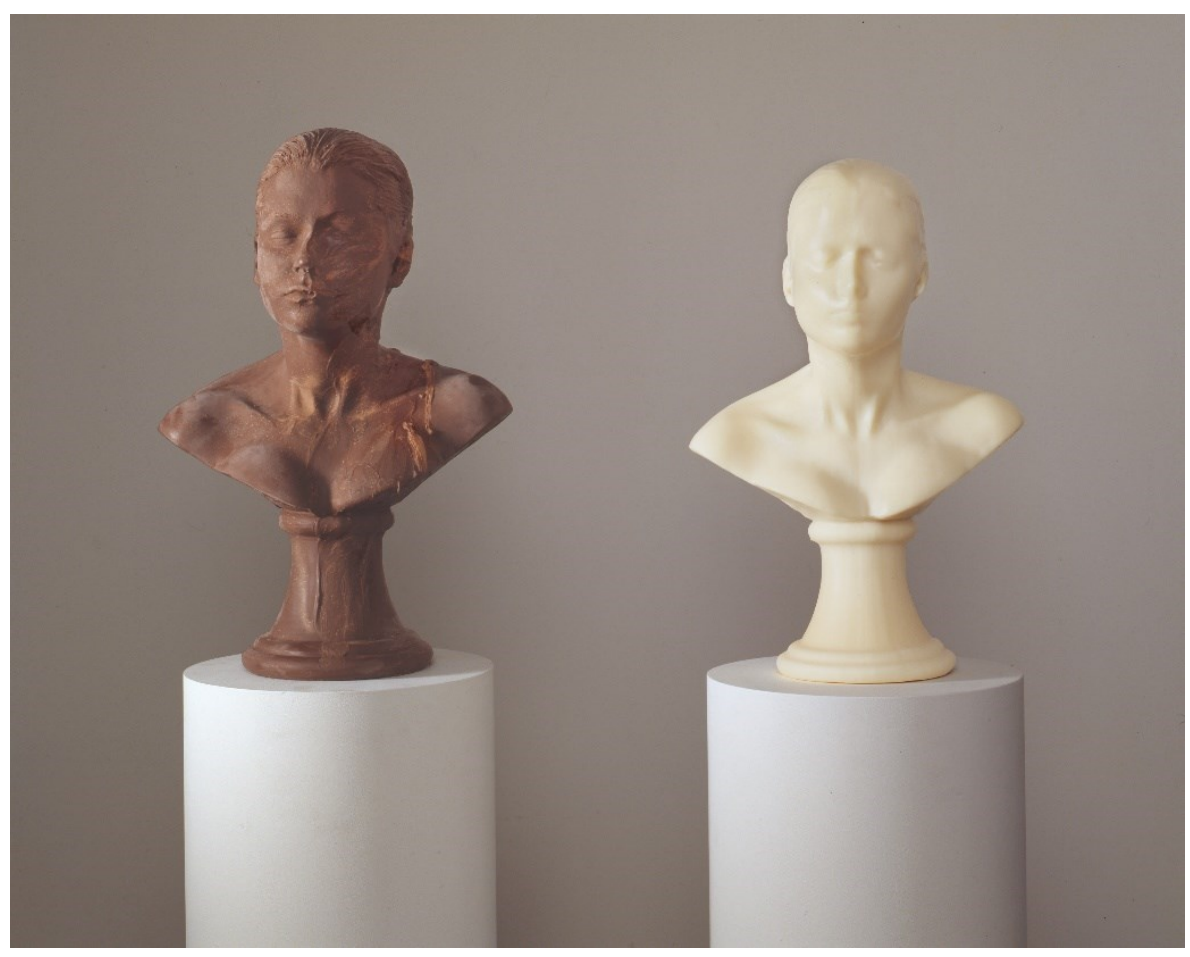


Figure 3.3 Janine Antoni, Butterfly Kisses, 1993. CoverGirl Thick Lash Mascara, 1124 winks per eye. Diptych, 22 1/8 x 15 inches (each) $(56.2$ x $38.1 \mathrm{~cm}$ (each)). C Janine Antoni; Courtesy of the artist and Luhring Augustine, New York.

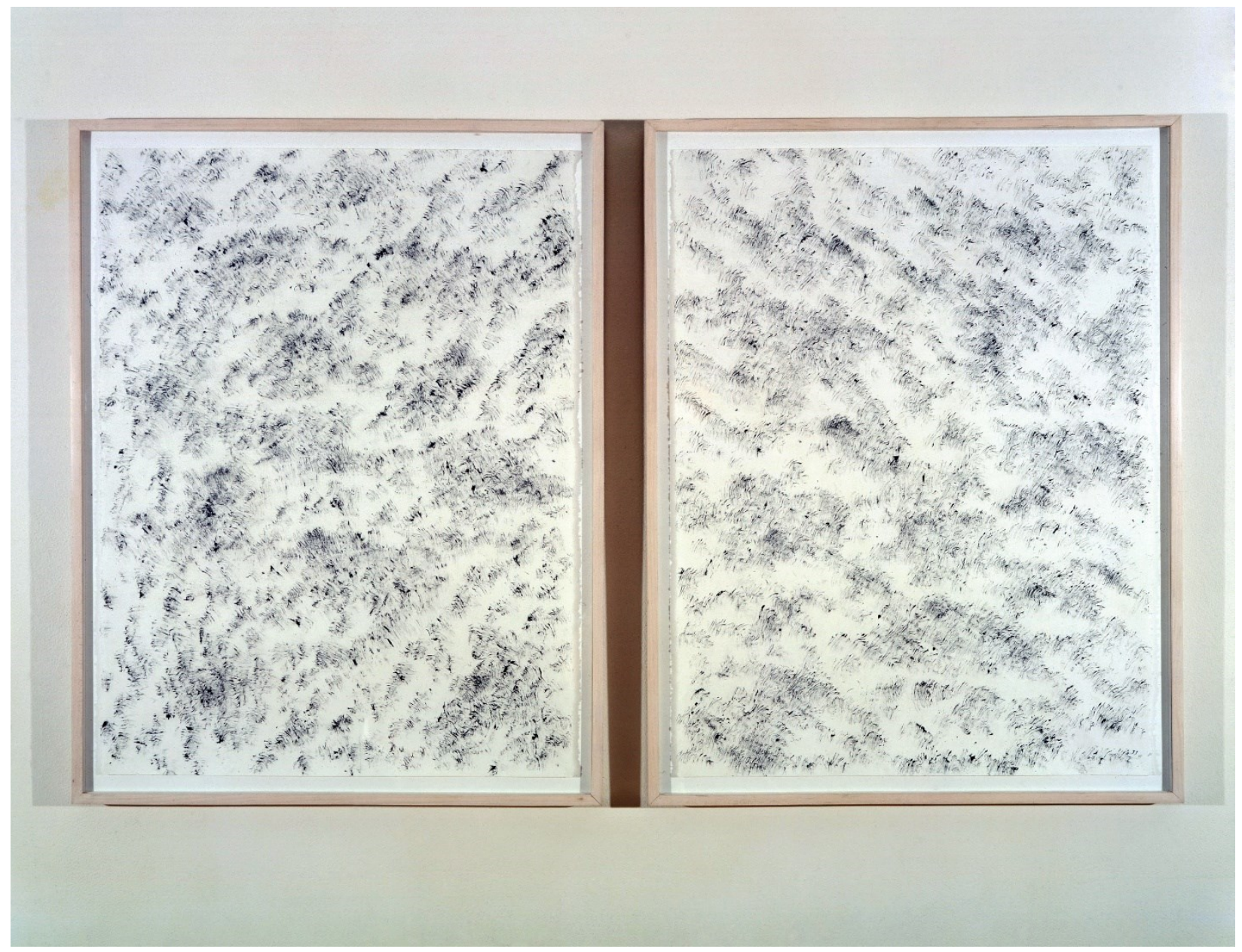


Figure 3.4 Jessa Laframboise, Butterfly Kisses Experiment, 2020. Photograph of the experiment as Laframboise butterfly kisses the paper.

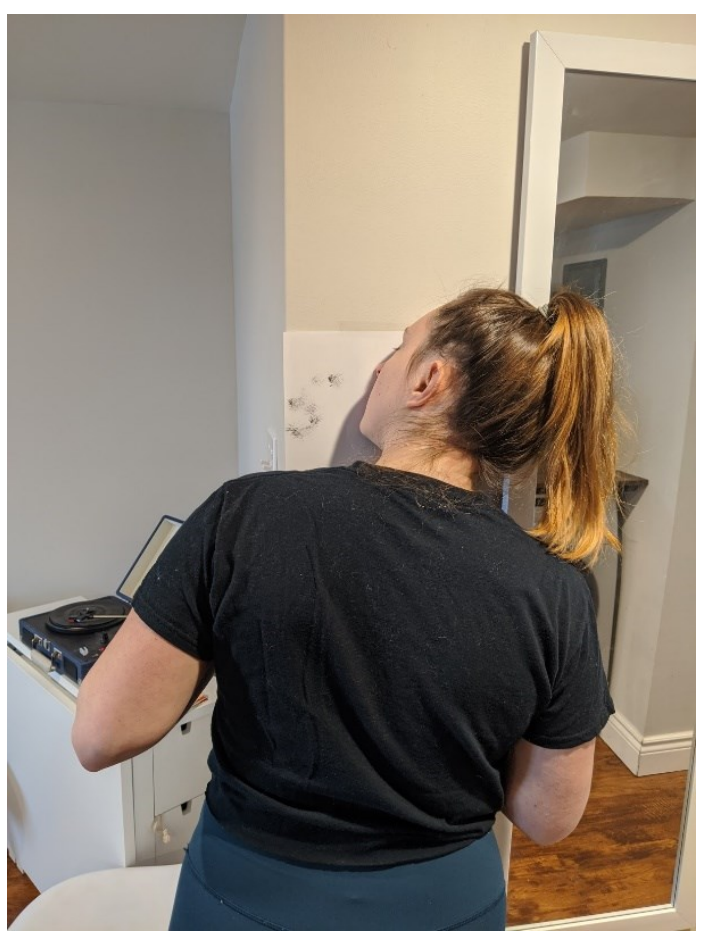

Figure 3.5 Jessa Laframboise, Butterfly Kisses Experiment, 2020. Photograph of the experiment as Laframboise applies the mascara.

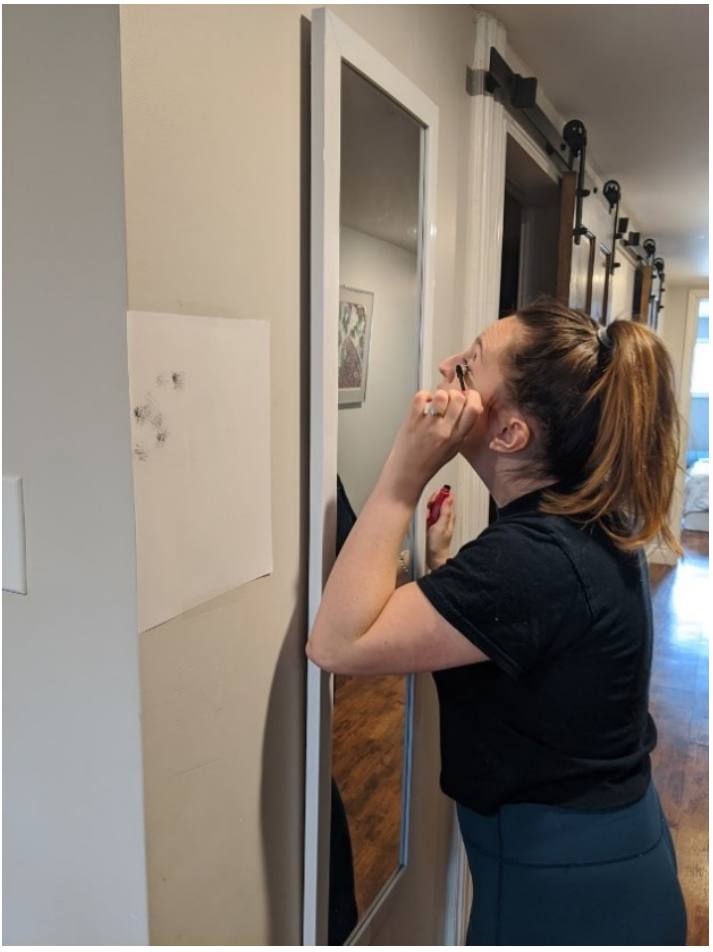


Figure 3.6 Jessa Laframboise, Butterfly Kisses Experiment, 2020. Photograph of the experiment as Laframboise's face is pressed against the paper.

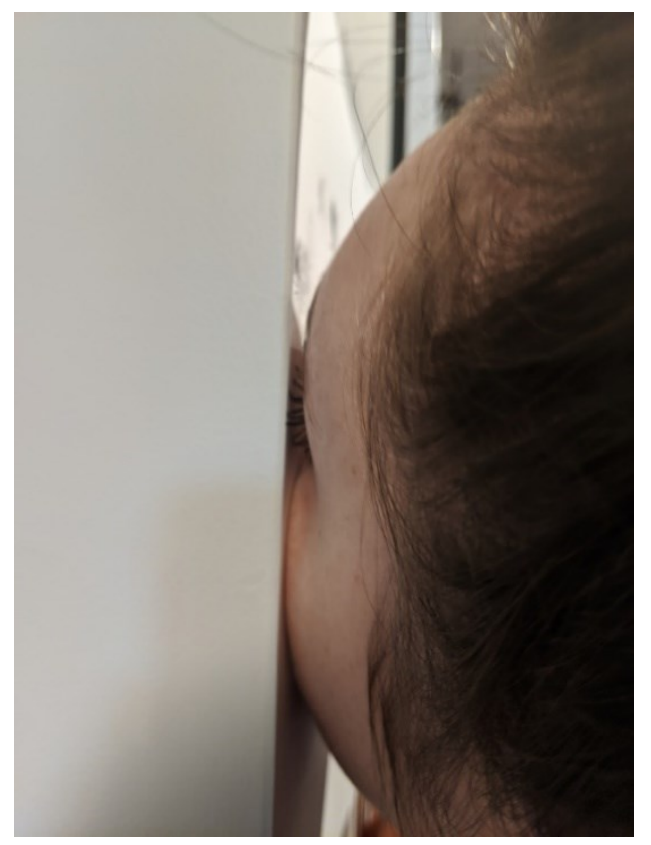

Figure 3.7 Jessa Laframboise, Butterfly Kisses Experiment, 2020. CoverGirl Thick Lash Mascara on paper.

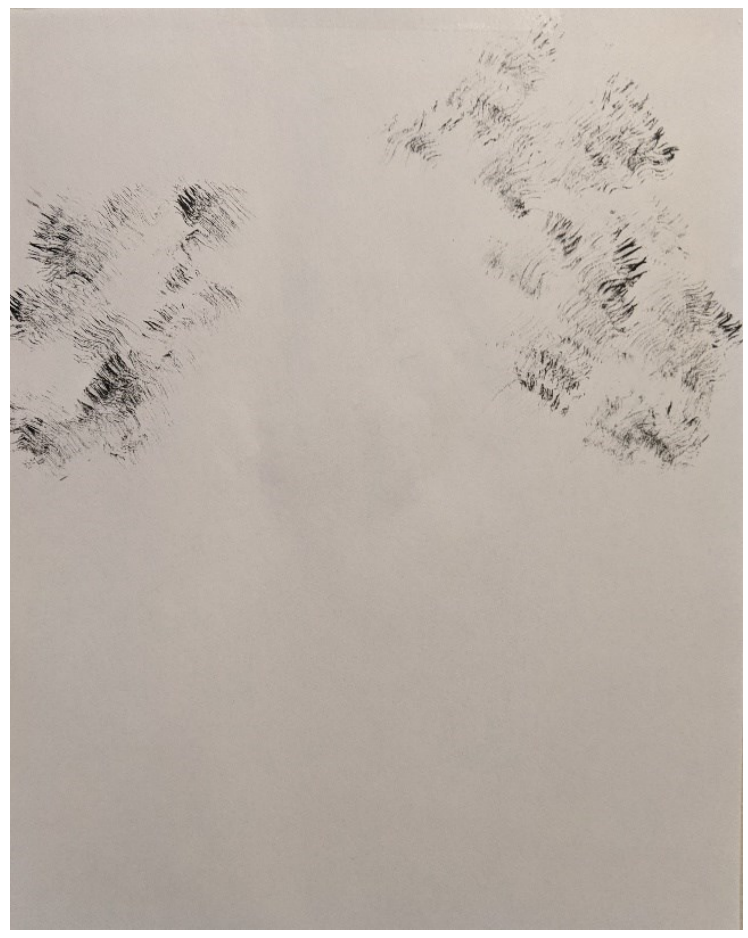


Figure 3.8 Jessa Laframboise, Butterfly Kisses Experiment progress, 2020. CoverGirl Thick Lash Mascara on paper.

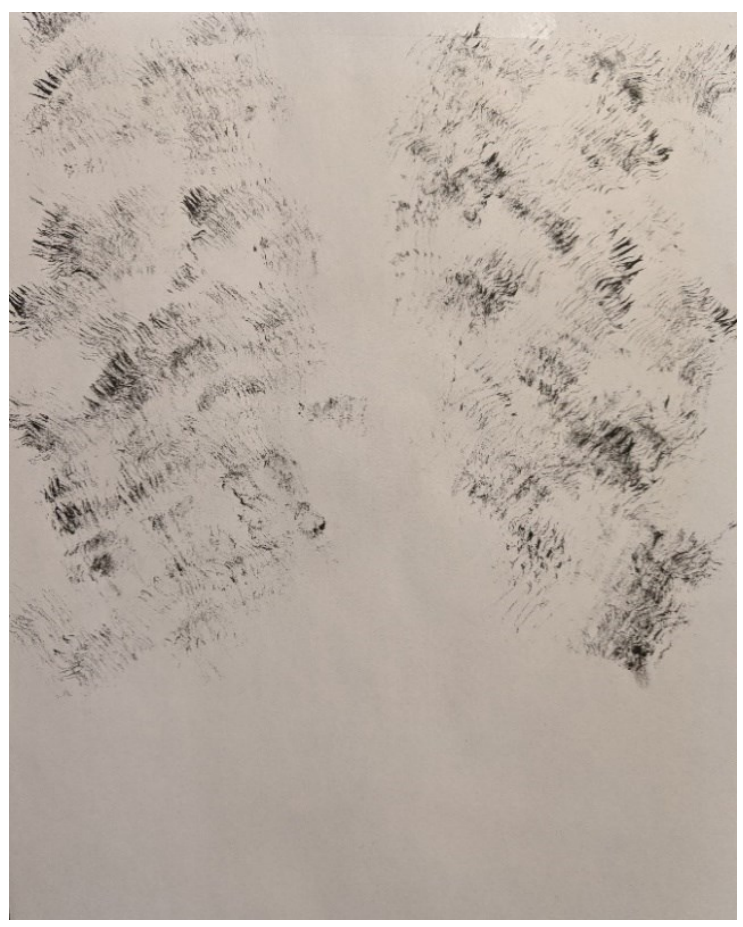

Figure 3.9 Jessa Laframboise, Butterfly Kisses Experiment, 2020. Photograph of the experiment after Laframboise's face is pressed against the paper.

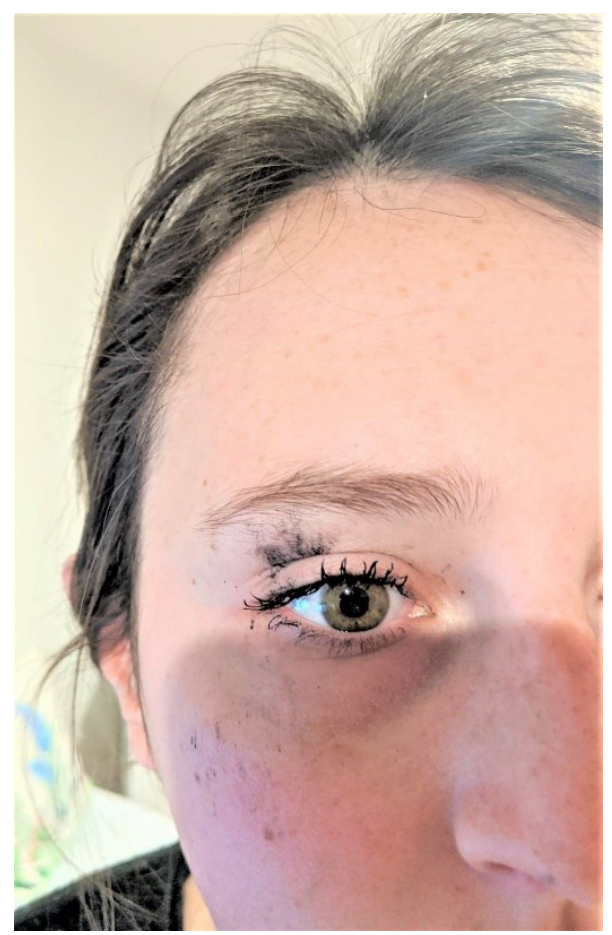


Figure 3.10 Jessa Laframboise, Butterfly Kisses Experiment, 2020. Used disposable makeup wipes, CoverGirl Thick Lash Mascara.

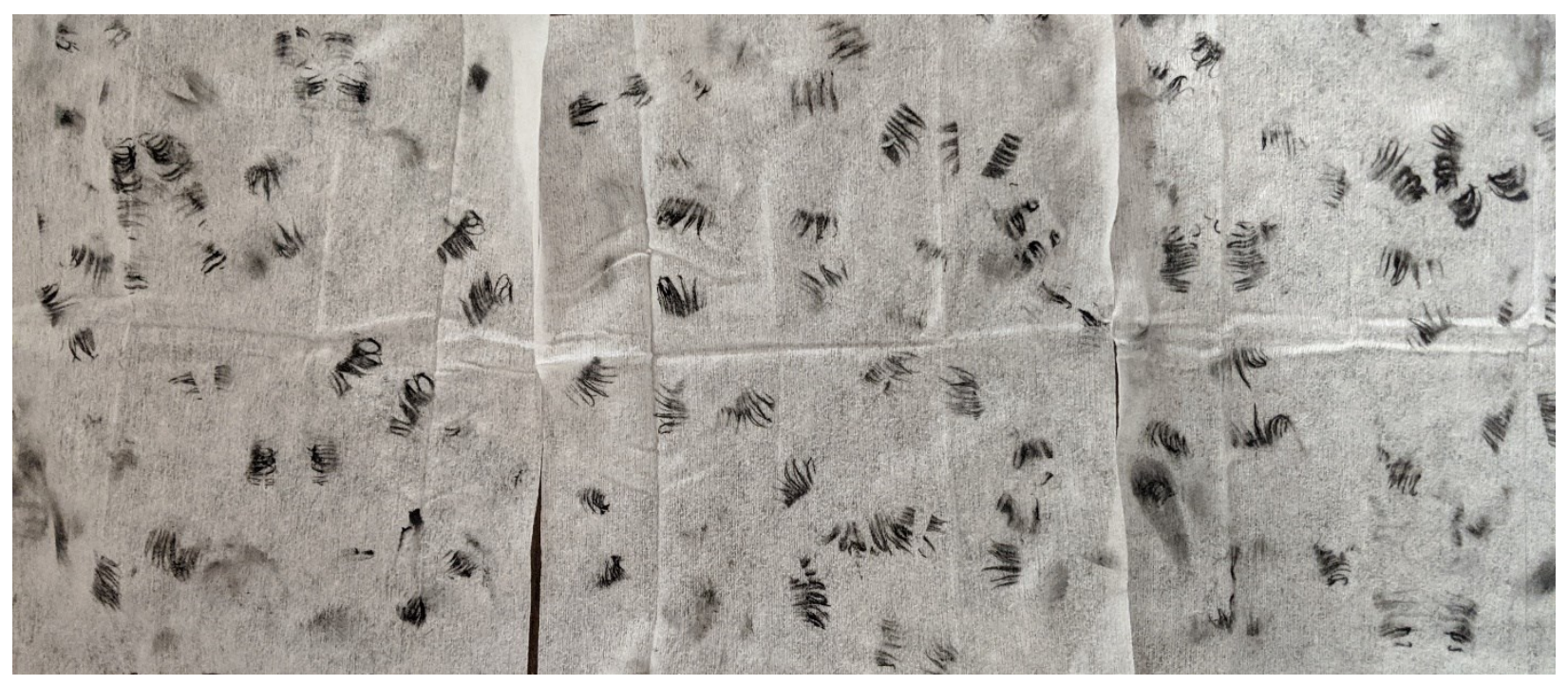




\section{Bibliography}

“Abstract Expressionism.” MoMA Learning. Accessed May 26, 2020.

https://www.moma.org/learn/moma_learning/themes/abstract-expressionism/.

“About FAC.” Feminist Art Collective. Accessed October 27, 2020.

https://www.factoronto.org/mandate.

Andrews, Jane. "Can You Name These Makeup Brands from Their Motto?" howstuffworks PLAY. Accessed July 14, 2020. https://play.howstuffworks.com/quiz/can-you-name-these-makeupbrands-from-their-motto.

Antoni, Janine and Adrian Heathfield. "Touching Remains." In Perform, Repeat, Record: Live Art in History, edited by Amelia Jones and Adrian Heathfield, 511-528. Bristol; Chicago: Intellect Books Ltd, 2012.

Antoni, Janine. "Elson Lecture 2018: Janine Antoni." Filmed March 1, 2018 at the National Gallery of Art, Washington, DC. Video. Accessed June 2, 2020. https://www.youtube.com/watch?v=Zay35tG7B3c\&feature=emb_title.

Antoni, Janine. "Janine Antoni." Interview by Stuart Horodner. Bomb Magazine, January 1, 1999. https://bombmagazine.org/articles/janine-antoni/.

Antoni, Janine. "My Body is Your Vehicle: In Conversation with Janine Antoni." Interview by Joshua Reiman. Sculpture, May 1, 2015.

Antoni, Janine, Robert Ryman, and Fred Tomaseli. "New Materials, New Ideas: Issues in Conversation.” Interview by Kirk Varnedoe and James Coddington. Museum of Modern Art 4, no. 6 (2001): 6-9.

Antoni, Janine. “The Artists Guide: Making a Living Doing What You Love.” Interview by Jackie Battenfield. Reality Check Interviews, April 29, 2008. https://www.artistcareerguide.com/interviews/pdf/Janine\%20Antoni\%20Artist\%20interview.PD F. 
Applin, Jo. "From Infinity Nets to Minimalism." In Yayoi Kusama Infinity Rooms - Phalli's Field, 3037. London: Afterall Books, 2012.

Auslander, Philip. "Live Performance in a Mediatized Culture." In Liveness: Performance in a Mediatized Culture, 10-60. London; New York: Routledge, 1999.

Auslander, Philip. "The Performativity of Performance Documentation." A Journal of Performance Art 28, no. 3 (2006): 1-10.

Ayerbe, Nera. "Documenting the Ephemeral: Reconsidering the Idea of Presence in Discussions on Performance." Brazilian Journal on Presence Studies 7, no. 3 (2017): 551-572.

B., Bonnie. "Janine Antoni, in person at BU." Big Red and Shiny, November 22, 2013. Accessed June 3, 2020. http://bigredandshiny.org/14661/janine-antoni-in-person-at-bu/.

Badischer Kunstverein Germany. "Suzy Lake Artist Talk." YouTube video, 2013. Accessed June 8, 2020. https://www.youtube.com/watch?v=1zr19uPBcB4.

Baez, Anulfo. "Dance/Draw - The ICA's Newest Exhibition Will Have You Dancing and Drawing." The Evolving Critic, October 5, 2011. Accessed May 27, 2020, https://evolvingcritic.org/2011/10/05/review-dancedraw-the-icas-newest-exhibition-will-haveyou-dancing-and-drawing/.

Baird, Daniel. "Self-Inventions: The Photography of Suzy Lake." Border Crossings 30, no. 3 (Fall 2011): 98-105.

Bao, Weihong et al. "Reflections on Durational Art." Representations, no. 136 (Fall 2016): 132-172.

Barry, Christopher T. et al., ““'Let Me Take Another Selfie': Further Examination of the Relation Between Narcissism, Self-Perception, and Instagram Posts." Psychology of Popular Media Culture 8, no. 1 (2019): 22-33. 
Barthes, Roland. Camera Lucida. New York: Hill and Wang, 1981.

Battista, Kathy. Renegotiating the Body: Feminist Art in 1970s London. London: I.B. Tauris \& Co Ltd, London; New York: Palgrave Macmillan, 2013.

Bay-Cheng, Sarah. “Temporality.” In Mapping Intermediality in Performance, edited by Sarah BayCheng, Chiel Kattenbelt, Andy Lavender and Robin Nelson, 85-90. Amsterdam: Amsterdam University Press, 2010.

Bishop, Claire. "Black Box, White Cube, Grey Zone: Dance Exhibitions and Audience Attention." The Drama Review 62, no. 2 (Summer 2018): 22-42.

Bishop, Claire. "Delegated Performance: Outsourcing Authenticity.” October 140 (Spring 2012): 91112.

"Bodyscapes.” The Israel Museum. Accessed May 27, 2020. https://www.imj.org.il/en/exhibitions/bodyscapes.

Bonner, Hannah. "Performing Archives in the Present: Exploring Feminist Performance Art, The Politics of (In)Visibility, and the Archive in \#Metoo and \#Timesup." South Central Review 36, no. 2 (Summer 2009): 33-51.

Boxer, Sarah. "Yayoi Kusama’s Existential Circus.” The Atlantic Monthly 320, no. 1 (2017): 94-103.

Brandon, Ruth. "Beauty is Power!” In Ugly Beauty: Helena Rubinstein, L'Oreal and the Blemished History of Looking..., edited by Ruth Brandon, 1-38. Toronto: McClelland \& Stewart Ltd, 2011.

"Bridget Riley." Tate Modern. Accessed May 26, 2020. https://www.tate.org.uk/art/artists/bridget-riley1845.

Brower, Matthew, Carla Garnet, and Dot Tuer. Suzy Lake: Political Poetics. Toronto: University of Toronto Art Centre, 2011. Exhibition Catalogue. 
Bull, Stephen. "Photography as Art.” In Photography, 123-146. London; New York: Routledge, 2010.

Burnham, Lynn Frye. ““'High Performance,' Performance Art, and Me.” The Drama Review 30, no. 1 (Spring 1986): 15-51.

Buskirk, Martha. The Contingent Object of Contemporary Art. Cambridge: The MIT Press, 2003.

Bustamante, Nao. "The Personal Evolution of the Performance Object (Or, What to Do with Leftovers)." In Perform, Repeat, Record: Live Art in History, edited by Amelia Jones and Adrian Heathfield. Bristol; Chicago: Intellect Books Ltd, 2012.

Butler, Judith. Gender Trouble: Feminism and the Subversion of Identity. London; New York: Routledge, 1990.

Butler, Judith. "Performative Acts and Gender Constitution: An Essay in Phenomenology and Feminism." Theatre Journal 40, no. 4 (December 1988): 519-531.

Butler, Judith. "The Body You Want: Liz Kotz Interview with Judith Butler." Interviewed by Liz Kotz, Art Forum 31, no. 3 (November 1992): 82-89.

“Butterfly Kisses.” Janine Antoni Immaculate Conception Inc. Accessed December 13, 2019. http://www.janineantoni.net/butterfly-kisses.

Brough, John B. "Time and the One and the Many (In Husserl's Bernauer Manuscripts on Time Consciousness)." Philosophy Today 46 (2002): 142-155.

Cahill, Ann J. "Feminist Pleasure and Feminine Beautification." Hypatia 18, no. 4 (Autumn-Winter 2003): $42-64$.

Campbell, Lee. "Beyond Pollock: on visual art objects as non-traditional forms of performance document." International Journal of Performance Arts and Digital Media 10, no. 1 (2014): 3547. 
Chapkis, Wendy. Beauty Secrets: Women and the Politics of Appearance. Boston: South End Press, 1986.

Cappo, Nancy. "Photo Meditation/Introspection.” In Healing with Art and Soul: Engaging One's Self through Art Modalities, edited by Kathy Luethje, 194-205. Newcastle Upon Tyne: Cambridge Scholars Publishing, 2009.

Chau, Christina. "Introduction: Peculiar Time." In Movement, Time, Technology, and Art, 1-20. Singapore: Springer Singapore, 2017.

Chave, Anna. "Minimalism and the Rhetoric of Power." Art Magazine 64, no. 5 (January 1990): 44-63.

Childs, Elizabeth C. “Collection Online: Mark Tobey.” Solomon R. Guggenheim Museum. Accessed May 26, 2020. https://www.guggenheim.org/artwork/4057.

Church Gibson, Pamela. "Cindy Sherman in a New Millennium: Fashion, Feminism, Art and Ageing." Australian Feminist Studies 33, no. 98 (2018): 481-497.

Clarke, Bill. “A Maker of Change.” Canadian Art 29, no. 4 (Winter 2013).

Cohen, Alina. "Body Issues: Artists' Maps of the Human Body Reveal Our Desire for Immortality." Artsy, March 24, 2020. Accessed May 27, 2020. https://www.artsy.net/article/artsy-editorialbody-issues-artists-maps-human-body-reveal-desire-immortality.

Cottingham, Laura. "Janine Antoni: Biting Sums Up My Relationship to Art History." Flash Art (Summer 1993): 104-105.

Cray, Wesley D. "Conceptual Art, Ideas, and Ontology." The Journal of Aesthetics and Art Criticism 72, no. 3 (Summer 2019): 235-245.

Cutler, Jody B. "Makeup and Art." Afterimage 40, no. 1 (2012): 31-32. 
"Dance/Draw." Institute of Contemporary Art Boston. Accessed May 27, 2020, https://www.icaboston.org/exhibitions/dancedraw.

Davis, Heather. Desire Change: Contemporary Feminist Art in Canada. Montreal; Kingston: McGillQueen's University Press, 2017.

Davis, Kathy. “"My Body is My Art': Cosmetic Surgery as Feminist Utopia?” The European Journal of Women's Studies 4 (1997): 23-37.

Davis, Kathy. "Remaking the She-Devil: A Critical Look at Feminist Approaches to Beauty." Hypatia 6, no. 2 (Summer 1991): 21-43.

De Lauretis, Teresa. Technologies of Gender: Essays on Theory, Film and Fiction. Bloomington: Indiana University Press, 1987.

Deutsche, Rosalyn et al. "Feminist Time: A Conversation." Grey Room, no. 31 (Spring 2008): 32-67.

Diamond, Elin. "Brechtian Theory/ Feminist Theory: Toward a Gestic Feminist Criticism." TDR 32, no.1 (Spring 1988): 82-94.

Dictionary.com. s.v. "Empathy.” Accessed January 2020. https://www.dictionary.com/browse/empathy?s=t.

Doane, Mary Ann. "Indexicality: Trace and Sign: Introduction." A Journal of Feminist Cultural Studies 18, no. 1 (2007): 1-6.

Dobryznski, Judith H. "Is This A Portrait If I Say So? A Gusty Exhibition." Real Clear Arts. Accessed May 27, 2020. https://www.artsjournal.com/realcleararts/2016/07/is-this-a-portrait-if-i-say-so-agutsy-exhibition.html.

Doss, Erika. Twentieth-Century American Art. Oxford: Oxford University Press, 2002. 
Dow, Bonnie. "Feminism, Miss America, and Media Mythology.” Rhetoric \& Public Affairs 6, no. 1 (2003): $127-160$.

- "The Movement Meets the Press: The 1968 Miss America Pageant Protest." In Watching Women's Liberation 1970: Feminism's Pivotal Year on the Network News, edited by Bonnie Dow, 29-51. Ubrana; Chicago: University of Illinois Press, 2014.

Dow, Hilary. "Suzy Lake vs. Cindy Sherman: Americanism and the Forgotten Canadian Feminist Art of the 70s." University of Toronto. Accessed June 8, 2020. https://sites.utm.utoronto.ca/historyinternships/blog/11282016-0157/suzy-lake-vs-cindysherman-americanism-and-feminist-art-70s.

Dua, Tanya. "CoverGirl is Ditching its Iconic Slogan." Business Insider, October 10, 2017. Accessed May 29, 2020. https://www.businessinsider.com/cover-girl-has-ditches-its-signature-easybreezy-slogan-2017-10.

Dyhouse, Carol. Glamour: Women, History, Feminism. London; New York: Zed Books, 2010.

Edelist, Yael. "Innovative Exhibition Exploring the Body, Nature, and Knowledge Across Time and Media to Premiere at The Israel Museum, Jerusalem in February 2020." Resincow and Associates, January 7, 2020. Accessed May 27, 2020. https://resnicow.com/clientnews/innovative-exhibition-exploring-body-nature-and-knowledge-across-time-and-mediapremiere.

Eileraas, Karina. "Fantasizing the Self: Identifying with and Against Images." In Between Image and Identity: Transnational Fantasy, Symbolic Violence, and Feminist Misrecognition, 28-67. Maryland: Lexington Books, 2007.

Elder, R. Bruce. “Dream Flesh.” Millennium Film Journal 54 (2011): 42-50.

Eldridge, Lisa. Face Paint: The Story of Makeup. New York: Abrams Image, 2015. 
Elias, Ana, Rosalind Gill, and Christina Scharff. "Aesthetic Labour: Beauty Politics in Neoliberalism." In Aesthetic Labour: Rethinking Beauty Politics in Neoliberalism, edited by Ana Elias, Rosalind Gill, and Christina Scharff, 3-49. London; New York: Palgrave Macmillan, 2017.

Enright, Robert. “The Many Faces of Suzy Lake.” Border Crossings 33, no. 4 (December 2014 February 2015): 24-36.

Enright, Robert and Meeka Walsh. “The Beautiful Trap: Janine Antoni’s Body Art.” Border Crossings 29, no. 1 (February 2010): 38-54.

Erickson, Jon. "Performing Distinctions." PAJ: A Journal of Performance and Art 21, no 3 (1999): 98104.

Erikson, Matthew. "It Was Only A Kiss... Or Was It?” The Hartford Courant, October 18, 2005. Accessed May 29, 2020. https://www.courant.com/news/connecticut/hc-xpm-2005-10-180510180609-story.html.

"Ewa Partum.” Culture Artists. Accessed July 2, 2020. https://culture.p1/en/artist/ewa-partum.

“Ewa Partum.” React Feminism. Accessed July 2, 2020.

http://www.reactfeminism.org/nrl/artists/partum_en.html.

Ewing, William E. “Canada's Artists with Cameras.” ARTnews, April 1978.

"Facing Claude Cahun and Marcel Moore." Ottawa Art Gallery. Accessed July 3, 2020. https://oaggao.ca/facing-claude-cahun-marcel-moore.

Faludi, Susan. Backlash: The Undeclared War Against American Women. New York: Crown Publishing Group, 1991.

Felski, Rita. “'Because it is beautiful' New feminist perspectives on beauty." Feminist Theory 7, no. 2 (2006): 273-282. 
. Doing Time: Feminist Theory and Postmodern Culture. New York; London: NYU Press, 2000.

"Feminist Art." Museum of Modern Art. Accessed October 27, 2020. https://www.moma.org/collection/terms/168.

"Feminist Avant-Garde of the 1970s." Centre for Art and Media. Accessed June 7, 2020. https://zkm.de/en/exhibition/2017/11/feminist-avant-garde-of-the-1970s.

Feral, Josette and Ron Bermingham. "Alienation Theory in Multi-Media Performance." Theatre Journal 39, no. 4 (December 1987): 461-472.

Fields, Jill. "Frontiers in Feminist Art History." Frontiers: A Journal of Women Studies 33, no. 2 (2012): $1-21$.

Findlay, Judith. “Press Me, Push Me, Feel Me, Find Me.” Women's Art Magazine 64 (May-June 1995): 14.

Finkelstein, Joanne. "Chic Outrage and Body Politics.” In Embodied Practices: Feminist Perspectives on the Body, edited by Kathy Davis, 150-167. London; Thousand Oaks: Sage Publications, 1997.

Fisher, Jennifer. "Interperformance: The Live Tableaux of Suzanne Lacy, Janine Antoni, and Marina Abramovic." Art Journal 56, no.4 (1997): 28-33.

Fisher, Jennifer. "Relational Sense: Towards a Haptic Aesthetics." Parachute: Contemporary Art Magazine 87 (July-September 1997): 4-11.

Forte, Jeanie. "Women's Performance Art: Feminism and Post-Modernism." Theatre Journal 40, no. 2 (May 1988): 217-235.

Fortin, Jocelyn. Attitudes et comportments, Suzy Lake. Musée Regional de Rimouski, 2002. Exhibition Catalogue. 
Fox, Oriana. "Once More with Feeling: an abbreviated history of feminist performance art." Feminist Review, no. 96 (2010): 107-121.

Garnet, Carla. "Contradiction and Oscillation in Suzy Lake's 'Choreographed Puppets." Carla Garnet. Accessed June 10, 2020. https://www.carlagarnet.com/suzie-lakes-puppets.

Garrigan, Siobhan. "When Bodies Met Galleries: How Performance Art Changed the Art World's View of Painting." Modernism/modernity 20, no. 3 (2013): 585-588.

“Genuine Examples of Showing Empathy." Your Dictionary. Accessed November 25, 2020. https://examples.yourdictionary.com/genuine-examples-of-showing-empathy.html.

Glahn, Philip. “Brechtian Journeys: Yvonne Rainer's Film as Counterpublic Art.” Art Journal 68, no. 2 (Summer 2009): 76-93.

“Gnaw.” Janine Antoni Immaculate Conception Inc. Accessed June 4, 2020. http://www.janineantoni.net/gnaw.

Goldstein, Judith L. “The Female Aesthetics Community.” Poetics Today 14, no. 1 (Spring 1993): 143163.

Gombrich, E.H. "Moment and Movement in Art." Journal of the Warburg and Courtauld Institutes 27 (1964): 293-306.

Goodman-Soellner, Elise. "Poetic Interpretations of the 'Lady at Her Toilette' Theme in SixteenthCentury Painting." The Sixteenth Century Journal 14, no. 4 (Winter 1983): 426-442.

Goodyear, Anne Collins et al., This Is a Portrait If I Say So: Identity in American Art, 1912 to Today. New Haven: Yale University Press, 2016.

Gordin, Misha. “Conceptual Photography: Idea, Process, Truth.” World Literature Today 87, no. 2 (March/April 2013): 76-81. 
Goscilo, Helena. "The Mirror in Art: Vanitas, Veritas, and Vision." Studies in $20^{\text {th }} \& 21^{\text {st }}$ Century Literature 34, no.2 (2010): 282-219.

Gotschall, Mary. "Poisoned Apple," review of The Beauty Myth, by Naomi Wolf. National Review, July $8,1991$.

Grant, Catherine. "Private Performances: Editing Performance Photography." A Journal of the Performing Arts 7, no. 1 (2002): 34-44.

Graves, Jen. “The Man Behind Mark Tobey’s Famous Breakthrough.” The Stranger, May 14, 2014. Accessed May 28, 2020. https://www.thestranger.com/seattle/the-man-behind-mark-tobeysfamous-breakthrough/Content?oid=19531227.

Green, Gaye Leigh. "The Return of the Body: Performance Art and Art Education." Art Education 52, no. 1 (January 1999): 6-12.

Gurrieri, Lauren and Jenna Drenten. "The Feminist Politics of Choice: Lipstick as a Marketplace Icon." Consumption Markets \& Culture (September 2019): 1-16.

Haley, Rochelle. "Constructions of the moving body: drawing and dancing." Studies in Theatre and Performance 38, no. 3 (2018): 289-301.

Hanna, Martha. Suzy Lake: Point of Reference. Ottawa: Canadian Museum of Contemporary Photography, National Gallery of Canada, 1993. Exhibition Catalogue.

Hanisch, Carol. "The Personal Is Political.” In Radical Feminism: A Documentary Reader, edited by Barbara A. Crow, 113-116. New York; London: New York University Press, 2000.

Hauptman, Jodi. Drawing from the Modern: 1975-2005. New York: Museum of Modern Art, 2005.

Hatfield, Zack. "Review: Suzy Lake.” Arsenal Contemporary Art, March 2020. Accessed June 6, 2020. https://www.arsenalcontemporary.com/press/2020/03/suzy-lake-artforum-zack-hatfield?tag=ny. 
Hawkin, Kate. "Site of Action: An Investigation of Performative Painting and Spectatorship." PhD diss., Winchester School of Art, 2013.

Havlin, Natalie and Jillian M Báez. "Introduction: Revisiting Beauty.” Women's Studies Quarterly 46, no. $1 / 2$ (Spring/ Summer 2018): 13-26.

Heiferman, Marvin. "In Front of the Camera, Behind the Scene: Cindy Sherman's 'Untitled Film Stills." MoMA, no. 25 (Summer 1997): 16-19.

Hess, Liam. "The Radical Surrealist Who Challenged Gender Norms with Make-up.” Dazed Digital, February 12, 2018. Accessed July 2, 2020. https://www.dazeddigital.com/beauty/head/article/42430/1/radical-surrealist-claude-cahungender-norms-make-up.

Hodgdon, Barbara. "Material Remains at Play.” Theatre Journal 64, no. 3 (2012): 373-388.

Hogan, Jan. “A Touching Contract.” Touch, edited by Caterina Nirta, et al, 84-119. London: University of Westminster Press, 2020.

Holmes, Kristy A. "Feminist Art History in Canada: A Limited Pursuit?" In Negotiations in a Vacant Lot: Studying the Visual in Canada, edited by Lynda Jessup, Kristy Robertson and Erin Morton, 47-65. Montreal: McGill-Queen's University Press, 2014.

Hyde, Melissa. "The 'Makeup' of the Marquise: Boucher's Portrait of Pompadour at Her Toilette." The Art Bulletin 82, no. 3 (2000): 453-475.

Iannacci, Anthony. “Janine Antoni.” Kunst Bulletin (June 1994): 16-25.

“In conversation: Suzy Lake.” Interview by Anna Kovler. Arsenal Contemporary Art, November 2019. Accessed January 19, 2020. https://www.arsenalcontemporary.com/press/2019/11/inconversation-suzy-lake?tag=ny.

“Interview: 'Touch' and 'Moore' Janine Antoni." Art21. Accessed May 1, 2020. https://art21.org/read/janine-antoni-touch-and-moor/. 
Jackson, Shannon and Julia Bryan-Wilson. "Time Zones: Durational Art and its Context." Representation, no. 136 (Fall 2016): 1-20.

Jacobsen, Lisa. "Fashion, Feminism, and the Pleasures and Perils of Consumer Fantasy," review of Fresh Lipstick: Redressing Fashion and Feminism, by Linda M. Scott. Journal of Women's History 22, no. 1 (Spring 2010): 178-187.

Jagodzinski, Jan. "Women's Bodies of Performative Excess: Miming, Feigning, Refusing and Rejecting the Phallus," Journal of Psychoanalysis of Culture and Society 8, no. 1 (2003): 23-41.

Janiak, Edyta. “'Inhabit' of Janine Antoni as a metaphor of female creation.” DYSKURS Pismo Naukowo-Artystyczne ASP we Wroctawiu 2, no. 26 (2018): 174-185.

“Janine Antoni. Butterfly Kisses. 1996-99.” Museum of Modern Art (MoMA), August 30, 2006. Accessed December 19, 2019. https://www.moma.org/collection/works/82074

“Janine Antoni. Butterfly Kisses. 1996-99 (English).” Museum of Modern Art (MoMA) Kids, 2006. Accessed February 2, 2020. https://www.moma.org/audio/playlist/224/2895.

Jeffreys, Sheila. Beauty and Misogyny. London; New York: Routledge, 2005.

Johnson, Clare. Femininity, Time and Feminist Art. London; New York: Palgrave Macmillan, 2013.

Jones, Amelia. Body Art/Performing the Subject. Minneapolis: University of Minnesota Press, 1998.

- "Dis/playing the Phallus: Male Performance Artists Perform their Masculinity." Art History 17, no. 4 (December 1994): 546-584.

- "Material Traces: Performativity, Artistic 'Work', and New Concepts of Agency." Power Publications. June 2, 2015. Audio. https://www.powerpublications.com.au/podcast-materialtraces/ 
_. "'Presence' in Absentia: Experiencing Performance Art as a Documentation." Art Journal 56, no. 4 (1997): 11-18.

. “"'The Artist is Present': Artistic Re-enactments and the Impossibility of Presence.” TDR 55, no. 1 (Spring 2011): 16-45.

Jones, Geoffrey. Beauty Imagined: A History of the Global Beauty History. New York: Oxford University Press, 2010.

Jones, Patrick L., “The Mythical Speech of Janine Antoni.” Master's thesis, West Virginia University, 2006.

Karamitsos, Stephanie Ann. "The Art of Janine Antoni: Labor, Gender and the Object of Performance." PhD diss., Northwestern University, 2006.

Kelleher, Katy. "The Portrait: Approaching a Modern Definition of Identity." Art New England. Accessed May 27, 2020. http://artnewengland.com/ed_picks/the-portrait/.

Klein, Sherri. "Comic Liberation: The FEMINIST FACE of Humor in Contemporary ART." Art Education 61, no. 2 (2008): 47-52.

Knafo, Danielle. "Dressing up and Other Games of Make-Believe: The Function of Play in the Art of Cindy Sherman." American Imago 53, no. 2 (Summer 1996): 139-164.

Korichi, Rodolphe et al. "Why Women Use Makeup: Implication of Psychological Traits in Makeup Functions." Journal of Cosmetic Science 59 (March/April 2008): 127-137.

Kotz, Liz. "Language Between Performance and Photography." October 111 (Winter 2005): 3-21.

Lajer-Burcharth, Ewa. “Antoni’s Difference.” In Janine Antoni, edited by Cristina Bechtler, 42-79. Küsnacht: Ink Tree, 2000. 
Lake, Suzy. “An Interview with Suzy Lake.” Interview by Becky Rynor, National Gallery of Canada, February 3, 2015. Accessed June 8, 2020. https:/www.gallery.ca/magazine/artists/an-interviewwith-suzy-lake.

Lake, Suzy. "Big Ideas Arts \& Culture: Suzy Lake.” Arts Everywhere Festival. Filmed January 19, 2017, Guelph, Ontario. Accessed June 6, 2020. http://festival.artseverywhere.ca/event/big-ideassuzy-lake/.

Lake, Suzy. "Discussing Feminism and Art: A Suzy Lake Interview." Interview by Hilary Dow.

University of Toronto. Accessed June 9, 2020.

http://sites.utm.utoronto.ca/historyinternships/blog/03052017-0151/discussing-feminism-and-artsuzy-lake-interview.

Lake, Suzy. "Interview: The Difficulty in Distilling Suzy Lake." Interview by Sky Goodden, Momus: Return to Art Criticism, March 23, 2015. Accessed January 19, 2020.

Lake, Suzy. "New Kind of Beauty in Bloom.” Interview by Leah Sandals. National Post, April 29, 2011. Accessed June 10, 2020. https:/www.pressreader.com/.

Lake, Suzy. "Portraits as an Issues of Identity: Artist Statement." Suzy Lake.ca. Accessed September 10, 2019. http://www.suzylake.ca/artist-statement\#1.

Lake, Suzy. "Portraits as an Issue of Identity: White Face.” Suzy Lake.ca. Accessed September 10, 2019. http://www.suzylake.ca/whiteface\#14.

Lake, Suzy. "Suzy Lake, Sophie Hackett and Georgina Uhlyarik: Meet the Artist.” Interview by Sophie Hackett and Georgina Uhlyarik. Art Gallery of Ontario. November $12^{\text {th }}$, 2014, audio. https://soundcloud.com/agotoronto/2014-podcast-suzylake-agotalk.

Lamy, Laurent. Suzy Lake par Suzy Lake: Images et metaphors. Vies des arts 20, no. 78 (1975): 32-33.

Lange-Berndt, Petra, editor. Materiality: Documents of Contemporary Art. London: White Chapel Gallery; Cambridge: The MIT Press, 2015. 
Laughlin, Karen. "Brechtian Theory and American Feminist Theory." In Brecht Sourcebook, edited by Henry Bial and Carol Martin, 213-226. London; New York: Routledge, 2000.

Lecoq, Jacques. "Imitation: From Mimicry to Miming." In Theatre of Movement Gesture, edited by David Bradby, 1-5. London; New York: Routledge, 2006.

Lecoq, Jacques. "Mime, the Art of Movement." In Theatre of Movement Gesture, edited by David Bradby, 76-93. London; New York: Routledge, 2006.

Lepeki, Andre. "Not as Before, But Simply: Again." In Perform, Repeat, Record: Live Art in History, edited by Amelia Jones and Adrian Heathfield, 151-170. Bristol; Chicago: Intellect Books Ltd, 2012. https://ebookcentral-proquest-com.proxy.library.carleton.ca/lib/oculcarletonebooks/reader.action?docID $=1719541 \& p p g=6 \#$.

Le Poidevin, Robin. The Images of Time: An Essay on Temporal Representation. Oxford: Oxford University Press, 2007.

Levin, Laura. "The Performative Force of Photography." Photography and Culture 2, no. 3 (2009): 327-336.

Lichtenstein, Jacqueline. "Making Up Representation: The Risks of Femininity." Representations, no. 20 (Autumn 1987): 77-87.

Linden, Liz. "Women with Cameras: The Invention of the Selfie in the Photography of Anne Collier." Camera Obscura 34, no. 2 (2019): 194-207.

Lindner, Stacie M. “Janine Antoni: Finding a Room of Her Own.” Master's thesis, Georgia State University College of Arts and Sciences, 2006.

Lomax, Yve. "Telling Times: Tales of Photography and other Stories." In Public Bodies Private States: New Views on Photography, Representation and Gender, edited by Jane Brettle and Sally Rice, 38-54. Manchester; New York: Manchester University Press, 1994. 
Lui, Jui Ch'i. "Female Spectatorship and the Masquerade: Cindy Sherman's Untitled Film Stills." History of Photography 34, no. 1 (2010): 79-89.

Luther Hillman, Betty. ““'The Clothes I Wear Help Me to Know My Own Power': The Politics of Gender Presentation in the Era of Women's Liberation." Frontiers 34, no. 2 (2013): 155-185.

Lutticken, Sven. "Performing Time." Art Journal 70, no. 3 (Fall 2011): 41-44.

MacDonald, Corina. "Scoring the Work: Documenting Practice and Performance in Variable Media Art." Leonardo 42, no. 1 (2009): 59-63.

Manninen, Saini. “'In theatre, as in love, the subject is disappearance': On Absence and Archival Logic in Performance." Art, Design and Architectural Collection 69, no. 2 (2016): 162-175.

Manninen, Saini. "On Consuming Encounters: Short Duration and the Material Conditions of Performance.” Performance Research 17, no. 5 (2012): 92-97.

"Marcel Duchamp, Nude Descending a Staircase No. 2." Khan Academy. Accessed June 24, 2020. https://www.khanacademy.org/humanities/art-1010/dada-and-surrealism/dada2/a/marcelduchamp-nude-descending-a-staircase-no-2.

Marranca, Bonnie. "Performance, A Personal History." PAJ: The Journal of Performance and Art 28, no. 1 (January 2006): 3-19.

Mars, Tanya and Johanna Householder, editors. Caught in the Act: An Anthology of Performance Art by Canadian Women. Toronto: YYZBooks, 2006.

Maureen Connor. "Maureen Connor by Amanda Means." Interview by Amanda Means. Bomb Magazine, October 1, 1989. Accessed June 23, 2020. https://bombmagazine.org/articles/maureen-connor/. 
Matravers, Derek. "What is Art? Yves Klein's Anthropometries.” In Introducing Philosophy in Art: In Eight Case Studies, edited by Derek Matrevers, 11-29. Durham; Bristol: Acumen Publishing Ltd, 2013.

Maxwell, Angie and Todd Shields. "Introduction: Toward a New Understanding of Second-Wave Feminism." In The Legacy of Second-Wave Feminism in American Politics, 1-18. London; New York: Palgrave Macmillan, 2018.

McCabe, Maryann, Timothy de Waal Malefyt and Antonella Fabri. "Women, Makeup, and Authenticity: Negotiating Embodiment and Discourses of Beauty." Journal of Consumer Culture 20, no. 4 (2017): 1-22.

Meagher, Michelle. "Against the Invisibility of Old Age: Cindy Sherman, Suzy Lake and Martha Wilson.” Feminist Studies 40, no. 1 (2014): 101-218.

Meagher, Michelle. “Improvisation within a Scene of Constraint: Cindy Sherman's Serial SelfPortraiture." Body \& Society 13, no. 4 (2007): 1-19.

Merriam-Webster.com Dictionary, s.v. "Empathy." Accessed January 2020. https://www.merriamwebster.com/dictionary/empathy.

_., s.v. “Genuine.” Accessed October 13, 2020. https://www.merriamwebster.com/dictionary/genuine.

_., s.v. "Simulation." Accessed October 13, 2020. https://www.merriamwebster.com/dictionary/simulation.

Meyer, Laura. "Power and Pleasure: Feminist Art Practice and Theory in the United States and Britain." In A Companion to Contemporary Art Since 1945, edited by Amelia Jones, 317-342. Malden Oxford: Blackwell Publishing, 2006.

Meyers, Holly. "Time to Analyze the Roles We Play.” Los Angeles Times, June 13, 2007. Accessed June 10, 2020. https://www.latimes.com/archives/la-xpm-2007-jun-08-et-theft8-story.html. 
Micchelli, Thomas. "The Feminist Avant-Garde, Now More than Ever.” Hyperallergic, May 20, 2017. Access June 7, 2020. https://hyperallergic.com/380348/woman-feminist-avant-garde-of-the1970s-sammlung-verbund-mumok-2017/.

Miller, Lynn Carol and Cathryn Leigh Cox. "For Appearances' Sake: Public Self-Consciousness and Makeup Use." Personality and Social Psychology Bulletin 8, no. 4 (December 1982): 748-751.

“Minimalism.” MoMA Learning. Accessed May 26, 2020.

https://www.moma.org/learn/moma_learning/themes/minimalism/.

Morgan, Robert C. "Thoughts of Re-performance, Experience, and Archivism." PAJ: The Journal of Performance Art 32, no. 3 (September 2010): 1-15.

"More Love: Art, Politics, and Sharing Since the 1990s." Auckland Art Museum. Accessed May 27, 2020. https://ackland.org/exhibition/more-love-art-politics-and-sharing-since-the-1990s/.

Negrin, Llewellyn. "Cosmetics and the Female Body: A Critical Appraisal of Poststructuralist Theories of Masquerade." European Journal of Cultural Studies 3, no. 1 (2000): 83-101.

Nelson, Robin et al. "Node: Modes of Experience." In Mapping Intermediality in Performance, edited by Sarah Bay-Cheng, Chiel Kattenbelt, Andy Lavender and Robin Nelson, 45-47. Amsterdam: Amsterdam University Press, 2010.

Niezink, Lidewij and Katherine Train. "The Self in Empathy: Self Empathy." Psychology Today. July 13, 2020. Accessed November 26, 2020. https://www.psychologytoday.com/us/blog/empathicintervision/202007/the-self-in-empathy-self-empathy.

Nolan, Erin Hyde. "This Is a Portrait If I Say So: Identity in American Art, 1912 to Today." Sequitur, December 2, 2016. Accessed May 27, 2020. http://www.bu.edu/sequitur/2016/12/02/nolanportrait/.

O’Dell, Kathy. "Displacing the Haptic: Performance Art, the Photographic Document, and the 1970s." $A$ Journal of the Performing Arts 2, no. 1 (1997): 73-81. 
Owens, Clifford. "Performance Art and Drawing." A Journal of Performance and Art 36, no. 2 (2014): 74-77.

Paoletti, Jo B. "Feminism and Femininity." In Sex and Unisex: Fashion, Feminism, and the Sexual Revolution, edited by Jo B. Paoletti, 35-58. Bloomington; Indianapolis: Indiana University Press, 2015.

Parkins, Ilya. "Fresh Lipstick: Redressing Fashion and Feminism by Linda M. Scott (Palgrave Macmillan, 2005)." Review of Fresh Lipstick: Redressing Fashion and Feminism, by Linda M. Scott. Feminist Theory 11, no. 2/3 (2007): 365-368.

Phelan, Peggy. “Feminist Theory, Poststructuralism, and Performance.” TDR 32, no. 1 (Spring 1988): 107-127.

Phelan, Peggy. Unmarked: The Politics of Performance. London; New York: Routledge, 1996.

Philips, Kelly. “'Feminism Under Glass' WACK! Art and the Feminist Revolution.” FUSE 32, no. 2 (2009): 33-36.

Piess, Kathy. Hope in a Jar. The Making of America's Beauty Culture. New York: Metropolitan Books, 1998.

Piess, Kathy. "On Beauty ... and the History of Business." Enterprise \& Society 1, no. 3 (September 2000): 485-506.

Plante, Rebecca F. "Putting of Makeup." In Popular Culture as Everyday Life, edited by Dennis D. Waskul and Phillip Vannini, 165-174. London; New York: Routledge, 2016.

Point \& Shoot: Performance and Photography. Edited by France Choinière and Michèle Thériault. Montreal: Dazibao, 2004. Exhibition Catalogue. 
Pontbriand, Chantal. Suzy Lake: A Genuine Simulation of .... Montreal: Galerie Gilles Gheebrant, 1975. Exhibition Catalogue.

Purvis, Jennifer. "Grrrls and Women Together in the Third Wave: Embracing the Challenges of Intergenerational Feminism(s)." NWSA Journal 16, no. 3 (Autumn 2004): 93-123.

Reckitt, Helena. Suzy Lake. Steidl/Scotiabank, 2017.

Reckitt, Helena. The Art of Feminism: Images that Shaped the Fight for Equality, 1857-2017. London: Elephant Book Company Ltd, 2018.

Reilly, Maura. "Painting: What it Became." In Carolee Schneemann: Within and Beyond the Premises, edited by Brian Wallace, 27-30. New York: Samuel Dorsky Museum of Art, 2010.

Reinelt, Janelle. “Beyond Brecht: Britain's New Feminist Drama.” Theatre Journal 38, no. 2 (May 1986): 154-163.

Rice, Carla. "In the Mirror of Beauty Culture." In Becoming Women: The Embodied Self in Image Culture, 234-266. Toronto: University of Toronto Press, 2014.

Richards, Judith Olch. Inside the Studio: Two Decades of Talks with Artists in New York. New York: Independent Curators International, 2004.

Roben, Scott. "Dance/Draw.” Frieze, March 20, 2012. Accessed May 1, 2020. https://frieze.com/article/dancedraw.

Routhier, Jessica Skwire. "This Is a Portrait If I Say So: Identity in American Art, 1912 to Today." Antiques and the Arts Weekly, July 15, 2016. Accessed May 27, 2020.

https://www.bowdoin.edu/art-museum/pdf/2016-July-15-Antiques-and-the-Arts-Weekly.pdf.

Ruby, Jennie. "Backlash: Susan Faludi Lays Reaction Against Feminism," review of Backlash: The Undeclared War Against American Women, by Susan Faludi. Off Our Backs 22, no. 4 (April 1992): 22-23. 
Rudd, Nancy Ann. "Cosmetic Consumption and Use Among Women: Ritualized Activities that Construct and Transform the Self." Journal of Ritual Studies 11, no. 2 (Winter 1997): 59-77.

Russell, Kirstin. "Feminism and Yves Klein's Anthropometries." Walker, January 19, 2011. Accessed May 30, 2020. https://walkerart.org/magazine/feminism-and-yves-kleins-anthropometries.

Saccoccia, Susan. "ICA's Dance/Draw Exhibition Worthy of Second Look. And Third and Fourth." The Bay State Banner, November 2, 2011. Accessed May 27, 2020. https://www.baystatebanner.com/2011/11/02/icas-dance-draw-exhibition-worthy-of-secondlook-and-a-third-and-a-fourth/.

Schechner, Richard. Performance Studies: An Introduction. London; New York: Routledge, 2006.

Schimmel, Paul. "Leap into the Void: Performance and the Object." In Out of Actions: Between Performance and the Object, 1949-1979, edited by Russell Ferguson, 17-119. New York: Thames and Hudson Inc, 1998.

Schneider, Rebecca. Explicit Body in Performance. London; New York: Routledge, 1997.

__. "In the Meantime: Performance Remains." In Performing Remains: Art and War in Times of Theatrical Reenactment, edited by Rebecca Schneider, 87-110. London; New York: Routledge, 2011.

- "Performance Remains." In Perform, Repeat, Record: Live Art in History, edited by Amelia Jones and Adrian Heathfield, 137-150. Bristol; Chicago: Intellect Books Ltd, 2012. https://ebookcentral-proquest-com.proxy.library.carleton.ca/lib/oculcarletonebooks/reader.action?docID $=1719541 \& p p g=6 \#$.

. "What Happened; or, Finishing Live." Representations 136, no. 1 (2016): 96-111.

Schor, Mira. "Patrilineage." In Wet: On Painting, Feminism, and Art Culture, 98-117. Durham; London: Duke University Press, 1997. 
Schweitzer, Marlis. “"The Mad Search for Beauty': Actresses' Testimonials, the Cosmetic Industry, and the 'Democratization of Beauty'." The Journal of the Gilded Age and Progressive Era 4, no. 3 (July 2005): 255-292.

Shusterman, Richard. "Photography as Performative Process." The Journal of Aesthetics and Art Criticism 70, no. 1 (Winter 2012): 67-77.

“Slumber.” Janine Antoni Immaculate Conception Inc. Accessed June 4, 2020. http://www.janineantoni.net/\#/slumber/.

Smith, Angela. "Introduction." In Twenty-First Century Feminism: Forming and Performing Femininity, edited by Claire Nally and Angela Smith, 1-16. London; New York: Palgrave MacMillan, 2015.

Smith, Lindsay. "The Politics of Focus: Feminism and Photography Theory.” In New Feminist Discourses: Critical Essays on Theories and Texts, edited by Isobel Armstrong, 238-262. London; New York: Routledge, 2012.

Smith, Sidonie. "Bodies of Evidence: Jenny Saville, Faith Ringgold, and Janine Antoni Weigh In." In Interfaces: Women, Autobiography, Image, Performance, edited by Sidonie Smith and Julia Watson, 132-159. Ann Arbor: The University of Michigan Press, 2002.

Snyder, R. Claire. "What is Third-Wave Feminism? A New Directions Essay." Signs 34, no. 1 (Autumn 2008): 175-196.

Spector, Nancy. "Slumber: A Fairytale.” In Janine Antoni, edited by Cristina Bechtler, 10-23. Küsnacht: Ink Tree, 2000.

Steinmetz, Julia, Heather Cassils and Clover Leary. "Behind Enemy Lines: Toxic Titties Infiltrate Vanessa Breecoft." Signs 31, no. 3 (Spring 2006): 753-783.

Stern, Nathanial. "The Implicit Body as Performance: Analyzing Interactive Art." Leonardo 44, no. 3 (2011): 232-238. 
Stuart, Avelie and Ngaire Donaghue. "Choosing to Conform: The Discursive Complexities of Choice in Relation of Feminine Beauty Practices.” Feminism \& Psychology 22, no. 1 (2011): 98-121.

"Suzy Lake: Artist Talk." Scotiabank Photography Award. Filmed June 9, 2017 at Ryerson University, Toronto, Ontario. Accessed June 8, 2020. https://ryecast.ryerson.ca/48/Watch/11447.aspx.

Suzy Lake: Point of Reference. Edited by Martha Hanna. Ottawa: Canadian Museum of Contemporary Photography, 1988. Exhibition Catalogue.

Synnott, Anthony. "Truth and Goodness, Mirrors and Masks Part II: A Sociology of Beauty and the Face." The British Journal of Sociology 41, no. 1 (1990): 55-76.

Tannenbaum, Judith. PerForms: Janine Antoni, Charles Ray, Jana Sterbak. Philadelphia: Institute of Contemporary Art University of Pennsylvania, 1995. Exhibition Catalogue.

Taylor, Allan. "Performance, Photography, Performativity: What 'Performance' does in the still image." PhD diss., University of the Arts London, 2017.

"This Is a Portrait if I Say So: Identity in American Art, 1912 to Today." Bowdoin College Museum of Art, accessed May 27, 2020, https://www.bowdoin.edu/art-museum/exhibitions/2016/this-is-aportrait-if-i-say-so.shtml.

“Tinuiti Renewed e.l.f. Cosmetics' Presence with Millennial and Gen-Z Audiences Through a FullFunnel Digital Campaign.” Tinuiti, July 7, 2020. Accessed July 15, 2020. https:/tinuiti.com/news/press-release/tinuiti-renewed-e-l-f-cosmetics-presence-with-millennialand-gen-z-audiences-through-a-full-funnel-digital-campaign/.

Topdjian, Carolyne. "Shape-Shifting Beauty: The Body, Gender and Subjectivity in the Photographs of Claude Cahun.” Resources for Feminist Research 32, no. 3/4 (2007): 63-86.

Uhlyarik, Georgiana. Introducing Suzy Lake. London: Black Dog Publishing, 2014. 
"Up to And Including Her Limits." Carolee Schneemann. Accessed May 28, 2020. http://www.caroleeschneemann.com/works.html.

Vandenberg, Allison. "Toward a Phenomenological Analysis of Historicized Beauty Practices." Women's Studies Quarterly 46, no. 1/2 (Spring/ Summer 2018): 167-180.

van der Tuin, Iris. "The Arena of Feminism: Simone de Beauvoir and the History of Feminism." In Doing Gender in Media, Art and Culture: A Comprehensive Guide to Gender, edited by Rosemarie Buikema, Liedeke Plate and Kathrin Thiele, 7-23. Hoboken: Taylor and Francis, 2009.

Van Gelder, Hilde and Helen Westgeest. "Time in Photography: The Rivalry with Time-Based Arts." In Photography Theory: In Historical Perspective, 64-111. Chichester; Malden; Oxford: WileyBlackwell, 2011.

Varnedoe, Kirk. "Minimalism and After." Museum of Modern Art 4, no. 1 (2001): 2-5.

Vason, Manuel and David Evans, editors. Double Exposure: Performance as Photography, Photography as Performance. Bristol: Intellect Books Ltd, 2015.

Vivash, Kelsy. "Abjection, Remembering and the Still-Performing Document." Performance Research 19, no. 1 (2014): 102-110.

Vogel, Wendy. “Turning Inside Out: Janine Antoni’s New Perspective on Sculpture and Dance.” Modern Painters, March 2015, https://static1.squarespace.com/static/56flc1b44c2f85b03ad8b240/t/57a24acde3df28e8b81e5a07 /1470253785414/Vogel_ModernPainters_2015.pdf.

Wade, Nicolas J. "Movements in Art: From Rosso to Riley.” Perception 32, no. 9 (2003): 1029-1036.

Wakefield, Niki. "Time Based History: Perspectives on Documenting Performance." Performance Matter 1, no. 1-2 (2015): 167-179. 
Walker, Anna. "The Evolution of: Makeup.” Reader's Digest. Accessed January 14, 2020. https://www.readersdigest.co.uk/lifestyle/fashion-beauty/the-evolution-of-makeup.

Walker, Robert. Camerart. Galerie Optica, Montreal, 1974. Exhibition Catalogue.

Ward, Frazer. "Introduction: Reimagining the Audience." In No Innocent Bystanders: Performance Art and Audience, edited by Frazer Ward, 1-26. Hanover: Dartmouth College Press, 2012.

Ward, Frazer. "Performing After Minimalism: Fantasies of Public and Private." In No Innocent Bystanders: Performance Art and Audience, edited by Frazer Ward, 27-51. Hanover: Dartmouth College Press, 2012.

Ward, Frazer. "Some Relations Between Conceptual and Performance Art.” Art Journal 56, no. 4 (Winter 1997): 36-40.

Wark, Jane. Radical Gestures: Feminism and Performance Art in North America. Montreal; Kingston: McGill-Queen's University Press, 2006.

Warr, Tracey. "The Body in Your Lap." In Intimacy Across Visceral and Digital Performance, edited by Maria Chatzichristodoulou and Rachel Zerihan. London; New York: Palgrave Macmillan, 2012.

Warr, Tracey and Amelia Jones. The Artist's Body. London: Phaidon, 2000.

Welby-Everard, Miranda. "Imaging the Actor: The Theatre of Claude Cahun." Oxford Art Journal 29, no. 1 (2006): 3-24.

"What is Empathy?" Greater Good Magazine. Accessed November 25, 2020. https://greatergood.berkeley.edu/topic/empathy/definition.

White, Michele. "Beauty as an 'act of political warfare': Feminist Makeup Tutorials and Masquerades on YouTube." Women's Studies Quarterly 46, no. 1/2 (Spring/Summer 2018): 138-156. 
Whyte, Murray. "Suzy Lake at the Art Gallery of Ontario: Enduring beauty, up close and very personal.” The Star, November 12, 2014. Accessed January 19, 2020.

https://www.thestar.com/entertainment/visualarts/2014/11/12/suzy_lake_at_the_art_gallery_of_o ntario_beauty_and_determination_up_close.html.

Wiebe, Christabel. "What's a Girl to Do?” Border Crossings 26, no. 3 (August 2007): 112-117.

Woolley, Michael J.H. "Documenting Performance Art: Documentation in Practice." The International Journal of Performance Arts and Digital Media 10, no. 1 (2014): 48-66.

Wright, Ellen. “Come to Your Senses, Remembering Belongings: A Pedagogy of Making, Memory and the Haptics of Home.” PhD diss., York University, 2019.

"Yayoi Kusama: White Infinity Nets.” Victoria Miro. Accessed May 28, 2020. https://www.victoriamiro.com/exhibitions/444/.

Zarzycka, Marta. "Cindy Sherman Confronting Feminism and (Fashion) Photography.” In Doing Gender in Media, Art and Culture: A Comprehensive Guide to Gender, edited by Rosemarie Buikema, Liedeke Plate and Kathrin Thiele, 151-162. Hoboken: Taylor and Francis, 2009.

" $50+$ sexist vintage ads so bad, you almost won't believe they were real." Click Americana: Memories and Memorabilia. Accessed July 2, 2020. https://clickamericana.com/topics/culture-andlifestyle/50-sexist-vintage-ads-so-bad-you-almost-wont-believe-they-were-real. 